\title{
Caracterização e modelagem da atividade eletrofisiológica em pacientes com epilepsia
}

\author{
Abner Cardoso Rodrigues Neto \\ TESE APRESENTADA \\ $\mathrm{AO}$ \\ Instituto DE MATEMÁticA E EstatísticA \\ DA \\ UNIVERSIDADE DE SÃO PAULO \\ PARA \\ OBTENÇÃO DO TÍTULO \\ $\mathrm{DE}$ \\ DOUTOR EM CIÊNCIAS
}

Programa: Interunidades em Bioinformática

Orientador: Prof. Dr. Koichi Sameshima

Coorientador: Prof. Dr. André Fujita

Durante o desenvolvimento deste trabalho o autor recebeu auxílio financeiro da CAPES

São Paulo, Agosto de 2015 


\section{Caracterização e modelagem da atividade eletrofisiológica em pacientes com epilepsia}

Esta versão da dissertação/tese contém as correções e alterações sugeridas pela Comissão Julgadora durante a defesa da versão original do trabalho, realizada em 20/04/2016. Uma cópia da versão original está disponível no

Instituto de Matemática e Estatística da Universidade de São Paulo.

Comissão Julgadora:

- Prof. Dr. Koichi Sameshima (orientador) - FM-USP

- Prof. Dr. André Fujita - IME-USP

- Prof. Dr. Renato Ramos - FM-USP

- Prof. Dr. Ronaldo Fumio Hashimoto - IME-USP

- Prof. Dr. Raphael Yokingawa de Camargo - UFABC 


\section{Agradecimentos}

Agradeço ao meu avô Abner pelo apoio e incentivo para seguir no doutorado, meu irmão Caio pela ajuda com ideias e na correção do texto, ao Bira pela colaboração ao longo desses anos e à Patricia e Cristiane, secretárias da bioinformática, por me ajudarem várias vezes com os processos burocráticos durante o doutorado. 


\section{Resumo}

RODRIGUES, A. C. Caracterização e modelagem da atividade eletrofisiológica em pacientes com epilepsia. 2015. 67 f. Tese (Doutorado) - Instituto de Matemática e Estatística, Universidade de São Paulo, São Paulo, 2010.

Redes complexas aplicadas em sinais de atividade cerebral mostraram a presença de anormais padrões de conectividade em pacientes que sofriam com doenças e outros distúrbios psiquiátricos. Logo, passou-se a cogitar a influência dessas estruturas na causa desses problemas e o que leva ao desenvolvimento desses padrões anormais. Do ponto de vista teórico, vários trabalhos mostram como a topologia de uma rede pode alterar um processo que se sustenta nela, por exemplo o modo como a rede influencia a propagação de falhas de um sistema, a sincronização ou processos de dispersão. Nesse sentido, o objetivo do trabalho é caracterizar as redes funcionais de pacientes durante episódios de crises de epilepsia, fazendo um paralelo entre a estrutura dessas redes e os processos dinâmicos envolvidos na crise, em especial a sincronização. Para isto, dados reais foram analisados e as redes inferidas em um primeiro passo. Depois, simulações de sistemas artificiais usando os parâmetros obtidos das análises, mostram o impacto dessas redes nos processos dinâmicos. Os resultados apontam para estruturas que podem aumentar a sincronização e a influência do modo de acoplamento nesses sistemas.

Palavras-chave: conectividade cerebral, redes complexas, processamento de sinais. 


\section{Abstract}

RODRIGUES, A. C. Characterization and modeling of electrophysiological activity in patients with epilepsy. 2015. 67 f. Tese (Doutorado) - Instituto de Matemática e Estatística, Universidade de São Paulo, São Paulo, 2010.

Complex networks applyed to brain activity signals show the presence abnormal of connectivity patterns in patients suffering with diseases and others psychiatric disorders. From this, some authors began to question the influence of these structures in the cause of these problems and how it leads to the development of these abnormal patterns. From a theoretical point of view, several studies show how the topology of a network can change a process that maintains it, for example how a network influences the propagation of a system failure, synchronization or difussion processes. In this sense, the objective of this study is to characterize the functional networks of patients during episodes of seizures, making a parallel between the structure of these networks and the dynamic processes involved in the epilepsy, in particular the synchronization. For this, real data were analyzed and the inferred networks in a first step. And then, artificial simulations using the parameters obtained from the analysis were employed to show the impact of these networks in dynamic processes. The results indicate structures that can enhance the synchronization and the influence of the coupling mode on these systems.

Keywords: brain connectivity, complex networks, signal analysis. 


\section{Sumário}

$\begin{array}{ll}\text { Lista de Abreviaturas } & \text { ix }\end{array}$

Lista de Símbolos $\quad$ xi

Lista de Figuras $\quad$ xiii

Lista de Tabelas $\quad$ xvii

1 Introdução $\quad 1$

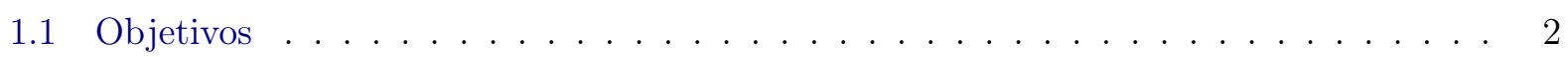

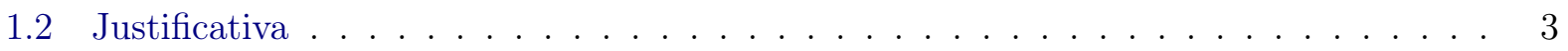

1.3 Organização do Trabalho . . . . . . . . . . . . . . . . . . . . . . . 3

2 Conceitos de redes complexas $\quad 5$

2.1 Fundamentos . . . . . . . . . . . . . . . . . . . . . 5

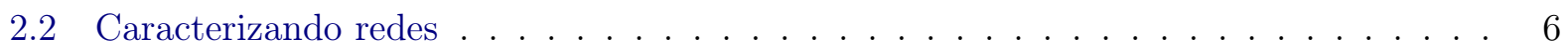

2.3 Inferindo as Redes . . . . . . . . . . . . . . . . . . . . . . . . . 8

2.3.1 Correlação de Pearson . . . . . . . . . . . . . . . . . . . . . 9

2.3.2 Causalidade de Granger . . . . . . . . . . . . . . . . . . . . . . 9

2.3.3 Coerência Parcial Direcionada . . . . . . . . . . . . . . . . . . . . . 10

2.3 .4 Phase Locking Value . . . . . . . . . . . . . . . . . . . . . . . . 10

2.4 Redes Complexas na Epilepsia . . . . . . . . . . . . . . . . . . . 11

3 Relações entre estrutura e atividade epileptiforme $\quad 13$

3.1 Metodologia . . . . . . . . . . . . . . . . . . . . . . . . . 13

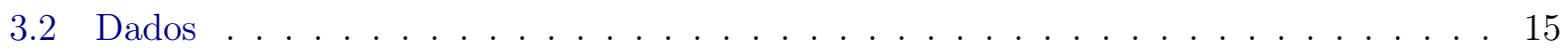

3.3 Relação entre estrutura e sincronização . . . . . . . . . . . . . . . . . . . . . . . 16

3.3 .1 Métodos . . . . . . . . . . . . . . . . . . . 16

3.3 .2 Resultados . . . . . . . . . . . . . . . . . . . . 16

3.4 Padrões de conectividade revelados através de entropia cruzada . . . . . . . . . . 17

3.4 Métodos . . . . . . . . . . . . . . . . . . . . . . . . 20

3.4 .2 Resultados . . . . . . . . . . . . . . . . . . . 21

3.5 Evolução do acoplamento entre os sinais ao longo da crise . . . . . . . . . . . . . . 23

3.5.1 Dados . . . . . . . . . . . . . . . . . . . . . 25

3.5.2 Resultados . . . . . . . . . . . . . . . . . . . 25

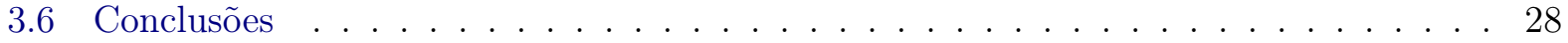


4 Simulações de redes de epilepsia $\quad 29$

4.1 Simulação de redes de neurônios artificiais com estruturas da epilepsia . . . . . . . . . 29

4.1 .1 Métodos . . . . . . . . . . . . . . . . . . . . . . . . . 29

4.1 .2 Resultados . . . . . . . . . . . . . . . . . 30

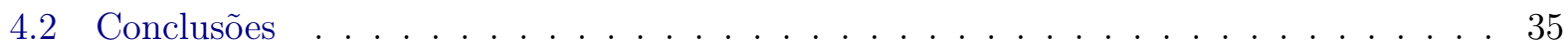

5 Conclusões $\quad 37$

5.1 Considerações Finais . . . . . . . . . . . . . . . . . . . . 37

5.2 Sugestões para Pesquisas Futuras . . . . . . . . . . . . . . . 37

$\begin{array}{ll}\text { A Sincronização em sistemas não-lineares acoplados } & 39\end{array}$

A.0.1 Métodos . . . . . . . . . . . . . . . . . . . . . . 39

A.0.2 Resultados . . . . . . . . . . . . . . . . . . . 42

$\begin{array}{ll}\text { B Uso dos dados } & 47\end{array}$

$\begin{array}{ll}\text { Referências Bibliográficas } & 49\end{array}$

$\begin{array}{ll}\text { Índice Remissivo } & 58\end{array}$ 


\title{
Lista de Abreviaturas
}

\author{
AR Modelo Auto Regressivo (Autoregressive Model) \\ EEG Eletroencefalograma (Eletroencephalogam) \\ fMRI Ressonância Magnética Funcional (Functional Magnetic Resonance Imaging) \\ PS Espectro de Potência (Power Spectrum) \\ KLD Divergência de Kullback-Leibler (Kullback-Leibler Divergence) \\ LZC Complexidade de Lempel-Ziv (Lempel-Ziv Complexity) \\ AIC Critério de Informação de Akaike (Akaike Information Criterion) \\ PLV (Phase Locking Value)
}




\title{
Lista de Símbolos
}

\author{
$\omega$ Frequência angular \\ $\psi$ Função de análise wavelet \\ $\Psi$ Transformada de Fourier de $\psi$
}




\section{Lista de Figuras}

2.1 Dois exemplos de grafos com suas matrizes de adjacências. Algumas operações podem ser transformar a matriz, por exemplo podando as conexões fracas através de um limiar ou simetrizando a matriz em relação a diagonal. Adaptado de Rubinov e Sporns

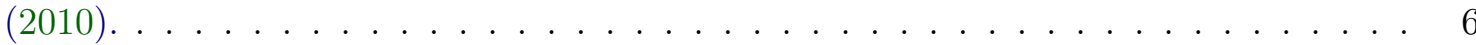

2.2 Conceitos estruturais dos grafos. O nó $V_{e}$ em vermelho é o de maior grau da rede, o menor caminho que liga o nó $V_{i}$ ao $V_{c}$ está destacado em verde, as conexões $E_{h g}$, $E_{h f}$ e $E_{f g}$ formam um triângulo, a presença de muitos triângulos ao redor de um nó indica um forte agrupamento naquela região. Esse grafo exibe dois módulos claros, a

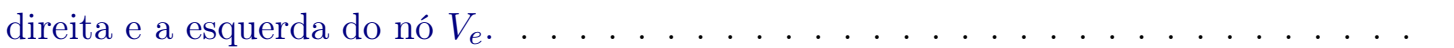

3.1 Fluxograma dos passos para ajustar o modelo auto-regressivo em uma série temporal. 14

3.2 Trecho de 2 segundos de duração de um sinal de EEG durante uma crise de ausência. A crise é caracterizada por um aumento na amplitude e uma sincronização comum em todos os eletrodos. . . . . . . . . . . . . . . . . . . . 15

3.3 Exemplo de duas matrizes de conectividade para o Paciente 1 em diferentes momentos. O tom de cinza representa o valor do PLV (mais escuro, mais alto): (a) durante o período inter-ictal, $\tilde{R}=0,036$; e (b) do período ictal, $\tilde{R}=0,097$. Note que as conexões estão mais distribuídas e aleatórias em (a) enquanto que em (b) existe um claro padrão nos nós 30 e 33. Adaptado de Rodrigues et al. (2014). . . . . . . . . . . . 18

3.4 Resultados para o Paciente 1, o mesmo trecho do sinal utilizado para inferir a rede na figura 3.3 foi utilizado para calcular o PLV. (a) é a matriz de PLV para o período inter-ictal e (b) a matriz de PLV para o período ictal. Os histogramas mostram uma linha pontilhada indicando a mediana, 0,462 para o período inter-ictal e 0,641 para o período ictal. Note que durante o inter-ictal os valores do PLV estão em torno de 0,4 , enquanto que durante a crise, o PLV fica em torno de valores mais altos. Adaptado de Rodrigues et al. (2014). . . . . . . . . . . . . . . . . . . . . . . . . 18

3.5 Nessa figura tem-se a mediana do PLV, o $C$ e o $R$ para os Pacientes 1 e 5 . As linhas verticais marcam o início e fim da crise, que foram determinadas por neurologistas utilizando informação de vídeo e EEG. Para esses dois pacientes, após o início da crise percebe-se um aumento na mediana do PLV, que foi observado em 6 dos 8 pacientes. A presença dos hubs é caracterizada pelo aumento no valor de $\tilde{R}$. Note que o Paciente 5 apresenta dois picos no $\tilde{R}$, mas que não foram em períodos de crise, provavelmente devido a curta duração do evento. Adaptado de Rodrigues et al. (2014). 19 
3.6 PS para dois eletrodos durante inter-ictal e ictal. Figura (a) e (b) mostra o PS para os eletrodos F3 (azul) e F8 (preto) durante o inter-ictal $\left(D_{\mathrm{KL}}=0,787 ; \mathrm{PLV}=0,467\right)$ e ictal $\left(D_{\mathrm{KL}}=0,310 ; \mathrm{PLV}=0,625\right)$, (c) e (d) é o PS estimado durante o inter-ictal $\left(D_{\mathrm{KL}}=0,418 ; \mathrm{PLV}=0,712\right)$ e ictal $\left(D_{\mathrm{KL}}=0,042 ; \mathrm{PLV}=0,916\right)$ para os eletrodos CZ (preto) e PZ (azul), para a mesma janela de tempo usada em (a) e (b) . . . . . . .

3.7 Matrizes de adjacência para o paciente S8. A parte superior da figura mostra a média da entropia cruzada para o período ictal (direita) e inter-ictal (esquerda) durante 7 segundos. A diagonal é a entropia $H(\mathrm{PS}(\cdot))$ de cada eletrodo. A parte inferior mostra o $L_{i}$ para ambos períodos. Dois nós independentes podem ser observados no lobo frontoparietal (eletrodos FP1 e FP2) durante o período ictal. Quatro nós independentes são observados durante o inter-ictal (PZ, O1, OZ e O2), mas com menor valor de entropia cruzada. Note que os eletrodos FP1 e FP2 não eram classificados como independentes durante o inter-ictal.

$3.8 L(t)$ para nós independentes (em azul sólido) e sincronizáveis (tracejado vermelho) de quantro pacientes com diferentes duração de ictal. As linhas verticais indicam o ínicio e término da crise . . . . . . . . . . . . . . . . . . . .

3.9 KLD entre todos os eletrodos. a) $\bar{D}_{\mathrm{KL}}(t)$ para três eletrodos. KLD para os eletrodos b) $\mathrm{O} 1$ e c) FP1 em relação a todos os outros. O período ictal corresponde ao intervalo que vai de 50 até 70 segundos.

3.10 Matrizes de conectividade inferidas usando PDC na frequência de $3 \mathrm{~Hz}$. A matriz superior é para uma janela antes da crise para os pacientes 1 (esquerda) e 7 (direita), no centro as matrizes estimadas através dos primeiros 5 segundos de crise e na parte inferior mostra o grafo estimado para imediatamente após a crise. Os tons de cinza são a intensidade das relações causais. Adaptado de (Rodrigues et al., submetido) . .

3.11 Média da intensidade ao longo do tempo, as linhas verticais marcam o início e fim da crise. Adaptado de (Rodrigues et al., submetido) . . . . . . . . . . . . 27

3.12 Intensidade ao longo do tempo para dois canais do mesmo paciente. . . . . . . . . . . 27

4.1 Um exemplo do LFP e disparos de neurônios com HR 0,3 (esquerda) e 0,7 (direita). Adaptado de Rodrigues, Abner Cardoso et al. (2016) . . . . . . . . . . . . . . . . . 32

4.2 (a) Diferença entre a mediana da LZC para as redes aleatórias e não aleatórias. As redes com conexões aleatórias apresentam um LFP de maior complexidade que as redes não-aleatórias. (b) p-valor do teste de Wilcoxon entre os LZC para as redes aleatórias e não-aleatórias. A linha tracejada indica o alpha de 0,01. Adaptado de Rodrigues, Abner Cardoso et al. (2016). . . . . . . . . . . . . . . . . . . . .

4.3 (a) Evolução dos dois sinais de LFP ao longo do tempo, o vermelho é a rede que não recebeu hubs enquanto que o preto recebe hubs para o intervalo de 300 até $500 \mathrm{~ms}$. As linhas verticais marcam o período de tempo onde os hubs estavam presentes no sinal preto. (b) boxplot para o $H$ calculado para 10 janelas de tempo com 100 pontos cada. Adaptado de Rodrigues, Abner Cardoso et al. (2016) . . . . . . . . . . . . . . . 
A.1 (A) Reconstrução do espaço de estados do Rössler e (B) Lorenz, com parâmetro de acoplamento $\beta=0$. (C) Projeção no plano $\left(y_{1}, \tilde{y}_{1}\right) ; y_{1}(t)$ e $\tilde{y}_{1}(t)$ são duas séries com condições iniciais diferentes $y_{1}(0) \neq \tilde{y}_{1}(0)$. (D) $\mathrm{O}$ atrator de Lorenz depois de acoplado com o Rössler e (E) as respectivas projeções $\left(y_{1}, \tilde{y}_{1}\right)$. A diagonal $y_{1}(t)=$ $\tilde{y}_{1}(t)$ indica que os dois sistemas estão funcionalmente relacionados. Adaptado de Martins, V.S.G. et al. (2016). . . . . . . . . . . . . . . . . 40

A.2 Erro de previsão $\eta$ em função de $\beta$. A predição foi calculada considerando a dependência causal $x \rightarrow y$. Adaptado de Martins, V.S.G. et al. (2016). . . . . . . . . . . 41

A.3 Diagrama de conectividade da rede de neurônios. Adaptado de Martins, V.S.G. et al.

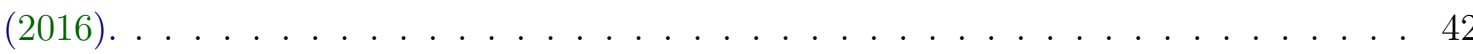

A.4 PLV para o sistema Rössler-Lorenz usando parâmetro de acoplamento $\beta=0$. A curva azul é o $\operatorname{PLV}_{i j}(d)$ para dois sinais $i$ e $j$, enquanto que a linha tracejada em vermelho corresponde ao PLV com o sinal permutado de $j$. Adaptado de Martins, V.S.G. et al.

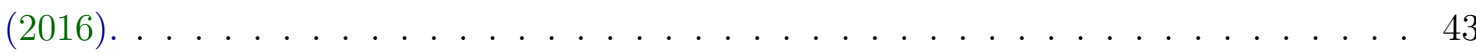

A.5 PLV para o sistema Rössler-Lorenz usando parâmetro de acoplamento $\beta=5$. A curva azul corresponde ao $\operatorname{PLV}_{i j}(d)$ para dois sinais $i$ e $j$, enquanto que a linha tracejada em vermelho corresponde ao PLV do sinal permutado de $j$ Adaptado de

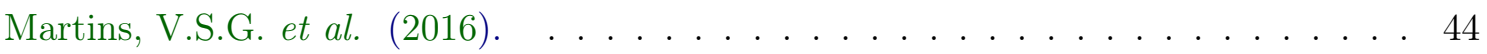

A.6 (A) PLV $(d)$ para o par $\left(z_{1}, z_{1}\right)$, (B) para $z_{2},(\mathrm{C})$ para $z_{3}$, e (D) para $z_{4}$. A linha azul é o $\operatorname{PLV}(d)$ considerando o acoplamento entre as redes enquanto que a linha preta é para as redes desconectadas. Adaptado de Martins, V.S.G. et al. (2016). . . . . . . 45 


\section{Lista de Tabelas}

2.1 Tabela com resumo de alguns trabalhos que aplicaram medidas de redes complexas na caracterização da atividade eletrofisiológica de pacientes com epilepsia. A maioria dos trabalhos utilizou $\bar{C}$ e $\bar{l}$ como medidas e utilizando dados de crise focal. A coluna Crise, identifica se o trabalho usou dados de crise focal (F) ou generalizada $(G)$. Em relação a inferência da rede, Sincronização na tabela significa que foi empregada alguma medida que tenta medir essa característica, mas não necessariamente o PLV.

3.1 Medidas de grafo e sincronização para todos os 8 pacientes. Os valores na tabela são as médias para cada medida com o desvio padrão entre parênteses. Adaptado de Rodrigues et al. (2014). . . . . . . . . . . . . . . . . . . . 17

3.2 Número de nós importantes para os périodos ictal e inter-ictal. O $L_{i}$-positivo (negativo) médio é indicado por $\bar{L}_{+}\left(\bar{L}_{-}\right)$. Foi considerado um nível de significância de 0,05. Nenhum nó sincronizável foi observado para o paciente S5 devido ao baixo número de nós com $L_{i}<0$, neste caso, foram escolhidos os com maior valores. $\Delta \bar{D}_{\mathrm{KL}} \%$ é a porcentagem da variação do KLD médio, medido apenas para os nós independentes detectados durante o ictal. . . . . . . . . . . . . . . . . 24

3.3 Tabela com descrição dos pacientes com crise de ausência. . . . . . . . . . . . . 26

4.1 SD para redes com conexões aleatórias $\left(S D_{R}\right)$ e não-aleatórias $\left(S D_{N R}\right)$. A terceira coluna (ganho) é calculada como $1-S D_{r} / S D_{n r} \ldots \ldots \ldots \ldots$ 


\section{Capítulo 1}

\section{Introdução}

Sistemas complexos são formados por um grande número de componentes individuais que, ao interagirem entre si (de forma não-linear), levam à formação de um padrão emergente. Esse padrão não pode ser compreendido apenas analisando-se individualmente as partes do sistema. Dada a quantidade de componentes e a complexidade das interações entre eles, adquirir informações desses sistemas pode levar a um grande volume de dados, tornando sua análise mais difícil. Redes complexas surgiram como uma alternativa para modelar esse comportamento coletivo e integrado das partes individuais dos sistemas complexos. Em pouco tempo, essa abordagem foi aplicada em diversos campos da ciência, como na análise de interações entre proteínas (Jeong et al., 2001), redes metabólicas (Guimera e Nunes Amaral, 2005), ecologia (Krause et al., 2003); nas ciências sociais com estudos de redes de colaboradores (Newman, 2001) e relações pessoais (Han e Kim, 2008; Hu e Wang , 2009); e na engenharia com estudos de infraestruturas de transportes (Gastner e Newman, 2006; Guimerà et al., 2005). Esse sucesso da utilização de redes complexas é uma consequência do seu poder e flexibilidade para modelar praticamente qualquer sistema discreto (Costa et al., 2011).

As redes complexas identificaram padrões universais comuns à várias redes naturais e artificiais, por exemplo a propriedade de mundo-pequeno que é caracterizada pela presença de comunidades especializadas interligadas entre si (Watts e Strogatz, 1998), propriedade essa encontrada nas redes cerebrais (Friston et al., 1995; Tononi et al., 1994). Outra propriedade importante é a presença de lei de potência na distribuição de grau dos elementos da rede (Bassett e Bullmore, 2006; Sporns et al. , 2004); ou seja, poucos nós ligando-se a vários outros. A assortatividade: tendência de um nó se ligar aos elementos mais parecidos com ele, e vários outros padrões estruturais não aleatórios como: hierarquia (Eguiluz et al., 2005; Zhou et al., 2006), motifs (Sporns e Kötter, 2004) clube dos ricos (van den Heuvel e Sporns, 2011; van den Heuvel et al., 2012).

Redes complexas logo passaram a ser utilizadas para analisar dados de atividade cerebral, levantando mudanças nos padrões de conectividade sob diferentes condições, por exemplo em pacientes com Alzheimer (Stam et al., 2009, 2007), esquizofrenia (Bassett et al., 2008), depressão (Leistedt et al., 2009), déficit de atenção (Wang et al., 2009) e acidente vascular cerebral (Wang et al. , 2010). Esses e outros resultados sugerem a existência de uma relação entre a estrutura da rede e desordens neurológicas, e que talvez a causa dessas doenças estejam ligada às anomalias nas redes (Fornito e Bullmore, 2015; Sporns, 2014).

$\mathrm{Na}$ análise com redes complexas, a metodologia consiste em dois passos. Primeiro, é feita a representação da rede a partir dos dados. Depois, a estrutura da rede (grafo) é caracterizada através de medidas e assim fornecer algum significado no contexto do problema. A natureza dos dados e a inferência da rede variam de acordo com o problema, por exemplo, em uma rede social, a inferência pode ser feita monitorando a comunicação (por telefone, e-mail, etc.) entre as pessoas (nós da rede). Para o cérebro, os dados analisados são sinais coletados por eletroencefalografia (EEG), ressonância magnética funcional, eletrocorticografia, etc.; e o grafo pode ser calculado através de uma série de técnicas baseadas na teoria da sincronização, teoria da informação, processos estocásticos, métodos não lineares e física estatística (Lehnertz, 2011; Pereda et al., 2005). Em uma segunda etapa, as propriedades estruturais do grafo são mensuradas para então investigar as diferenças estruturais 
entre as redes inferidas (Costa et al., 2007).

Por outro lado, sabe-se que essas redes sustentam algum tipo de sistema dinâmico, então, além do levantamento das propriedades estruturais, também é necessário esclarecer a relação recíproca entre a dinâmica e a estrutura do grafo. Em outras palavras, entender não só como o sistema depende das suas partes, mas como ele depende da maneira que essas partes são conectadas (Motter et al., 2006).

Esse parece ser o caso da epilepsia, já que é um sistema dinâmico onde a conectividade exerce um papel fundamental na formação e propagação da atividade epileptiforme (Lehnertz et al., 2014). A epilepsia pode ser definida como uma desordem caracterizada pela ocorrência de crises convulsivas, que são causadas por uma sincronização anormal e excessiva da atividade cerebral (Fisher et al., 2005). Atinge mais de 50 milhões de indivíduos no mundo e cerca de $30 \%$ dos pacientes não conseguem controlar totalmente as crises, mesmo com toda assistência médica disponível (Schuele e Lüders , 2008). Por possuir várias perguntas em aberto em relação à formação e propagação das crises, existe uma forte demanda para o desenvolvimento de novos tratamentos para a epilepsia (Stacey e Litt ,2008).

A importância da topologia do grafo para a epilepsia está no fato do tempo para o início e fim das convulsões compreende um intervalo de tempo bastante curto. Essa escala de tempo do início, propagação e fim da crise são várias ordens de magnitude menor que o tempo para quaisquer possíveis mudanças no número de neurônios, axônios, dendritos e sinapses. A estrutura do estado sadio é a mesma do estado patológico, dessa forma a epilepsia deve ser um problema que emerge das propriedades dinâmicas do cérebro. Além disso, os sintomas apresentados durante manifestação da epilepsia são semelhantes, mesmo que a crise comece por motivos diferentes, como lesões ou tumores, em uma microescala. Isso significa que, para a evolução da crise ocorrer, uma rede comum em macro escala passa a ser utilizada. Além disso, dado o fato que o conceito de foco da crise não é bem definido e que muitas cirurgias de remoção do foco falham em dar um fim à ocorrência de convulsões. É provável que não exista um foco claro responsável pela crise, mas sim um conjunto de elementos dinamicamente conectados (Lemieux et al., 2011).

Por esses motivos, analisar a epilepsia utilizando o framework de redes complexas, averiguando a influência da conectividade na dinâmica, parece ser essencial para a compreensão de um modelo unificado, que explique como diferentes mecanismos em microescala, do início da crise, emerge para um caminho de maior escala dos circuitos do cérebro (Richardson, 2012).

\subsection{Objetivos}

O objetivo do trabalho é caracterizar a epilepsia sob a análise de redes complexas, desenvolver técnicas para quantificar como a topologia da rede se altera ao longo do tempo. Mas também levar em consideração o papel da estrutura do grafo na dinâmica responsável pela formação e propagação da crise. Além disso, encontrar como podemos alterar a estrutura de uma rede para obter certo controle na dinâmica e minimizar (ou maximizar) possíveis efeitos.

Os objetivos específicos são:

- Levantar o estado da arte de aplicações de redes complexas na modelagem da epilepsia.

- Implementar uma pipeline de funções para inferência das redes a partir das séries temporais.

- Comparar as medidas e verificar quais as melhores para caracterizar as mudanças estruturais do grafo durante as crises.

- Investigar como as mudanças na topologia durante a crise influencia a dinâmica de sincronização na rede.

- Criar simulações com redes artificiais para identificar quais parâmetros da rede aumentam ou diminuem os efeitos da dinâmica no grafo. 


\subsection{Justificativa}

Utilizar redes complexas para análise de dados cerebrais fornece uma outra interpretação para o problema de análise de sinais. Ao invés de caracterizar os mecanismos geradores desse sinais o objetivo passa a ser investigar as interações entre esses geradores, caracterizando de forma global o relacionamento de várias regiões do cérebro.

As simulações com modelos de neurônios artificiais permitem testar hipóteses que seriam muito difíceis de verificar com dados reais, por exemplo, analisar como as configurações na estrutura de redes em micro-escala influenciam na sincronização entre neurônios. Os resultados das simulações ajudam a entender os achados dos experimentos empíricos.

Além disso, a utilização de diferentes medidas de inferência de grafos fornece várias interpretações para o mesmo fenômeno, de modo que é desejável não se limitar apenas a uma medida conhecida.

\subsection{Organização do Trabalho}

No Capítulo 2, apresentamos os conceitos básicos de redes complexas e uma revisão sobre os achados recentes. No Capítulo 3 apresentamos os resultados obtidos através da análise de sinais reais, com objetivo de caracterizar as estruturas das redes funcionais durante crises de epilepsia. No Capítulo 4 apresentamos simulações que tentam implementar características encontradas na estrutura das redes durante as crises para analisar o impacto dessas características na sincronização. Finalmente, no Capítulo 5 discutimos algumas conclusões obtidas neste trabalho e possíveis trabalhos futuros. 


\section{Capítulo 2}

\section{Conceitos de redes complexas}

Este capítulo é dividido em duas partes. Na primeira é feita uma revisão sobre os conceitos de grafos e, na segunda, os principais métodos de inferência de redes a partir de sinais neurobiológicos são discutidos. Por último, são levantados os achados de trabalhos relacionados de aplicações de redes complexas na epilepsia.

\subsection{Fundamentos}

Um grafo $G$ pode ser definido como um par de conjuntos $G=(V, E)$, onde $V$ é o conjunto de nós (vértices) e $E$ é o conjunto de arestas. O nó $i$ é adjacente ao nó $j$ se existe a aresta $(i, j)$ em $E$. O número de nós do grafo define seu tamanho $N$. As arestas dos grafos podem indicar uma direção, nesse caso o grafo é dito direcionado, ou possuírem valores (pesos) atribuídos a elas, formando um grafo ponderado. Uma forma conveniente de representar um grafo é através de da matriz de adjacências $A=\left\{a_{i j}\right\}$ de tamanho $N \times N$, onde cada elemento $a_{i, j}$ é definido como:

$$
a_{i, j}= \begin{cases}1 & \text { se }(i, j) \in E \\ 0 & \text { se }(i, j) \notin E\end{cases}
$$

Para grafos não direcionados, a matriz de adjacências é simétrica, ou seja, $a_{i j}=a_{j i}$. Para grafos ponderados, $a_{i j}$ possui um valor que geralmente representa alguma propriedade física da aresta, como sua capacidade, largura de banda, tráfego, etc.

A figura 2.1 mostra alguns conceitos de teoria dos grafos, onde dois grafos são apresentados com suas respectivas matrizes de adjacências. Na esquerda, tem-se um grafo direcionado e ponderado, obtido, por exemplo, através de medidas de causalidade em dados funcionais. Na direita, temse um grafo não direcionado (simétrico em relação a diagonal) e ponderado que pode ser obtido utilizando-se medidas de correlação sobre dados funcionais. Três operações comumente empregadas durante a análise de redes complexas são exemplificadas na imagem. Simetrizar consiste em remover a informação de direcionalidade das conexões. Também pode-se remover conexões consideradas fracas aplicando-se um limiar, por exemplo para remover conexões menos importantes. Por último, é possível transformar uma matriz ponderada em valores binários ao desprezar o valor dos pesos.

As redes que representam o cérebro podem detalhar diferentes níveis de organização, como macro escala, onde os nós representam regiões do cérebro, ou em escalas menores, até o nível de representar os neurônios como nós da rede. Na literatura, as arestas podem ser classificadas em conexões anatômicas, funcionais ou efetivas, de acordo com o tipo de dado utilizado na inferência da rede (Friston, 1994). Conexões anatômicas são inferidas analisando o trato de massa branca entre regiões do cérebro. Conexões funcionais são calculadas medindo a magnitude das correlações temporal entre duas regiões que podem até estar anatomicamente desconectadas. Conexões efetivas representam relações causais de uma região sobre a outra (Friston et al., 2003; Rubinov e Sporns, 2010). Embora este trabalho seja sobre redes em macro escala, toda a discussão aqui é igualmente aplicável à microescala. 


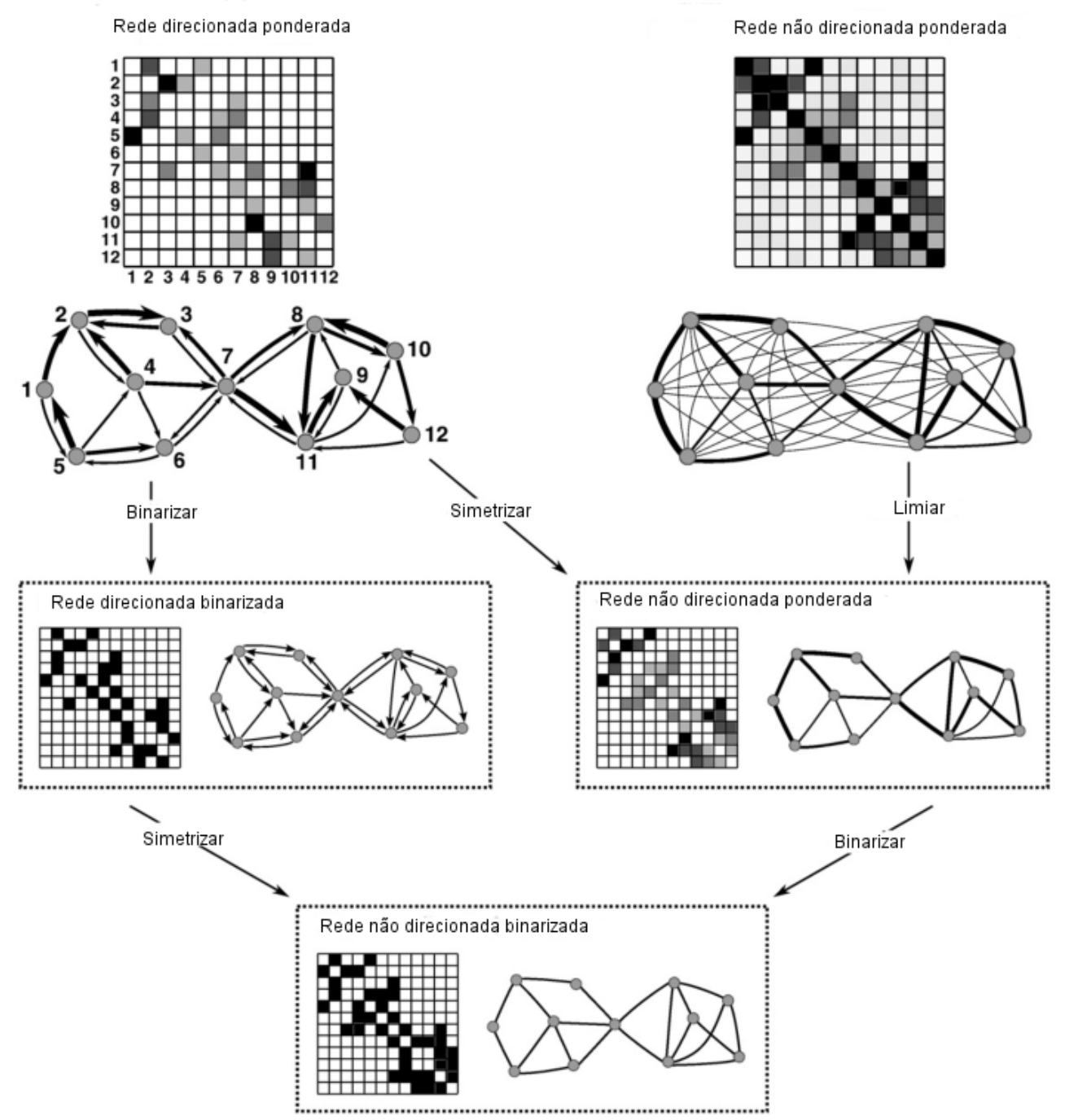

Figura 2.1: Dois exemplos de grafos com suas matrizes de adjacências. Algumas operações podem ser transformar a matriz, por exemplo podando as conexões fracas através de um limiar ou simetrizando a matriz em relação a diagonal. Adaptado de Rubinov e Sporns (2010).

Os pesos das arestas das redes do cérebro podem representar o tamanho ou densidade nas redes anatômicas, enquanto que nas redes funcionais pode significar a força (magnitude) das conexões. A direção nas redes funcionais depende do método de inferência da rede, se utilizado correlação, as arestas não possuem direção e a matriz é simétrica. Métodos que identificam causalidade e transferência de entropia podem inferir a direção da aresta.

\subsection{Caracterizando redes}

Após a inferência da rede, é necessário caracterizar sua estrutura para responder perguntas como: existem agrupamentos/módulos nessa rede? Quantas arestas precisam ser percorridas para sair de um nó e chegar a outro? Quais nós possuem mais conexões? Para obter respostas para essas perguntas, pode-se utilizar medidas que quantificam as propriedades estruturais dos grafos, ajudando a fornecer uma interpretação no contexto do problema Costa et al. (2007).

Um dos conceitos básicos na estrutura dos grafos é o caminho. Um caminho $P_{i_{0}, i_{n}}$ conecta os nós $i_{0}$ e $i_{n}$ em um grafo $G=(V, E)$ é uma coleção ordenada de $n+1$ nós $V_{p}=i_{0}, \ldots, i_{n}$ e $n$ arestas $E_{p}=\left(i_{0}, i_{1}\right),\left(i_{1}, i_{2}\right), \ldots,\left(i_{n-1}, i_{n}\right)$, tal que $i_{a} \in V$ e $\left(i_{\alpha-1}, i_{\alpha}\right) \in E$, para todo $\alpha$. O comprimento do 


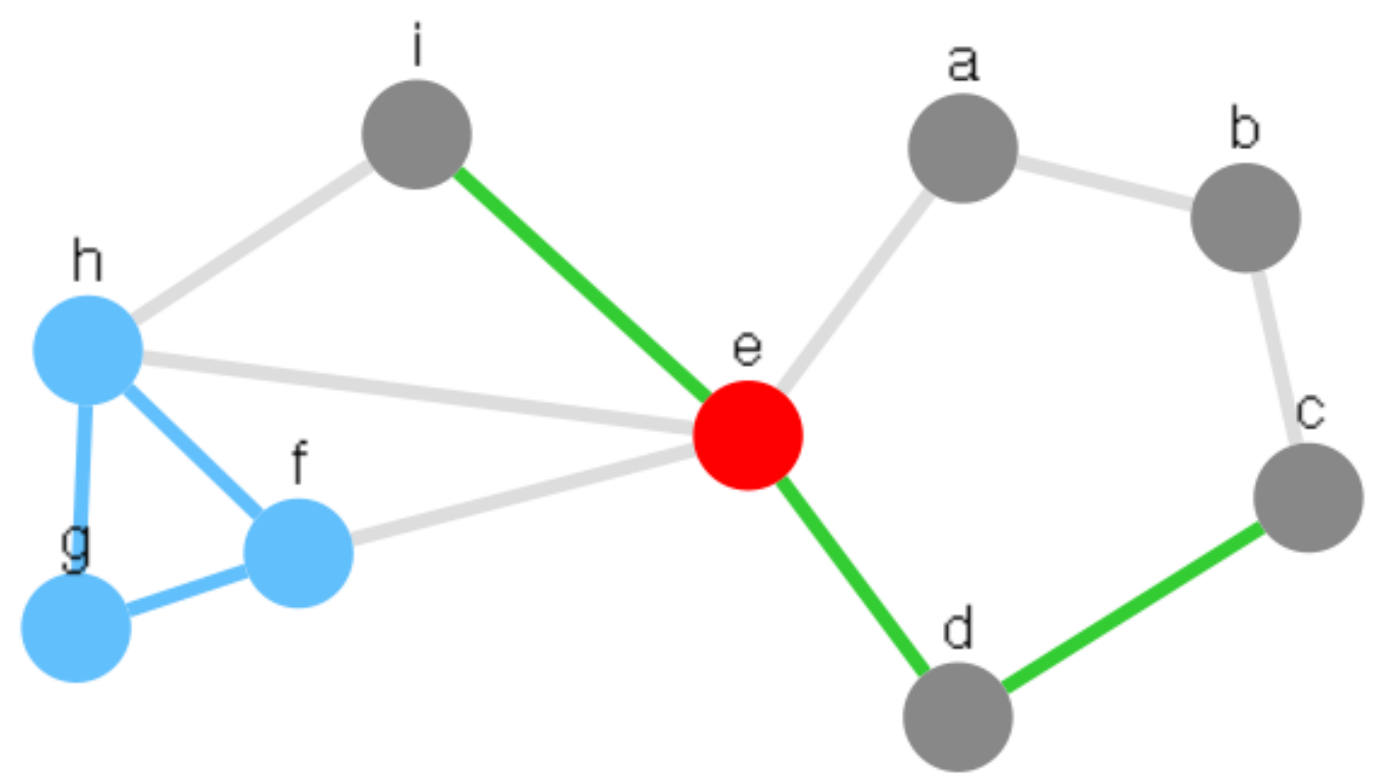

Figura 2.2: Conceitos estruturais dos grafos. O nó $V_{e}$ em vermelho é o de maior grau da rede, o menor caminho que liga o nó $V_{i}$ ao $V_{c}$ está destacado em verde, as conexões $E_{h g}$, $E_{h f}$ e $E_{f g}$ formam um triângulo, a presença de muitos triângulos ao redor de um nó indica um forte agrupamento naquela região. Esse grafo exibe dois módulos claros, a direita e a esquerda do nó $V_{e}$.

caminho $P_{i_{0}, i_{n}}$ é $n$, o número de arestas que formam o caminho. Uma medida importante baseada no caminho é o caminho mínimo entre dois nós, denominado $l_{i j}$. Quando dois nós não possuem um caminho entre eles $l_{i j}=\infty$. Para grafos não direcionados, $l_{i j}=l_{j i}$, mas isso não é necessariamente verdade em grafos direcionados. Na figura 2.2, o caminho mais curto entre os nós $V_{i}$ e $V_{c}$ está destacado na cor verde.

Uma medida baseada no caminho mais curto é o diâmetro do grafo, definido como

$$
d_{G}=\max _{i j} l_{i j}
$$

Outra medida bastante usada e baseada no caminho é a média do caminho mínimo, também chamada de caminho mínimo característico (Watts e Strogatz, 1998) e definida como:

$$
\bar{l}=\frac{1}{N(N-1)} \sum_{i j} l_{i j}
$$

Essas medidas definem a facilidade com a qual a informação circula em uma rede. No cérebro elas estão relacionadas com a capacidade de combinar informação processada em diferentes regiões, em outras palavras, são medidas de integração.

Para medir a importância de um nó na rede, se recorre às medidas de centralidade, que podem ser de grau, de proximidade ou intermediação. O grau de um nó $i$ é o número de arestas $k_{i}$ que se liga a $i$. Nas redes direcionadas o grau pode ser classificado como de entrada $k_{i}^{i n}$, ou seja, o número de arestas que chegam em $i$ ou grau de saída $k_{i}^{\text {out }}$ como o número de arestas saindo de $i$. O grau de um nó em grafos direcionados é a soma do grau de entrada e saída, que podem ser calculados como:

$$
k_{i}^{i n}=\sum_{j} a_{j i}
$$




$$
k_{i}^{\text {out }}=\sum_{j} a_{i j}
$$

Em grafos não direcionados, a matriz de adjacência é simétrica, portando $k_{j}^{i n}=k_{i}^{\text {out }}$. Nós com elevado valor de grau são denominados hubs e representam regiões que interagem com várias outras, possuindo um papel importante na integração de informação. A figura 2.2 destaca em vermelho um hub, o nó tem grau 5, que é o maior valor de grau na rede. A centralidade de proximidade é baseada na ideia que nós centrais participam de vários caminhos mínimos da rede e é definida como:

$$
g_{i}=\frac{1}{\sum_{j \neq i} l_{i j}}
$$

$g_{i}$ será maior para nós que possuírem menor caminho mínimo para outros nós. Uma medida semelhante é a centralidade de intermediação, definida como a fração de todos os caminhos mínimos que passam por um nó $i$ Freeman (1977). Essa última medida é mais usada para identificar nós que servem como pontes entre agrupamentos de nós. Se $\sigma_{h j}$ é o número de caminhos mínimos de $h$ até $j$ e $\sigma_{h j}(i)$ é o número desses caminhos que passam por $i$, então a centralidade de intermediação é definida como:

$$
b_{i}=\sum_{h \neq j \neq i} \frac{\sigma_{h j}(i)}{\sigma_{h j}}
$$

Um terceiro tipo de medida são as de agrupamentos que, para as redes do cérebro, pode ser interpretado como regiões densamente interconectadas e responsáveis por processamento especializado. O conceito de agrupamento na rede está relacionado com o número de triângulos, formados pelas arestas ao redor de um dado nó. Por exemplo, se o vértice $i$ está conectado ao vértice $j$, e $j$ está conectado ao $m$ e se $m$ se conecta ao $i$, tem-se um triângulo. Por exemplo, a figura 2.2 mostra um triângulo formado entre os vértices $h, g$ e $f$. A medida mais comum de agrupamento é o coeficiente de agrupamento. Para um vértice $i$, o coeficiente de agrupamento $C(i)$ é definido como o número de triângulos ao redor de $i$ pelo número máximo de arestas:

$$
\begin{aligned}
& C(i)=\frac{t_{i}}{k_{i}\left(k_{i}-1\right) / 2} \\
& t_{i}=\frac{1}{2} \sum_{j m} a_{i j} a_{j m} a_{m i}
\end{aligned}
$$

A média do coeficiente de agrupamento para todo o grafo é dada como:

$$
\bar{C}=\frac{1}{N} \sum_{i} C(i)
$$

Existem várias outras medidas que medem a segregação, integração e outras características dos grafos, uma lista bastante completa delas pode ser encontrada em Costa et al. (2007).

\subsection{Inferindo as Redes}

Redes cerebrais podem ser calculadas de diversas maneiras: redes anatômicas podem ser inferidas por tractografia, as redes funcionais são inferidas através de medidas de dependências entre séries temporais e foi o tipo de redes analisadas nesse trabalho. Existem dois frameworks básicos para calcular essas medidas, o orientado a dados que leva em conta apenas as séries temporais e o orientado a modelo, que primeiro levanta uma hipótese sobre as relações entre as séries e só depois um modelo é ajustado aos dados (Markus, 2012). Todas as medidas usadas aqui seguiram a abordagem orientada a dados. 
Os métodos orientados a dados podem considerar relações lineares ou não lineares entre os sinais ou ainda inferirem no domínio do tempo ou no domínio da frequência. Cada técnica tem suas restrições e geram grafos que podem ou não ser ponderados ou direcionados, de forma que a interpretação da rede pode depender do método.

\subsubsection{Correlação de Pearson}

Correlação de Pearson é uma medida de dependência linear entre duas séries temporais, retornando um valor no intervalo $[-1,1]$ em que 1 significa máxima correlação positiva, 0 significa ausência de correlação e -1 máxima correlação negativa.

Para duas séries $x$ e $y$ de tamanho $n$, a correlação $r(x, y)$ é calculada como:

$$
r(x, y)=\frac{\sum_{i=1}^{n}\left(x_{i}-\overline{(} x\right)\left(y_{i}-\bar{y}\right)}{\sqrt{\sum_{i=1}^{n}}\left(x_{i}-\bar{x}\right)^{2} \sqrt{\sum_{i=1}^{n}\left(y_{i}-\bar{y}\right)^{2}}}
$$

onde $\bar{x}$ e $\bar{y}$ são as médias de $x$ e $y$ respectivamente.

Nas redes inferidas por correlação, a matriz de adjacência é simétrica, pois $r(x, y)=r(y, x)$ e ponderada. É comum utilizar algum método de poda para remover conexões muito fracas já que o grafo resultado será totalmente conectado. As vantagens de usar correlação estão na simplicidade, fácil interpretação e no fato de não assumir restrições em relação aos dados, além da linearidade.

\subsubsection{Causalidade de Granger}

Wiener (1956) concebeu a noção que, se uma previsão de uma série temporal pode ser estatisticamente melhorada adicionando informação de outra série, então esta última possui uma relação causal com a primeira. Granger (1969) formalizou essa ideia no contexto de modelos autoregressivos bivariados. Para ilustrar esse conceito, suponha que temos duas variáveis $x(t)$ e $y(t)$. Considere duas previsões para $x(t)$, uma usando apenas os termos passados de $x(t)$ e outra usando $x(t)$ e $y(t)$. Se a segunda previsão for significativamente melhor, então o passado de $y(t)$ possui informações para a previsão de $x(t)$ que não está em $x(t)$. Neste caso, $y(t)$ Granger-causa $x(t)$.

Esse conceito pode ser formalizado com modelos auto-regressivos, considere o modelo para previsão de $x(t)$ com base nos $m$ termos passados:

$$
x(t)=\sum_{j=1}^{m} \alpha_{j} x(t-j)+\epsilon_{x}(t)
$$

Onde $\epsilon_{x}(t)$ é o resíduo e cuja magnitude é medida pela variância $\operatorname{var}\left(e_{x}(t)\right)$. O mesmo modelo incluindo $y(t)$ ficaria como:

$$
x(t)=\sum_{j=1}^{m} a_{j} x(t-j)+\sum_{j=1}^{m} b_{j} y(t-j)+\epsilon_{x \mid y}(t)
$$

Se $\operatorname{var}\left(\epsilon_{x \mid y}(t)\right)<\operatorname{var}\left(\epsilon_{x}(t)\right)$, então $y(t)$ possui uma relação causal em $x(t)$. Analogamente, podemos considerar o mesmo para $y(t)$ :

$$
\begin{gathered}
y(t)=\sum_{j=1}^{m} \beta_{j} y(t-j)+\epsilon_{y}(t) \\
y(t)=\sum_{j=1}^{m} c_{j} x(t-j)+\sum_{j=1}^{m} d_{j} y(t-j)+\epsilon_{y \mid x}(t)
\end{gathered}
$$

e novamente se $\operatorname{var}\left(\epsilon_{y \mid x}(t)\right)<\operatorname{var}\left(\epsilon_{y}(t)\right)$, então $x(t)$ possui influência causal em $y(t)$. Isto pode ser testado utilizando o teste- $F$. Para o caso com mais de duas variáveis, $y(t)$ Granger-causa $x(t)$ caso essa última melhorar a previsão da primeira quando as outras variáveis $(z(t)$, etc.) também forem levadas em consideração. Este seria a causalidade de Granger condicional (Ding et al., 2006). 
Apesar de ter sido mostrado aqui o conceito de causalidade de Granger formulado como modelos autoregressivos lineares, outras extensões foram propostas. Por exemplo para considerar padrões não-lineares (Ancona et al., 2004; Marinazzo et al., 2008), para conjuntos de séries temporais (Barrett et al., 2010; Ladroue et al., 2009), para o domínio da frequência (Dhamala et al., 2008b) e para processos pontuais (Nedungadi et al., 2009).

As redes inferidas por causalidade de Granger são direcionadas e binárias, no sentido de não apresentarem um peso para conexão, apenas a existência (quando o teste é significativo) ou ausência do link. Para ter uma ideia da força de interação entre os sinais, pode-se usar o log da estatística F (Bressler e Seth, 2011). Uma desvantagem dessa abordagem com modelo AR é a condição de estacionaridade, que nem sempre pode ser verdadeira. Para contornar este problema, pode-se segmentar o sinal em intervalos menores que são estacionários, ou tentar remover tendência linear, ou diferenciando os dados (von Bünau et al., 2009).

\subsubsection{Coerência Parcial Direcionada}

A coerência parcial direcionada (PDC) é um método para inferir relações de causalidade de Granger no domínio da frequência. Como a atividade cerebral é marcada por ritmos, pode ser interessante saber em qual ritmo a relação de causalidade está ocorrendo entre duas regiões cerebrais. No próximo capítulo, é demonstrado um exemplo de aplicação do PDC, empregado para analisar as relações de causalidade entre sinais durante uma crise de epilepsia cuja a atividade elétrica se concentra em torno dos $3 \mathrm{~Hz}$. Dessa forma, é possível verificar as relações relacionadas com fenômeno que se quer analisar, sem as contribuições de outras frequências.

O PDC do sinal $i$ para o sinal $j$ na frequência $\omega$, denotado como $\left|\pi_{i \leftarrow j}(\omega)\right|$ é definido como:

$$
\left|\pi_{i \leftarrow j}(\omega)\right|=\frac{\left|\boldsymbol{A}_{i j}(\omega)\right|}{\sqrt{\sum_{k}\left|\boldsymbol{A}_{k j}(\omega)\right|^{2}}}
$$

Onde $\boldsymbol{A}(\boldsymbol{\omega})$ é a diferença entre a matriz identidade $I$ de tamanho $n x n$, com $n$ igual o número de séries, pela transformada Fourier dos coeficientes do modelo AR:

$$
\boldsymbol{A}(\omega)=I-\sum_{r=1}^{m} \boldsymbol{a}(r) e^{-\mathrm{i} \omega \mathrm{r}}
$$

onde $m$ é a ordem do modelo, e $\boldsymbol{a}(r)$ é a matriz dos $n x n$ coeficientes do modelo AR. O efeito da normalização no denominador da equação 2.16 faz com que o resultado do PDC seja um número entre 0 e 1 , fornecendo uma ideia da força de interação entre dois sinais.

\subsubsection{Phase Locking Value}

O conceito de sincronização de fase foi discutido por Kurths et al. (2001) e tem sido bastante empregado desde então. Considerando a definição em que a diferença de fase é $m=n=1 \mathrm{em}$ $\left|\Delta \phi_{t}\right|=\left|m \phi_{i, t}-n \phi_{j, t}\right|$. Para calcular a sincronização de fase, é necessário conhecer a fase instantânea de ambos os sinais. Foi utilizada uma definição de fase que pondera a contribuição de energia em todas as escalas wavelets:

$$
\phi_{\tau}=\frac{1}{\Gamma_{\tau}} \sum_{\ell}\left|W_{\tau}(\ell)\right|^{2} \phi_{\tau}(\ell),
$$

onde $\phi_{\tau}(\ell)=\arctan \Im\left[W_{\tau}(e l l)\right] / \Re\left[W_{\tau}(\ell)\right], \Gamma_{\tau}=\sum_{\ell}\left|W_{\tau}(\ell)\right|^{2} \mathrm{e}$

$$
W_{\tau}(\ell)=\int_{-\infty}^{\infty} f(t) \psi_{\tau}(\ell, t) d t
$$

é a transformada wavelet de uma dada função $f(t)$ localizada em $\tau$ com escala $\ell$. O kernel da função usada é definida como $\psi_{\tau}(\ell, t)=\pi^{-1 / 4} \exp (-6$ it $) \exp \left(\frac{-\mathrm{t}^{2}}{2}\right)$. 
Com isto, é possível calcular o PLV, que caracteriza a estabilidade da diferença de fase entre duas séries por:

$$
\mathrm{PLV}_{i j}=\frac{1}{T}\left|\sum_{\tau=1}^{T} \exp \left(\mathrm{i} \Delta \phi_{\tau}\right)\right|,
$$

onde $T$ é o comprimento do sinal. Em um cenário de phase locking perfeito, o PLV é igual a 1, resultando em sincronização completa. Também é possível calcular o PLV considerando-se um lag de tempo $d$ :

$$
\operatorname{PLV}_{i j}(d)=\frac{1}{T}\left|\sum_{\tau=1}^{T} \exp \left(\mathrm{i} \Delta \phi_{\tau}(d)\right)\right|,
$$

onde $\Delta \phi_{\tau}(d)=\phi_{i, \tau}-\phi_{j, \tau-d}$ e $\phi_{j, \tau-d}$ são as fases estimadas para a série atrasada. Quando $i=j$, o PLV é calculado sobre o lag zero e portanto é o maior possível.

\subsection{Redes Complexas na Epilepsia}

Outros trabalhos utilizando diferentes métodos para análise conseguiram resultados semelhantes em relação a conectividade para pacientes com epilepsia. Uma lista dos achados de conectividade funcional é resumida a seguir.

\section{Coeficiente de agrupamento e caminho mínimo}

Tanto o coeficiente de agrupamento $(\bar{C})$ quanto o caminho mais curto $(\bar{l})$ apresentam uma evolução temporal no formato de concavidade, a medida que a crise avança. Esses resultados são consistentes em crises de ausência e focal (com ou sem generalização) (Bialonski et al., 2011; Gupta et al., 2011; Kramer et al., 2010; Kuhnert et al., 2010; Ponten et al., 2007, 2009; Schindler et al., 2008). Esses resultados indicam que a rede, antes da crise, possui um estado mais aleatório, e durante a crise, apresenta um estado mais organizado (Lehnertz et al., 2014).

\section{Assortatividade}

Em relação à assortatividade, outro trabalho reportou uma evolução côncava similar ao $\bar{C}$, com valores maiores durante a crise que antes e depois (Bialonski, 2012). Esse resultado indica que, durante a crise, surge uma rede de vários nós com alto valor de grau interconectados entre si (Lehnertz et al., 2014).

\section{Características dos nós}

Poucos estudos analisaram a evolução das propriedades dos nós ao longo da evolução da crise e, os que fizeram, concentraram-se nas medidas relacionadas com graus ou centralidade, na tentativa de encontrar alguma relação entre características dos nós e a região do foco (Kramer et al., 2008; Varotto et al., 2012; Wilke et al., 2011). Entretanto, não existe uma relação clara entre nós com alto valor de centralidade e o foco (Geier et al., 2015).

\section{Características topológicas durante o interictal}

Outros trabalhos comparam as redes de pessoas saudáveis com pacientes de epilepsia fora do estado da crise (Horstmann et al., 2010; Vlooswijk et al., 2011; Zhang et al., 2011). O objetivo desse tipo de comparação é encontrar se algo na rede ajuda a iniciar a crise. Horstmann et al. (2010) e Vlooswijk et al. (2011) mostraram diferenças nas medidas $\bar{C}$ e $\bar{l}$ entre os dois grupos, independente do estado comportamental dos indivíduos no momento da aquisição. Zhang et al. (2011) mostrou que, mesmo fora da crise, pacientes com epilepsia apresentem mais nós que funcionam como hubs. 


\begin{tabular}{|c|c|c|c|c|}
\hline Referência & Medidas & Crise & Dado & Método de Inferência \\
\hline Gupta et al. (2011) & $\bar{C}$ e $\bar{l}$ & G & MEG & Coerência \\
\hline Kuhnert et al. (2010) & $\bar{C}$ e $\bar{l}$ & $\mathrm{~F}$ & ECoG & Sincronização \\
\hline Kramer et al. (2010) & Outras & $\mathrm{F}$ & ECoG & Correlação \\
\hline Ponten et al. (2009) & $\bar{C}$ e $\bar{l}$ & G & EEG & Sincronização e Coerência \\
\hline Ponten et al. (2007) & $\bar{C}$ e $\bar{l}$ & $\mathrm{~F}$ & EEG & Sincronização \\
\hline Schindler et al. (2008) & $\bar{C}$ e $\bar{l}$ & $\mathrm{~F}$ & EEG & Correlação \\
\hline Varotto et al. (2012) & $g_{i}$ & $\mathrm{~F}$ & ECoG & PDC \\
\hline Wilke et al. (2011) & & $\mathrm{F}$ & ECoG & DTF \\
\hline Kramer et al. (2008) & $\bar{l}, \bar{C}, g_{i}$ e outras & $\mathrm{F}$ & ECoG & Correlação \\
\hline Geier et al. (2015) & Centralidade & $\mathrm{F}$ & ECoG & Correlação \\
\hline Zhang et al. (2011) & $\bar{C}, \bar{l}$ e $S$ & $\mathrm{~F}$ & ECoG & Sincronização \\
\hline Horstmann et al. (2010) & $\bar{C}$ e $\bar{l}$ & $\mathrm{~F}$ & EEG e MEG & Correlação e PLV \\
\hline Vlooswijk et al. (2011) & $\bar{C}, \bar{l}$ e $S$ & $\mathrm{~F}$ & fMRI & Correlação \\
\hline
\end{tabular}

Tabela 2.1: Tabela com resumo de alguns trabalhos que aplicaram medidas de redes complexas na caracterização da atividade eletrofisiológica de pacientes com epilepsia. A maioria dos trabalhos utilizou $\bar{C}$ e $\bar{l}$ como medidas e utilizando dados de crise focal. A coluna Crise, identifica se o trabalho usou dados de crise focal $(F)$ ou generalizada $(G)$. Em relação a inferência da rede, Sincronização na tabela significa que foi empregada alguma medida que tenta medir essa característica, mas não necessariamente o PLV. 


\section{Capítulo 3}

\section{Relações entre estrutura e atividade epileptiforme}

Neste capítulo são apresentados os resultados relacionados com inferência das redes a partir de dados reais de EEG e a relação entre a estrutura dessas redes e a epilepsia.

Na seção 3.3 são inferidas redes utilizando causalidade de Granger a partir do EEG de pacientes com epilepsia no lobo temporal. Junto com esse grafo de causalidade também é inferido o nível de sincronização par a par entre os canais. O objetivo é encontrar como a estrutura da rede modula a sincronização durante uma crise.

Na seção 3.4, um medida de entropia cruzada é utilizada no domínio da frequência e revela outra característica dos sinais, que não é clara quando se aplica as medidas de conectividade mais comuns: regiões que parecem independentes do resto do cérebro durante uma crise de epilepsia. Os sinais analisados foram EEG de pacientes com crises de ausência.

Na seção 3.5, o método de coerência parcial direcionada (PDC) é aplicado nos mesmos dados de crises de ausência da seção 3.4 com o objetivo de identificar a evolução do nível de acoplamento entre os sinais durante a crise.

\subsection{Metodologia}

Os métodos utilizados nesse capítulo para o processamento de sinais foram o PDC, causalidade de Granger utilizando o modelo auto-regressivo (AR), PLV e entropia cruzada. Como causalidade e PDC utilizam o modelo AR, foi utilizado uma sequência de passos para identificar, ajustar e validar o modelo AR, como descrito na literatura. Essa sequência pode ser vista na figura 3.1

O primeiro passo é checar se o sinal é estacionário, que é uma premissa que deve ser satisfeita quando se usa a modelagem AR. Um sinal é dito estacionário quando suas propriedades não mudam ao longo do tempo. Neste trabalho considera-se a definição de estacionariedade fraca, também conhecida como estacionariedade de segunda ordem, que necessita que duas condições sejam verdadeiras: a média e a auto-covariância do processo não podem variar ao longo do tempo.

Para testar se a série é estacionária recorre-se ao teste de Dickey-Fuller, caso não seja estacionário provavelmente existe tendência no sinal. Esta pode ser removida ajustando-se uma reta aos dados e subtraindo sua função dos dados (detrend na caixa do fluxograma). Outra forma de retirar tendência é fazer uma ou mais diferenciações: subtrair cada ponto da série por um ponto imediatamente anterior. Outra possível causa de não estacionariedade é a presença de ruído de linha, que pode ser removido aplicando-se filtro multitaper.

Este pré-processamento foi aplicado também quando se estimou a sincronização via PLV na seção 3.3. Apesar do método não exigir estacionariedade, como foi feito uma comparação entre a rede estimada por causalidade de Granger e a sincronização, os dois métodos receberam como entrada o mesmo sinal transformado.

Após essa primeira estapa vem a identificação do modelo AR, cujo objetivo é estimar a ordem do modelo. A identificação pode ser feita de forma visual, calculando-se a autocorrelação do sinal 


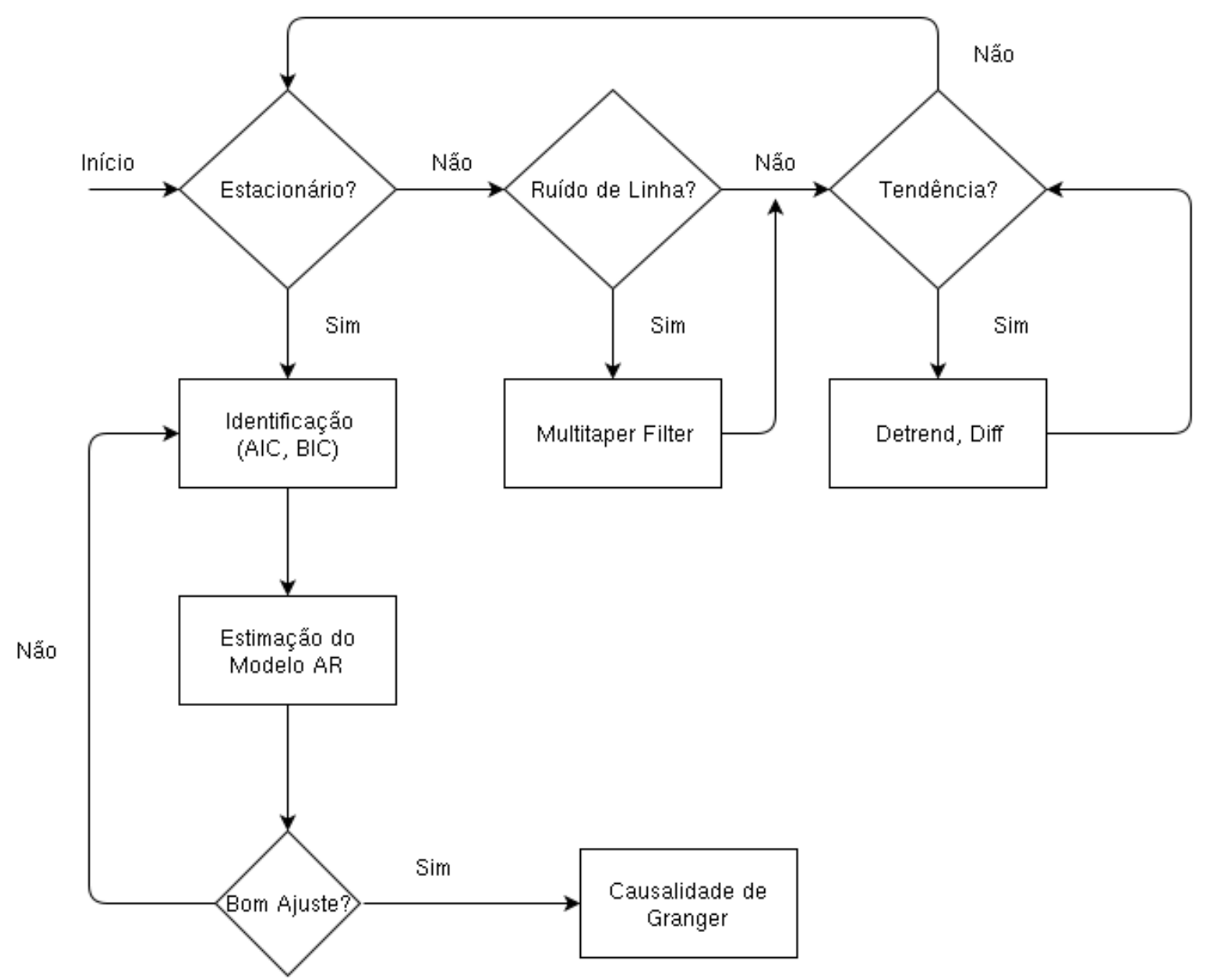

Figura 3.1: Fluxograma dos passos para ajustar o modelo auto-regressivo em uma série temporal. 


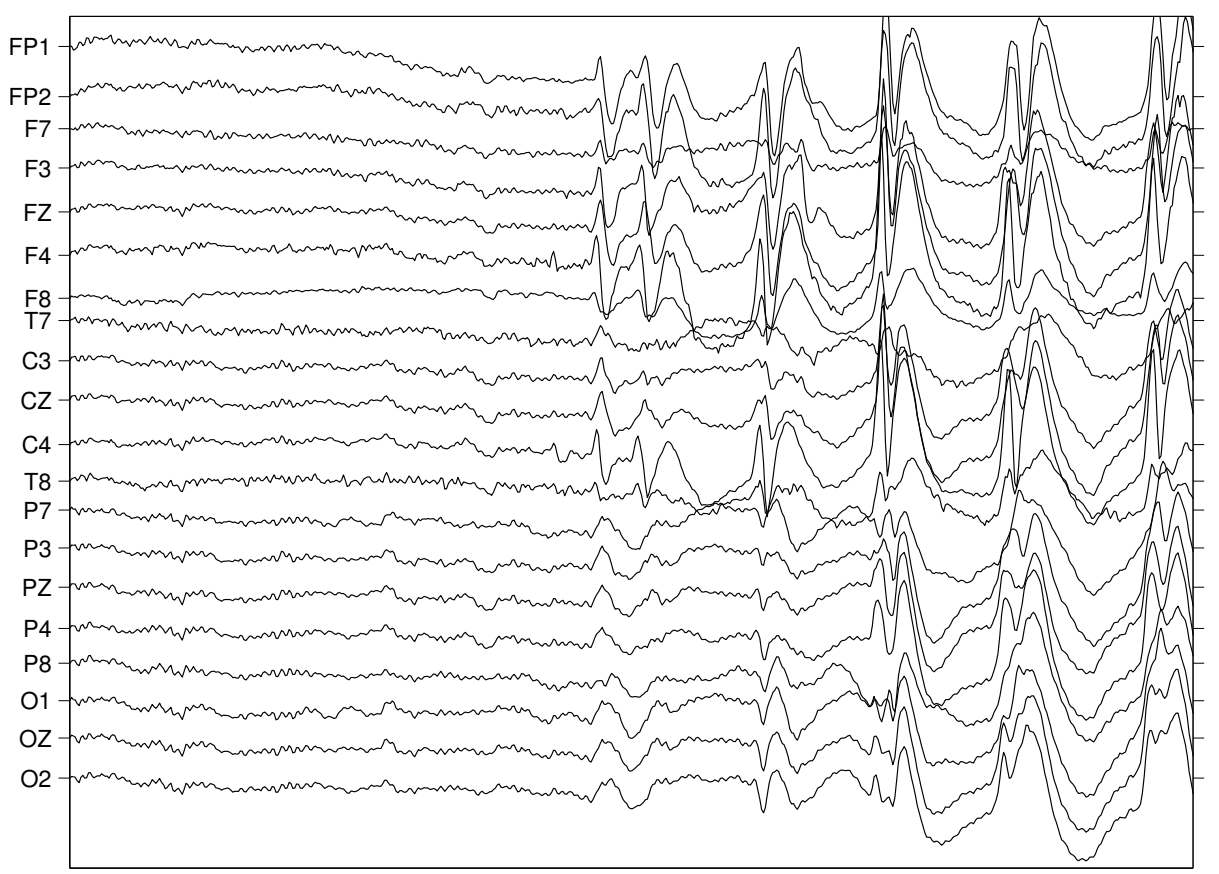

Figura 3.2: Trecho de 2 segundos de duração de um sinal de EEG durante uma crise de ausência. A crise é caracterizada por um aumento na amplitude e uma sincronização comum em todos os eletrodos.

e escolhendo como ordem o lag que ainda for significativo na autocorrelação. Um problema desse método é a falta de objetividade, já que pessoas diferentes podem escolher ordens diferentes e a falta de praticidade. Uma forma mais objetiva é utilizar o critério de informação de Akaike.

Depois da identificação, os coeficientes do modelo são estimados e a qualidade do ajuste é conferida verificando-se se os resíduos se comportam como ruído branco. Caso negativo, provavelmente a ordem escolhida foi errada e deve ser alterada. Por fim, se o ajuste estiver satisfatório, a causalidade de Granger pode ser verificada como foi descrito no capítulo 2.

\subsection{Dados}

Dois conjuntos de dados foram utilizados nas análises deste capítulo. Para a seção 3.3 foi utilizado o EEG de 8 crianças e adolescentes com epilepsia focal, coletados no Hospital das Clínicas de Ribeirão Preto. A disposição dos eletrodos segue o Sistema Internacional 10-10, com taxa de amostragem de $200 \mathrm{hz}$ e foram considerados 38 ou 40 eletrodos (esse é o número de nós das redes).

Esse tipo de epilepsia é caracterizado pelo início da atividade epileptforme ocorrer em uma região, podendo ou não generalizar para outros locais do cérebro. No caso destes dados, os pacientes eram resistentes ao medicamente e estavam sendo avaliados para a cirurgia de remoção do foco. Nos oito pacientes as crises generalizavam e sua duração é bastante variada, de 30 segundos até vários minutos.

As outras análises foram feitas usando dados de 8 pacientes com crises de ausência. A aquisição utilizou de 32 canais do equipamento (Biologic e Ceegraph). Eletrodos foram distribuídos de acordo com o Sistema Internacional 10-20. Todos os traçados foram coletados com um filtro passa alta de $1 \mathrm{~Hz}$ e passa baixa de $70 \mathrm{~Hz}$.

Essas crises são um tipo diferente da epilepsia focal, pois começam de forma generalizadas, não possuindo um foco claro. Além disso apresentam um padrão característico na forma do sinal: o complexo espícula-onda, que pode ser visto na figura 3.2. A duração das crises é geralmente mais curta que as focais, variando de 5 até 40 segundos e atinge em maior parte crianças.

Em todos os dados, o início e o final da crise foram determinadas por um eletrofisiologista.. 


\subsection{Relação entre estrutura e sincronização}

Nesse resultado, para cada 5 segundos de sinal, calculamos duas medidas: a sincronização de fase entre os pares dos canais de EEG e o grafo. Para o grafo, criamos duas medidas baseadas no grau dos nós e as comparamos com a sincronização, com o objetivo de encontrar alguma relação entre a estrutura do grafo e a sincronização. Vimos que, durante a crise, surgem mais nós com maior grau, os hubs, nos momentos que a sincronização também está alta. Acreditamos que essa característica na estrutura do grafo está relacionada com esse sincronismo mais alto.

A rede foi inferida para cada 5 segundos de sinal (1000 pontos), utilizado o teste de causalidade de Granger e a ordem do modelo auto-regressivo foi definido com o AIC (ficou entre 2 e 5 na maioria dos grafos). No pré-processamento, foi removido ruído de $60 \mathrm{hz}$ e tendência linear.

\subsubsection{Métodos}

Para caracterizar as redes, criamos duas medidas usando uma matriz de adjacência $n \times n G, T_{j}$ mede a porcentagem de nós com relação causal sobre outros nós:

$$
T_{j}=\frac{1}{n-1} \sum_{i=1, i \neq j}^{n} G_{i j} .
$$

Em outras palavras, $T_{j}$ é a fração dos $j$-ésimos graus de saída divididos pelo número de outros nós. A média para toda a rede de conexões causais é dada por $R=\sum_{j=1}^{n} T_{j} / n$. A razão de conexões direcionadas é dado por

$$
C=\frac{1}{n} \sum_{j=1}^{n} C_{j},
$$

onde $C_{j}=1$ se $T_{j}>\lambda$, caso contrário $C_{j}=0$ e $\lambda$ é um limiar. Neste trabalho usamos $\lambda=0$. A segunda medida é definida como

$$
\tilde{R}=\frac{1}{C \cdot n} \sum_{j}\left(C_{j} \cdot T_{j}\right),
$$

onde $C \cdot n$ é o numero de valores diferentes de zero de $T_{j} . \tilde{R}$ pode ser interpretado como a razão entre nós que causam outros nós pelo número total de nós que possuem conexões de saída. A diferença entre $R$ e $\tilde{R}$ é que o segundo é dependente do número de nós com conexões acima de um limiar $\lambda$.

\subsubsection{Resultados}

O resultado para o PLV, $C$ e $\tilde{R}$, com média e desvio padrão para as redes calculadas em 21 segundos de sinal, antes da crise e durante a crise, dos 8 pacientes, estão na Tabela 3.1.

Não observamos diferença significativa para medida $R$ entre os períodos ictal e inter-ictal. ( $p=$ $0,588$, teste pareado de Wilcoxon $)$. O mesmo pode ser dito em relação à medida $C(p=0,441$, W-teste). Entretanto, ao considerar o $\tilde{R}$, que também leva $C$ em consideração, percebemos uma diferença significativa entre o ictal e inter-ictal ( $p=0,003$, W-teste). Essa diferença coincide com o aumento de hubs no período ictal e reforça a importância de analisar as duas medidas em conjunto.

\section{Grafos com alto valor de grau de saída aparecem em janelas consecutivas durante a crise.}

Durante a crise, a matriz de adjacência é caracterizada pela presença de nós com alto grau de saída. Esses nós são menos frequentes em períodos anteriores a crise. Isso pode ser um indicativo de uma transição de uma estrutura mais aleatória para mais organizada. A figura 3.3 mostra duas matrizes da rede para o Paciente 1 da tabela 3.1, em 3.3 (a) tem-se um grafo do período anterior a 
Tabela 3.1: Medidas de grafo e sincronização para todos os 8 pacientes. Os valores na tabela são as médias para cada medida com o desvio padrão entre parênteses. Adaptado de Rodrigues et al. (2014).

\begin{tabular}{c|ccc|ccc}
\hline & \multicolumn{3}{|c|}{ Pre-ictal } & \multicolumn{3}{c}{ Ictal } \\
\hline Paciente & PLV & C & $\tilde{R}$ & PLV & C & $\tilde{R}$ \\
\hline 1 & $.538(.018)$ & $.410(.248)$ & $.042(.014)$ & $.642(.096)$ & $.589(.158)$ & $.112(.052)$ \\
2 & $.446(.016)$ & $.278(.039)$ & $.051(.007)$ & $.639(.025)$ & $.384(.057)$ & $.198(.041)$ \\
3 & $.483(.013)$ & $.394(.240)$ & $.064(.046)$ & $.611(.031)$ & $.373(.268)$ & $.107(.059)$ \\
4 & $.433(.040)$ & $.352(.118)$ & $.073(.032)$ & $.683(.028)$ & $.463(.223)$ & $.112(.056)$ \\
5 & $.439(.012)$ & $.155(.111)$ & $.078(.026)$ & $.510(.007)$ & $.615(.109)$ & $.185(.017)$ \\
6 & $.630(.028)$ & $.548(.056)$ & $.036(.003)$ & $.612(.019)$ & $.421(.203)$ & $.072(.046)$ \\
7 & $.627(.017)$ & $.657(.193)$ & $.086(.036)$ & $.628(.024)$ & $.510(.174)$ & $.129(.068)$ \\
8 & $.614(.009)$ & $.430(.073)$ & $.061(.008)$ & $.607(.029)$ & $.358(.148)$ & $.091(.116)$ \\
\hline
\end{tabular}

crise, é possível notar que as conexões estão mais distribuídas na matriz, sem alguma organização ou padrão muito claro, mas em (b) tem-se um grafo durante a crise, com dois nós, 30 e 33, possuindo um grande valor de grau de saída.

\section{Durante a crise a sincronização é mais elevada.}

Um exemplo da sincronização pode ser visto na figura 3.4 (a) e (b) durante os períodos pré-crise e crise, respectivamente, para o Paciente 1. Quanto mais escuro, maior o nível de sincronismo. Como esperado, a sincronização é maior durante a crise, esta é uma característica bem documentada do estado epiléptico. Os histogramas em (a) e (b) são dos valores dessa matriz de PLV, a linha pontilhada é a mediana da matriz. Pode-se perceber um valor maior na mediana e uma distribuição assimétrica na direção dos valores mais altos para a matriz do período da crise. Acreditamos que esse alto valor na sincronização está relacionado com a presença de hubs, indicando um possível papel dessa estrutura na formação ou propagação da crise. A relação entre as medidas dos grafos e a sincronização para dois pacientes pode ser observado na figura 3.5, cada coluna mostra o PLV, $C$ e $\tilde{R}$ para um paciente. Observamos que o período com alta sincronização coincide com um alto valor de $\tilde{R}$ em 6 dos 8 pacientes. Isso pode indicar uma importância do papel dos hubs: o número de conexões apenas não é responsável pela sincronização, mas sim a maneira de como essas conexões estão organizadas na estrutura do grafo.

Esses resultados são compatíveis com os achados de Morgan e Soltesz (2008) que estudou o papel dos hubs na formação da crise utilizando um modelo simulado do giro denteado do rato. Ele mostrou que, ao aumentar o valor do grau de alguns neurônios, as crises ficam maiores e mais fortes. Nós encontramos algo semelhante, com dados de EEG e vislumbrando rede de uma escala maior que as em Morgan e Soltesz (2008), que analisou no nível dos neurônios. Entretanto, essa abordagem ainda não revela quais são os mecanismos responsáveis pela formação dos hubs na conectividade normal dos pacientes. Também é importante ressaltar que existem vários tipos de epilepsia, mas os dados analisados aqui foram de pacientes com o mesmo tipo: epilepsia no lobo temporal mesial, é possível que outros tipos de epilepsia apresentem padrões diferentes na estrutura das redes.

\subsection{Padrões de conectividade revelados através de entropia cruzada}

Neste segundo trabalho foi desenvolvida uma medida para calcular interações entre sinais de EEG: a entropia cruzada no domínio da frequência. Essa medida possui as vantagens de ser nãolinear, não-paramétrica, ponderada e adaptada para o domínio da frequência. Além disso, é inversamente proporcional a intensidade das interações entre os sinais, ou seja, um valor alto de entropia cruzada entre duas regiões sugere que essas regiões estão exibindo atividades diferentes. Devido a essa propriedade, também foi investigado as conexões com valores elevados de entropia cruzada, que 
(a)

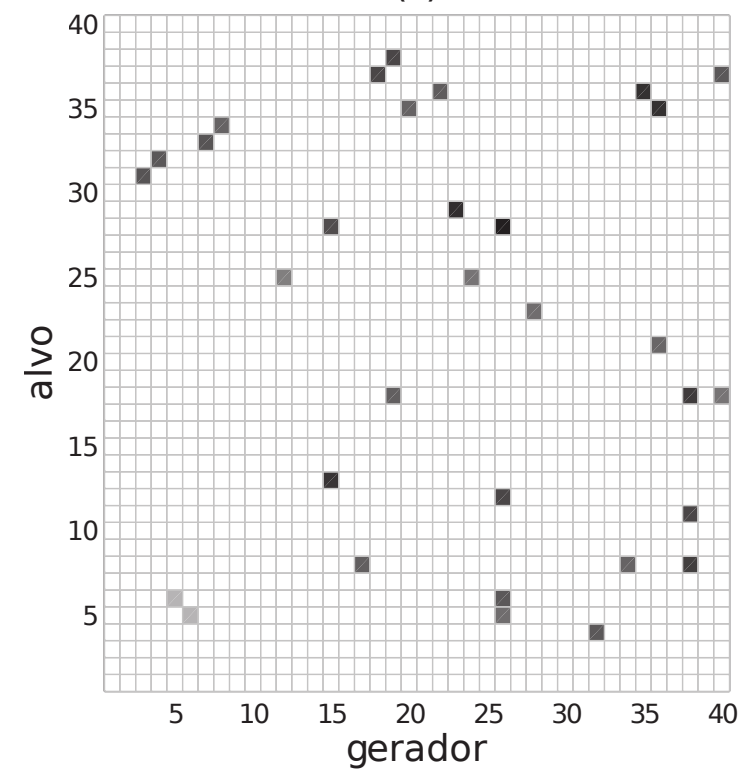

(b)

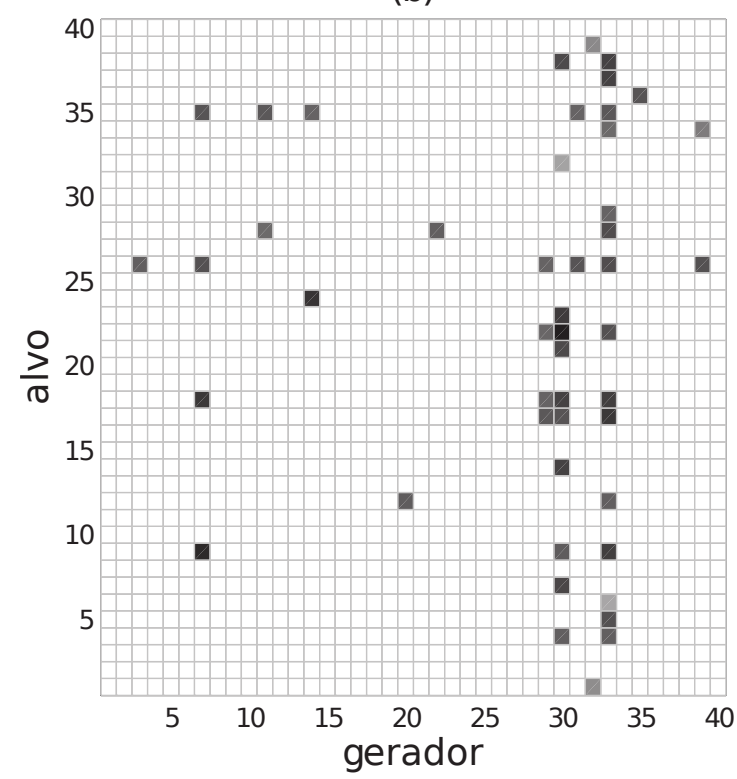

Figura 3.3: Exemplo de duas matrizes de conectividade para o Paciente 1 em diferentes momentos. $O$ tom de cinza representa o valor do PLV (mais escuro, mais alto): (a) durante o período inter-ictal, $\tilde{R}=0,036 ; e$ (b) do período ictal, $\tilde{R}=0,097$. Note que as conexões estão mais distribuídas e aleatórias em (a) enquanto que em (b) existe um claro padrão nos nós 30 e 33. Adaptado de Rodrigues et al. (2014).

(a)

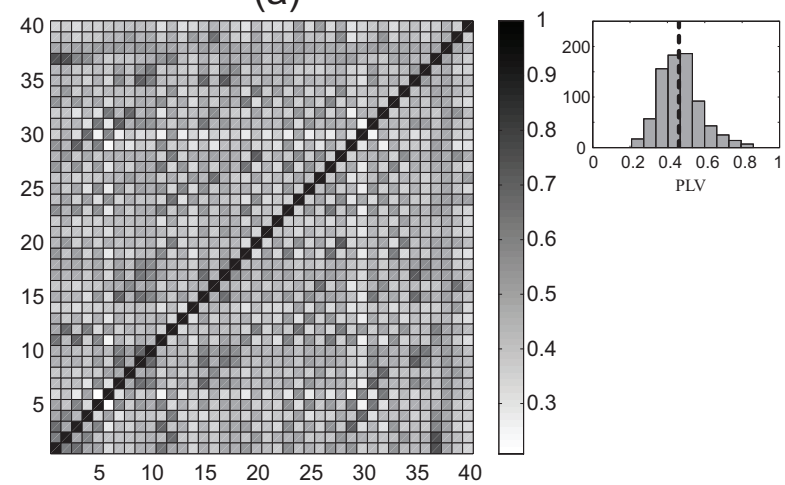

(b)

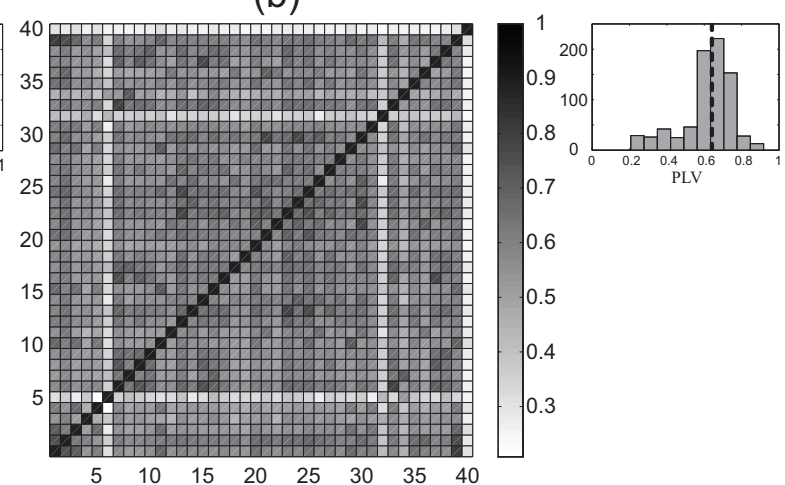

Figura 3.4: Resultados para o Paciente 1, o mesmo trecho do sinal utilizado para inferir a rede na figura 3.3 foi utilizado para calcular o PLV. (a) é a matriz de PLV para o período inter-ictal e (b) a matriz de PLV para o período ictal. Os histogramas mostram uma linha pontilhada indicando a mediana, 0,462 para o período inter-ictal e 0,641 para o período ictal. Note que durante o inter-ictal os valores do PLV estão em torno de 0,4, enquanto que durante a crise, o PLV fica em torno de valores mais altos. Adaptado de Rodrigues et al. (2014). 

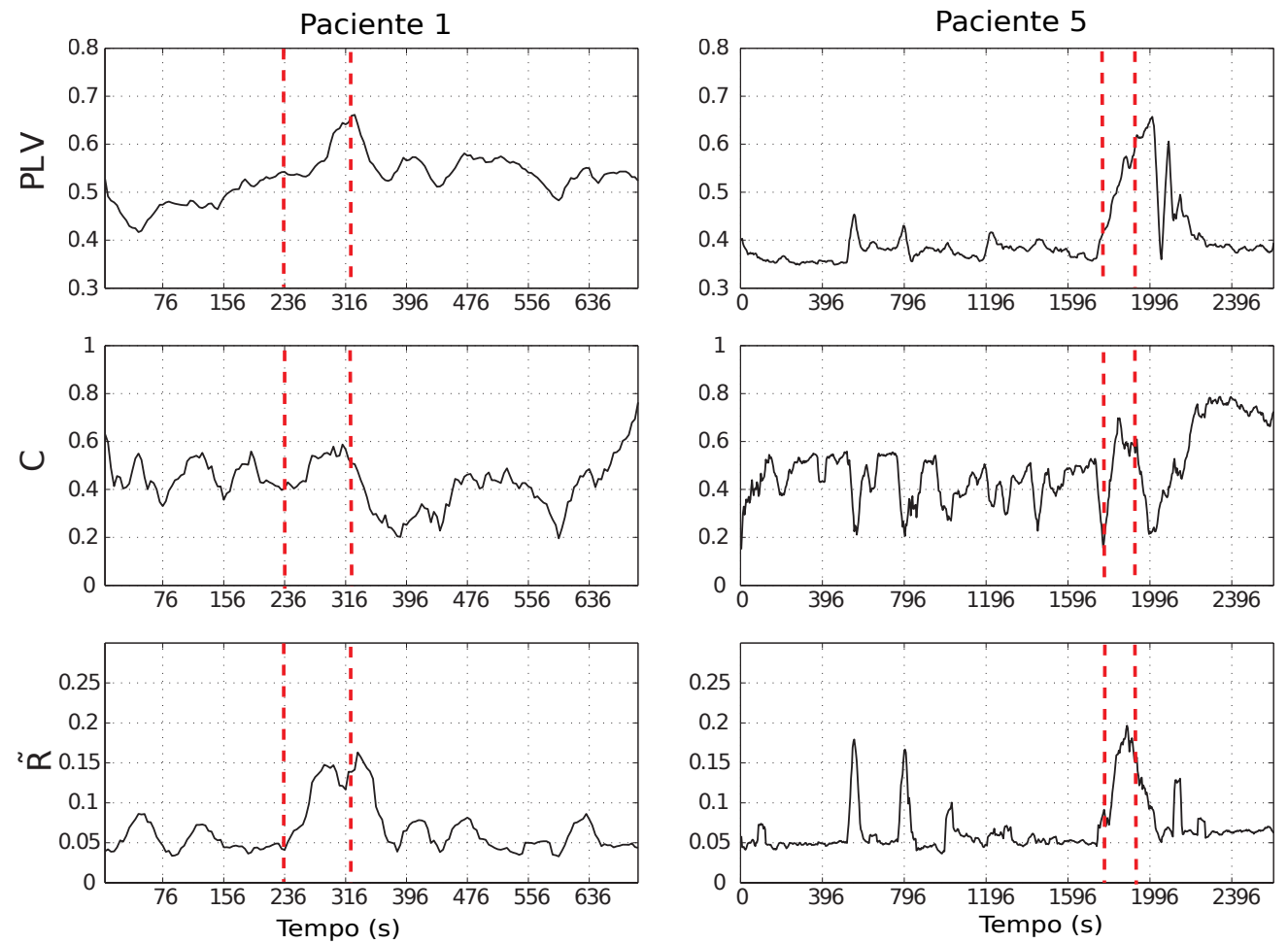

Figura 3.5: Nessa figura tem-se a mediana do PLV, o $C$ e o $R$ para os Pacientes 1 e 5 . As linhas verticais marcam o início e fim da crise, que foram determinadas por neurologistas utilizando informação de vídeo $e$ EEG. Para esses dois pacientes, após o início da crise percebe-se um aumento na mediana do PLV, que foi observado em 6 dos 8 pacientes. A presença dos hubs é caracterizada pelo aumento no valor de $\tilde{R}$. Note que o Paciente 5 apresenta dois picos no $\tilde{R}$, mas que não foram em períodos de crise, provavelmente devido a curta duração do evento. Adaptado de Rodrigues et al. (2014). 
representam interações fracas. Essas conexões são geralmente descartadas por análises de redes ponderadas que adotam alguma estratégia de poda (Papo et al., 2014a). Por outro lado, não considerar esses pesos mais baixos pode levar a um entendimento incompleto do processo em estudo, já que, devido a características multi-escala do cérebro, esses pesos podem possuir um papel importante nos processos dinâmicos do cérebro Papo et al. (2014b).

Considerar essas conexões mais fracas na análise permitiu encontrar algumas regiões que não se mantiveram sincronizadas com as regiões vizinhas. Essa observação enfraquece a noção de hipersincronização, característica das crises de ausência e aponta para uma descrição mais completa para a dinâmica das crises.

\subsubsection{Métodos}

Uma medida derivada da teoria da informação, a entropia cruzada, foi adaptada para ser utilizada no domínio da frequência, com o objetivo de analisar EEG de pacientes com crise de ausência. Nessa seção vamos introduzir a medida e uma aplicação em um toy model, Além disso, um procedimento foi sugerido para identificar nós importantes.

\section{Utilizando a entropia cruzada em sinais de EEG}

A divergência de Kullback-Leibler (KLD) é uma medida assimétrica que calcula a diferença entre duas distribuições de probabilidade. Considerando duas distribuições de probabilidade $F$ e $G$, o KLD é definido como:

$$
D_{\mathrm{KL}}(F, G)=\int_{-\infty}^{\infty} f(x) \ln \left(\frac{f(x)}{g(x)}\right) d x,
$$

onde $f$ e $g$ é a densidade de probabilidade de $F$ e $G$, com $D_{\mathrm{KL}}(F, G) \geq 0$. A medida calcula a diferença na quantidade de informação em $F$ quando comparado a distribuição $G$. É possível definir a entropia cruzada baseada no $D_{\mathrm{KL}}$ (Shore e Johnson, 1980) através da relação:

$$
H(F, G)=D_{\mathrm{KL}}(F, G)+H(F),
$$

onde $H(F)=-\int f(x) \ln f(x) d x \leq H(F, G)$ é a entropia (ou complexidade) de $F$. Dessa forma, $H(F, G)$ pode ser interpretado como a capacidade da distribuição $G$ de prever um evento da distribuição $F$. A melhor previsão ocorre quando $D_{\mathrm{KL}}(F, G)=0$.

Ao invés de calcular a entropia cruzada em distribuições de probabilidade, utilizou-se como entrada o espectro de potência (PS) de cada sinal. O PS, definido como $P(\omega)=|\tilde{x}(\omega)|^{2}$, onde $\tilde{x}(\omega)$ é a transformada de Fourier do sinal $x(t)$, foi estimada usando o método proposto por Welch (1967). O procedimento consiste em dividir as séries temporais em segmentos sobrepostos, calcular o PS para cada segmento e então encontrar a média para todos os segmentos. Dessa forma, a distribuição de probabilidade é normalizada e considera os ritmos delta, theta e alpha (de 0,5 até $14 \mathrm{~Hz}$ ) como eventos, ao invés de usar a amplitude do sinal.

Para ilustrar a medida, considere o sistema Lorenz, um sistema caótico definido pelas equações: $d x / d t=\sigma(y-x), d y / d t=x(\rho-z)-y$ e $d z / d t=x y-\beta z$, com $\sigma=10, \beta=8 / 3$ e $\rho=28$. Nesse caso, a medida obteve $H(x, y)=7,044$ e $H(x, \tilde{y})=9,519$, onde $\tilde{y}$ é a versão permutada do sinal $y$ $y$, e $H(\tilde{y}, x)=21,040$. Como esperado, o menor valor de entropia cruzada foi obtido quando os dois sinais possuem o mesmo mecanismo gerador. Com o sinal permutado $\tilde{y}$ como referência, o valor da medida aumenta, sugerindo uma incapacidade de um processo estocástico prever um sinal caótico. O maior valor de entropia cruzada foi obtido quando um sinal de baixa complexidade é usado como referência para avaliar a predição de um sinal mais complexo.

Uma vantagem de utilizar esta medida é sua propriedade de invariância, que aparece quando se calcula a diferença entre quanto de informação nos outros sinais é boa para prever um sinal de um eletrodo $i$ menos a capacidade do sinal $i$ modelar todos os outros sinais. Para um dado eletrodo $i$, essa subtração é definida como $L_{i}=\sum_{j}\left(H_{i j}-H_{j i}\right)$ onde $H_{i j}=H\left(F_{i}, F_{j}\right)$. Dessa forma, $L_{i}$ pode 
ser interpretado como uma medida relativa de independência. A invariância global é definida como $\sum_{i} L_{i}=0$, apesar de $L_{i} \neq 0$.

\section{Detectando nós importantes}

Dependendo da medida utilizada para inferência da rede, diferentes interpretações podem ser levadas em consideração para a estrutura encontrada, por exemplo hubs em redes anatômicas e funcionais são relacionadas com o fluxo de informação do cérebro (van den Heuvel e Sporns, 2013). Com a medida de entropia cruzada, dois tipos de nós podem ser definidos: nós independentes e sincronizáveis. Os independentes são aqueles que apresentam uma atividade muito diferente quando comparado aos outros nós da rede. Os sincronizáveis exibem um menor valor de entropia cruzada, devido a uma similaridade entre os PS e baixa complexidade.

Para inferir a significância desses nós, um teste estatístico pode ser utilizado, resumido nos seguintes passos para cada janela de tempo $w$ :

- para cada eletrodo $i$, calcule $L_{i}$;

- separe cada $L_{i}$ em dois conjuntos, um para $L_{i}>0$ e outro para $L_{i}<0$;

- normalize cada $L_{i}$ pelo total do conjunto que ele pertence, resultando em uma porcentagem;

- para cada $L_{i}>0$ normalizado, um teste de Wilcoxon (unicaudal a esquerda) é utilizado para saber se este valor é maior que a mediana do conjunto. Para o conjunto $L_{i}<0$ deve-se utilizar o teste unicaudal a direita.

Com o procedimento definido acima é possível encontrar regiões que são significativamente distantes da mediana de cada conjunto.

\section{Análise dos dados}

O sinal multivariado foi dividido em janelas de 5 segundos de duração com $80 \%$ de sobreposição entre elas. Os sinais possuem de alguns minutos até quase uma hora de duração. Em cada janela de tempo, o PS foi estimado e normalizado para cada eletrodo, depois a entropia cruzada é calculada entre todos os pares. Um exemplo do PS pode ser visto na figura 3.6, em (b) e (d) é o PS para dois eletrodos durante o período ictal, note o pico em torno de 3-4 Hz, uma bem conhecida característica das crises de ausência.

\subsubsection{Resultados}

\section{Durante o período ictal, poucas regiões concentram alto valores de entropia cruzada}

Um padrão bem definido pode ser visto quando se compara as matrizes de entropia cruzada inferidas durante o ictal com as matrizes calculadas durante o inter-ictal (parte superior da figura. 3.7). Durante o ictal, a maior parte dos valores são parecidos, com exceção de alguns poucos eletrodos que apresentam valores mais elevados de entropia cruzada, sugerindo uma atividade eletrofisiológica bem distinta. Em outras palavras, esses sinais possuem informação que não estão presente em outras regiões. Neste exemplo da figura 3.7, todas as regiões (com exceção da região frontoparietal) apresentam valores próximos, indicando uma atividade semelhante e, consequentemente, mais sincronizada.

A matriz do período inter-ictal também mostra valores elevados de entropia cruzada, mas eles são distribuídos entre os sinais, ao contrário da matriz calculada durante o ictal. Essa característica do inter-ictal sugere que diferentes regiões estão realizando atividades diferentes. As regiões mais importantes em cada período estão na parte inferior da figura 3.7. Neste gráfico, cada barra é o $L_{i}$ para cada eletrodo $i$ e o marcador $(*)$ aponta para aqueles que são significativamente maiores ou menores que os outros. Durante o período ictal, os eletrodos FP1 e FP2 concentram maior parte do total $L_{i}>0$. Por outro lado, os eletrodos T7, C3, T8 e P8 exibem grande quantidade de $L<0$. 
(a)

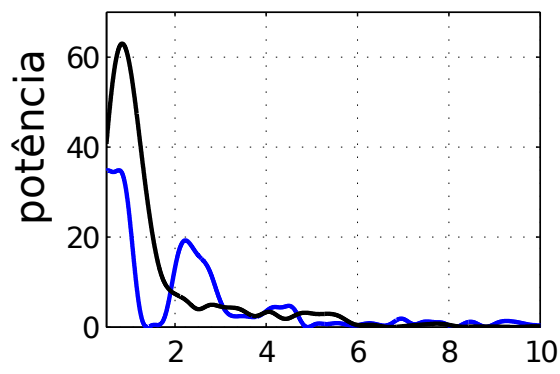

(c)

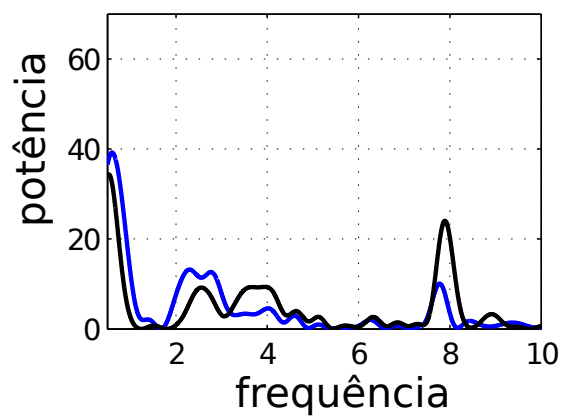

(b)

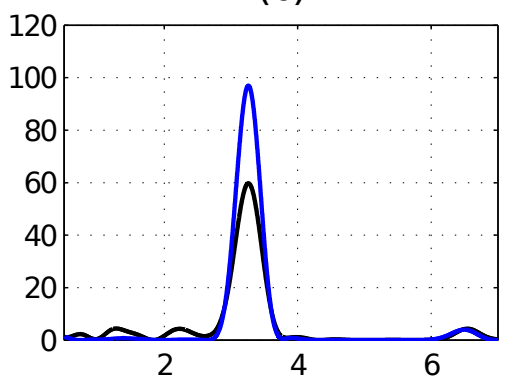

(d)

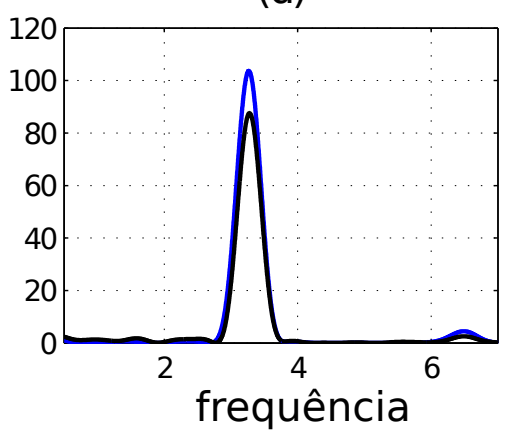

Figura 3.6: $P S$ para dois eletrodos durante inter-ictal e ictal. Figura (a) e (b) mostra o PS para os eletrodos F3 (azul) e F8 (preto) durante o inter-ictal $\left(D_{\mathrm{KL}}=0,787\right.$; PLV $\left.=0,467\right)$ e ictal $\left(D_{\mathrm{KL}}=0,310\right.$; $\mathrm{PLV}=$ $0,625),(c)$ e (d) é o PS estimado durante o inter-ictal $\left(D_{\mathrm{KL}}=0,418 ; \mathrm{PLV}=0,712\right)$ e ictal $\left(D_{\mathrm{KL}}=0,042\right.$; PLV = 0,916) para os eletrodos CZ (preto) e PZ (azul), para a mesma janela de tempo usada em (a) e (b).

Tabela 3.2 mostra o resumo dos resultados para os oito pacientes. É importante perceber o aumento no $L$ do inter-ictal para o ictal. Apesar do número de nós independentes serem maiores durante o inter-ictal, esses nós concentram a maior parte do $L>0$. Por outro lado, o número de nós com atividade parecida aumenta durante a crise, sugerindo uma possível condição necessária para a hipersincronização.

\section{Os nós significativos apresentam um padrão dinâmico bem definido}

Ambas as matrizes da figura 3.7 são a média da entropia cruzada: a da direita para um período ictal de sete segundos de duração e a esquerda para o mesmo período imediatamente antes da crise começar. Para analisar o comportamento dinâmico do $L$, veja na figura 3.8 o $L(t)$ para os nós independentes e os outros com a mesma atividade durante o período ictal. Para os primeiros, $L(t)$ atinge seu valor máximo e cai progressivamente após isso, enquanto que o comportamento inverso é observado para os sincronizáveis. Depois do período ictal, $L(t)$ para ambos os tipos de nós retorna para um nível basal observado antes do início da crise.

\section{Os nós independentes são menos sincronizados}

Considerando apenas o KLD, a sincronização entre os nós da rede é maior durante a crise, como pode ser visto na figura 3.9. Para fazer uma comparação do KLD de um dado eletrodo com os outros, dentro da mesma janela de tempo com comprimento $N$, a matriz de KLD foi normalizada pela sua média:

$$
D_{\mathrm{KL}}^{\prime}(i, j)=\frac{n^{2} D_{\mathrm{KL}}(i, j)}{\sum_{i=1}^{n} \sum_{j=1}^{n} D_{\mathrm{KL}}(i, j)},
$$

onde $n$ é o número de eletrodos. Dessa forma, pode-se medir quanto do eletrodo $i$ é desincroni- 


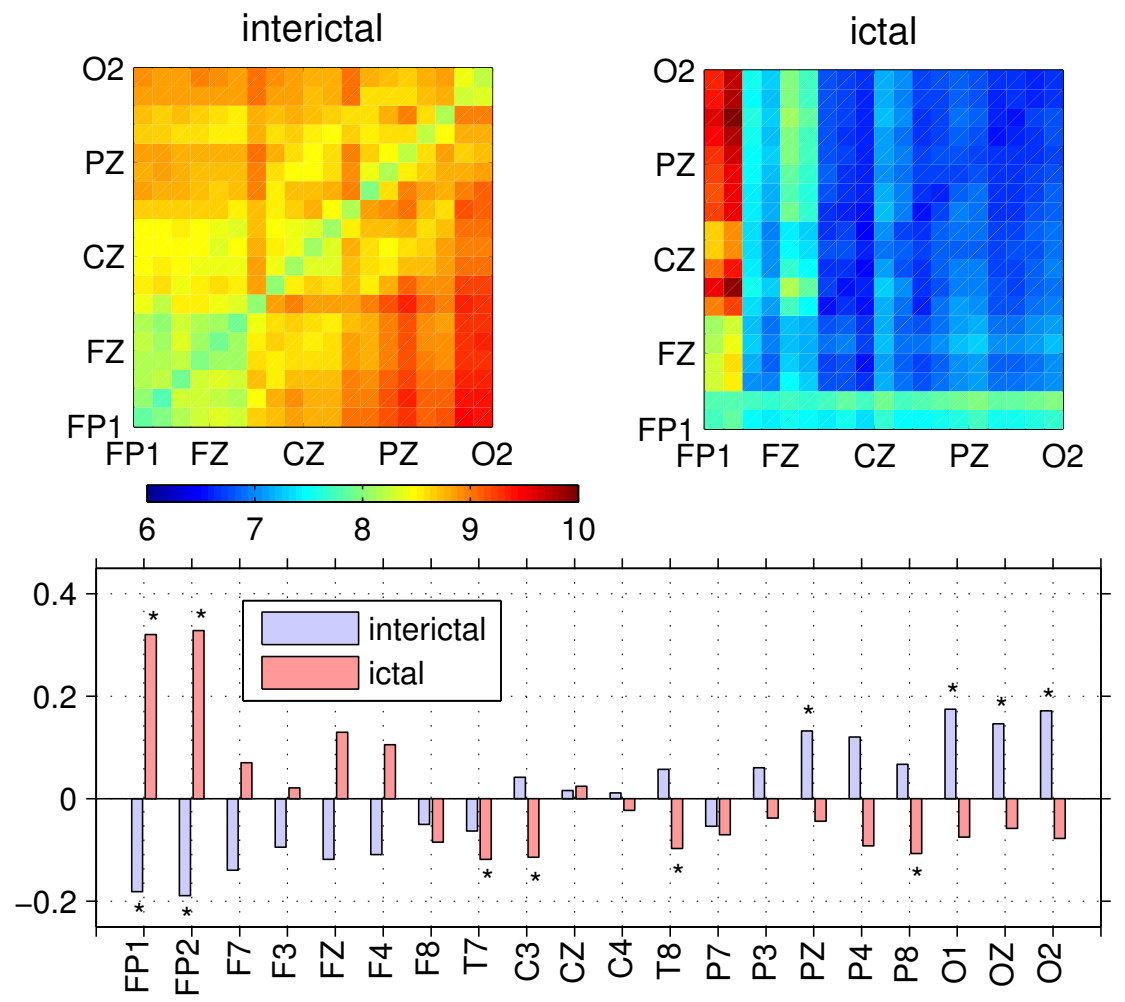

Figura 3.7: Matrizes de adjacência para o paciente S8. A parte superior da figura mostra a média da entropia cruzada para o período ictal (direita) e inter-ictal (esquerda) durante 7 segundos. A diagonal é a entropia $H(\mathrm{PS}(\cdot))$ de cada eletrodo. A parte inferior mostra o $L_{i}$ para ambos períodos. Dois nós independentes podem ser observados no lobo frontoparietal (eletrodos FP1 e FP2) durante o período ictal. Quatro nós independentes são observados durante o inter-ictal (PZ, O1, OZ e O2), mas com menor valor de entropia cruzada. Note que os eletrodos FP1 e FP2 não eram classificados como independentes durante o inter-ictal.

zado de $j$, tendo a sincronização da rede como referência.

Figura 3.9a) mostra o $\bar{D}_{\mathrm{KL}}(i)=\sum_{j=1}^{n} D_{\mathrm{KL}}^{\prime}(i, j) / n$ de três eletrodos: O1 que é um nó independente durante a crise, e os nós P7 e FP1. Antes da crise começar, eles apresentam um regime semelhante, compartilhando um mesmo nível basal. Com o início da crise, $\bar{D}_{\mathrm{KL}}(\mathrm{O} 1)$ aumenta, permanecendo mais alto que os outros dois até o fim da crise, quando então retorna ao nível basal. Para FP1 e P7, essa função diminui depois o início da crise, sugerindo uma sincronização entre a rede e esses nós. Figura $3.9 \mathrm{~b})$ mostra o $D_{\mathrm{KL}}^{\prime}(\mathrm{O} 1, j)$ para cada eletrodo $j$ e analogamente na figura 3.9c) é a mesma medida para o FP1.

Além disso, os nós independentes apresentam um baixo KLD entre si, indicando que existem possivelmente dois regimes oscilatórios, um compartilhado entre todos os nós independentes e outro para o restante dos nós. Essa diferença no KLD observada entre os nós independentes entre o pré-ictal e ictal pode ser visto na tabela 4.1.

\subsection{Evolução do acoplamento entre os sinais ao longo da crise}

Crises de ausência são caracterizadas por complexos espícula-onda generalizados na frequência $3 \mathrm{~Hz}$ cuja emergência é atribuída a um loop de feedback entre o tálamo e o cortex. Estudos mais recentes questionam esse mecanismo de geração da crise e sugerem a existência de um foco cortical (Meeren et al., 2005, 2002).

Para analisar as interações entre regiões corticais, o PDC foi utilizado para inferir as redes considerando apenas a frequência de $3 \mathrm{~Hz}$, que representa o pico do espectro do sinal durante a crise. Dessa forma, espera-se que o grafo fique livre de conexões espúrias ou artefatos de outras 
S2

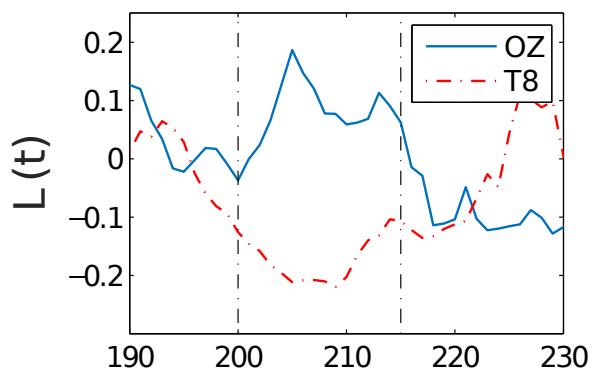

S5

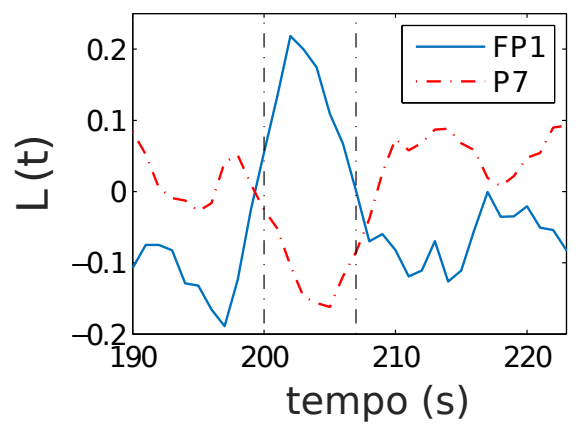

S4

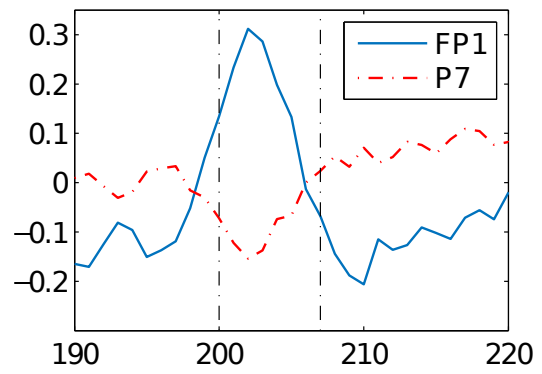

S6

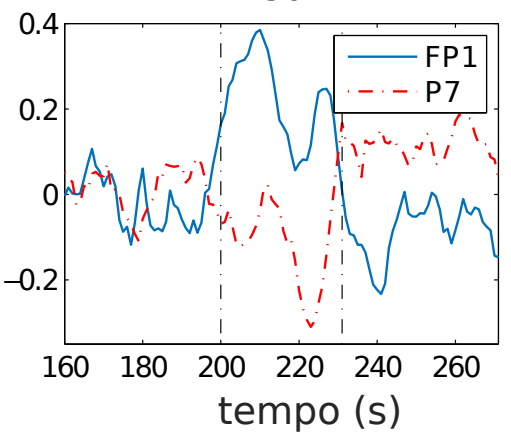

Figura 3.8: $L(t)$ para nós independentes (em azul sólido) e sincronizáveis (tracejado vermelho) de quantro pacientes com diferentes duração de ictal. As linhas verticais indicam o ínicio e término da crise.

\begin{tabular}{|c|c|c|c|c|c|c|c|c|c|}
\hline \multirow[b]{2}{*}{ patient } & \multicolumn{4}{|c|}{ período inter-ictal } & \multicolumn{5}{|c|}{ período ictal } \\
\hline & $\#$ ind & $\bar{L}_{+}$ & \# sync & $\bar{L}_{-}$ & $\#$ ind & $\bar{L}_{+}$ & \# sync & $\bar{L}_{-}$ & $\Delta \bar{D}_{\mathrm{KL}} \%$ \\
\hline $\mathrm{S} 1$ & 4 & 0,101 & 1 & $-0,311$ & 2 & 0,274 & 2 & $-0,241$ & $-35,85$ \\
\hline $\mathrm{S} 2$ & 2 & 0,200 & 3 & $-0,200$ & 2 & 0,235 & 4 & $-0,131$ & $-74,41$ \\
\hline S3 & 4 & 0,135 & 3 & $-0,227$ & 4 & 0,139 & 4 & $-0,89$ & $-52,34$ \\
\hline $\mathrm{S} 4$ & 3 & 0,140 & 1 & $-0,505$ & 2 & 0,381 & 3 & $-0,139$ & $-85,33$ \\
\hline S5 & 5 & 0,100 & 2 & $-0,300$ & 2 & 0,264 & 3 & $-0,197$ & $-82,93$ \\
\hline S6 & 3 & 0,193 & 1 & $-0,313$ & 2 & 0,358 & 4 & $-0,139$ & $-96,22$ \\
\hline $\mathrm{S} 7$ & 5 & 0,110 & 2 & $-0,273$ & 1 & 0,334 & 5 & $-0,119$ & - \\
\hline $\mathrm{S} 8$ & 4 & 0,160 & 2 & $-0,198$ & 2 & 0,321 & 4 & $-0,106$ & $-77,37$ \\
\hline
\end{tabular}

Tabela 3.2: Número de nós importantes para os périodos ictal e inter-ictal. O $L_{i}$-positivo (-negativo) médio é indicado por $\bar{L}_{+}\left(\bar{L}_{-}\right)$. Foi considerado um nível de significância de 0,05. Nenhum nó sincronizável foi observado para o paciente $S 5$ devido ao baixo número de nós com $L_{i}<0$, neste caso, foram escolhidos os com maior valores. $\Delta \bar{D}_{\mathrm{KL}} \%$ é a porcentagem da variação do KLD médio, medido apenas para os nós independentes detectados durante o ictal.

frequências.

Como os grafos inferidos com o PDC é direcionado e ponderado, foi caracterizado a evolução 
(a)

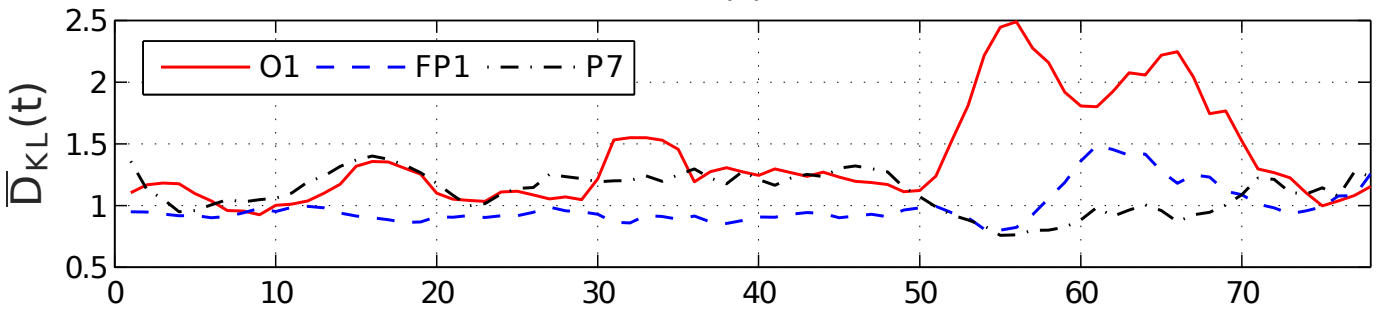

(b)

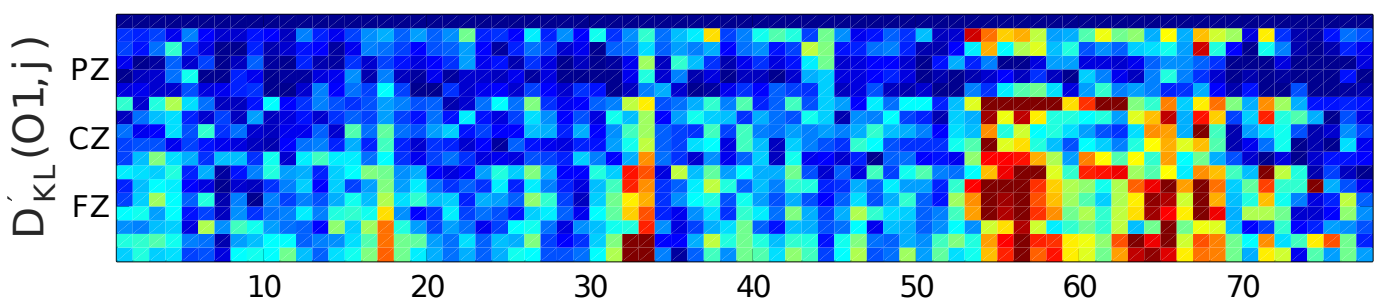

(c)

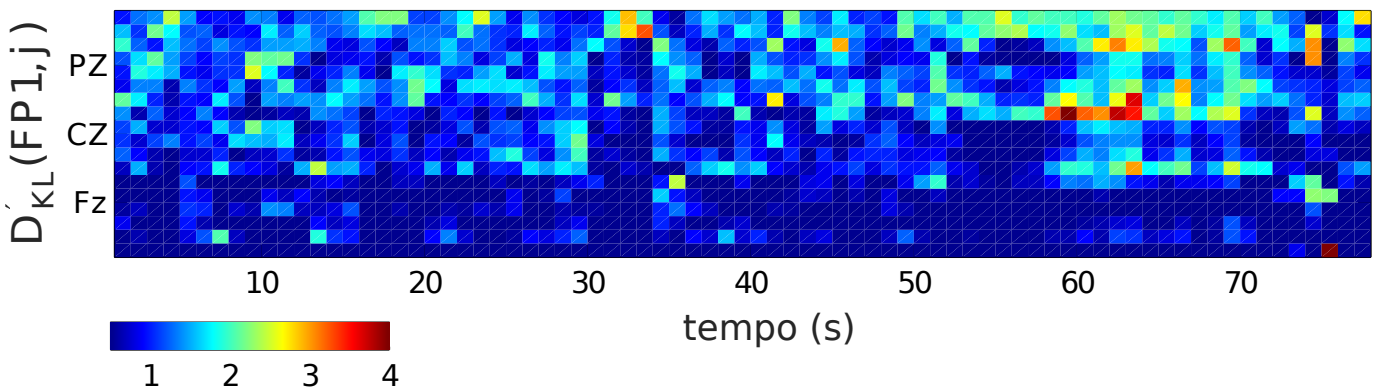

Figura 3.9: KLD entre todos os eletrodos. a) $\bar{D}_{\mathrm{KL}}(t)$ para três eletrodos. KLD para os eletrodos b) O1 e c) FP1 em relação a todos os outros. O periodo ictal corresponde ao intervalo que vai de 50 até 70 segundos.

do grau de saída médio de cada nó, antes e durante a crise. Essa medida fornece uma ideia da força de interação que uma região exerce sobre as outras e sua dinâmica ao longo do tempo mostra como essa interação muda com o início da crise.

\subsubsection{Dados}

Os dados foram coletados da mesma forma que os sinais da seção 3.4, porém com 5 pacientes a mais, pois como este trabalho foi desenvolvido depois, novos dados foram adquiridos. A tabela 3.3 resume as características de cada paciente e da crise analisada.

\subsubsection{Resultados}

A figura 3.10 mostra um exemplo das matrizes de conectividade estimadas para dois pacientes. Note que o grande nível de diferença intra-pessoal antes da crise muda para uma certa similaridade após o início da crise.

\section{PDC mostrou um aumento na intensidade dos relações causais durante a crise}

Uma vantagem do PDC sobre a causalidade de Granger é a capacidade de medir a intensidade da relação causal em uma determinada frequência. Essa característica pode ajudar a entender a dinâmica das conexões da rede, uma característica geralmente ignorada em trabalhos de conectividade, já que a maioria das pesquisas foca nas propriedades topológicas globais da rede (Lehnertz et al., 2014).

A figura 3.11 mostra a média de cada matriz de conectividade ao longo do tempo. Note o aumento durante a crise e seu retorno aos níveis anterior a início da crise no fim. Esse comportamento é 


\begin{tabular}{c|c|c|c}
\hline Paciente & Sexo & Idade & Duração da crise (s) \\
\hline 1 & $\mathrm{M}$ & - & 17 \\
2 & $\mathrm{~F}$ & 14 & 9 \\
3 & $\mathrm{~F}$ & 7 & 13 \\
4 & $\mathrm{M}$ & - & 30 \\
5 & $\mathrm{M}$ & 4 & 6 \\
6 & $\mathrm{~F}$ & 20 & 13 \\
7 & $\mathrm{~F}$ & 8 & 6 \\
8 & $\mathrm{~F}$ & 9 & 7 \\
9 & $\mathrm{~F}$ & - & 16 \\
10 & $\mathrm{M}$ & 5 & 32 \\
11 & $\mathrm{~F}$ & 6 & 12 \\
12 & $\mathrm{M}$ & - & 9 \\
13 & $\mathrm{~F}$ & 7 & 18 \\
\hline
\end{tabular}

Tabela 3.3: Tabela com descrição dos pacientes com crise de ausência.
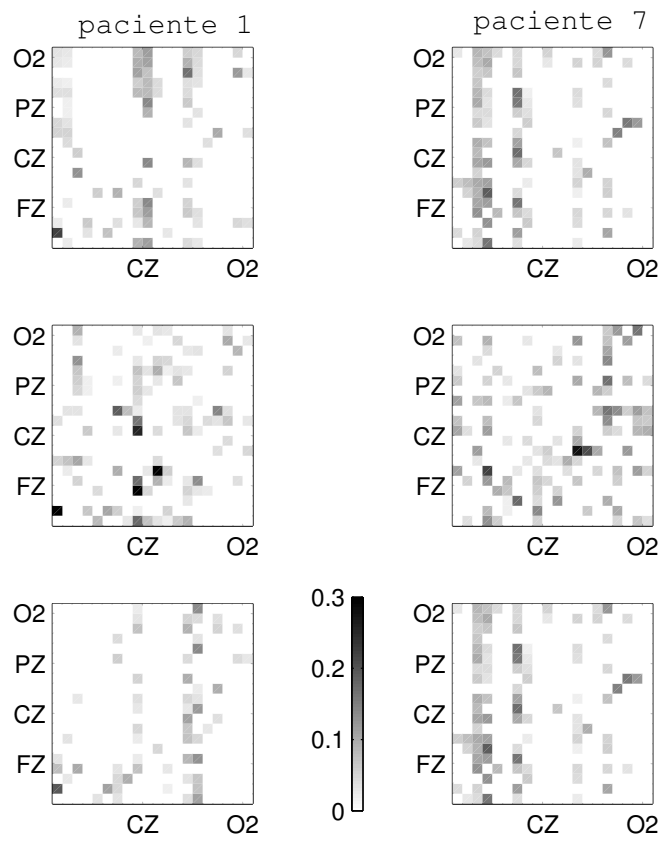

Figura 3.10: Matrizes de conectividade inferidas usando PDC na frequência de $3 \mathrm{~Hz}$. A matriz superior é para uma janela antes da crise para os pacientes 1 (esquerda) e 7 (direita), no centro as matrizes estimadas através dos primeiros 5 segundos de crise e na parte inferior mostra o grafo estimado para imediatamente após a crise. Os tons de cinza são a intensidade das relações causais. Adaptado de (Rodrigues et al., submetido)

provavelmente relacionado com a hipersincronização durante a crise, onde o acoplamento entre os sinais torna-se mais forte. Para verificar se esse aumento é significativo, foi utilizado o teste de Wilcoxon a esquerda sobre as médias da intensidade antes e durante a crise, para todos os canais. O p-valor retornado foi 0,003 rejeitando a hipótese nula em favor da hipótese alternativa que afirma que a mediana durante a crise é maior que a de antes da crise.

\section{Evolução da intensidade de acoplamento}

A média empregada na subseção anterior mostra apenas uma aproximação grosseira de todas relações causais da matriz. Para obter a evolução das conexões causais, de cada janela de tempo 

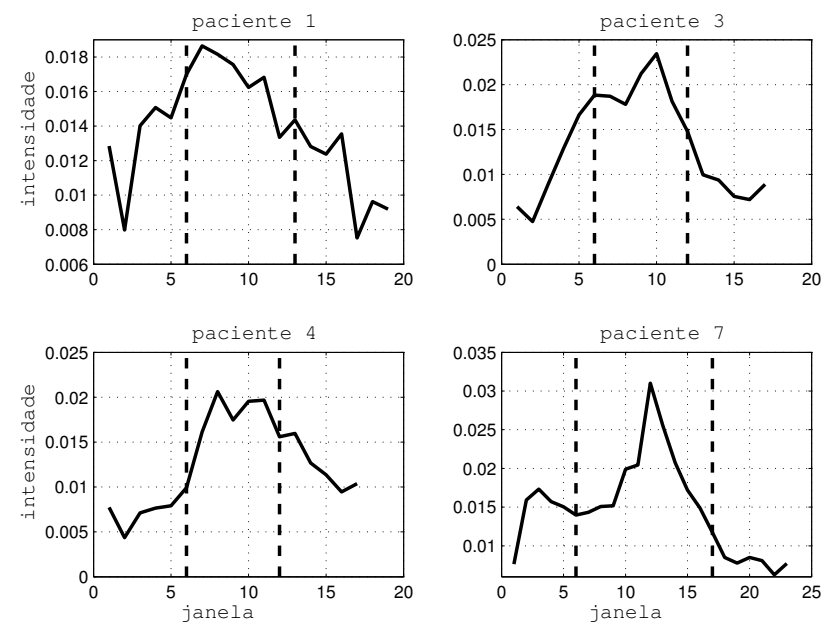

Figura 3.11: Média da intensidade ao longo do tempo, as linhas verticais marcam o início e fim da crise. Adaptado de (Rodrigues et al., submetido)

$t$, a média ponderada do grau de saída de cada nó foi calculado na forma $w_{t, j}=\sum_{i} M_{i, j} / n_{j}$ onde $M$ é a matriz da janela $t$ e $n_{j}$ é o número de conexões significativas de $j$. A figura 3.12 mostra a evolução da intensidade para dois canais, note que enquanto a curva em vermelha quase não se altera durante a crise, a outra curva apresenta um grande aumento na intensidade. Esse nós com grande valor no grau de saída (hubs) durante as crises também aparecem quando se estima as redes usando o conceito de Granger no domínio no tempo.

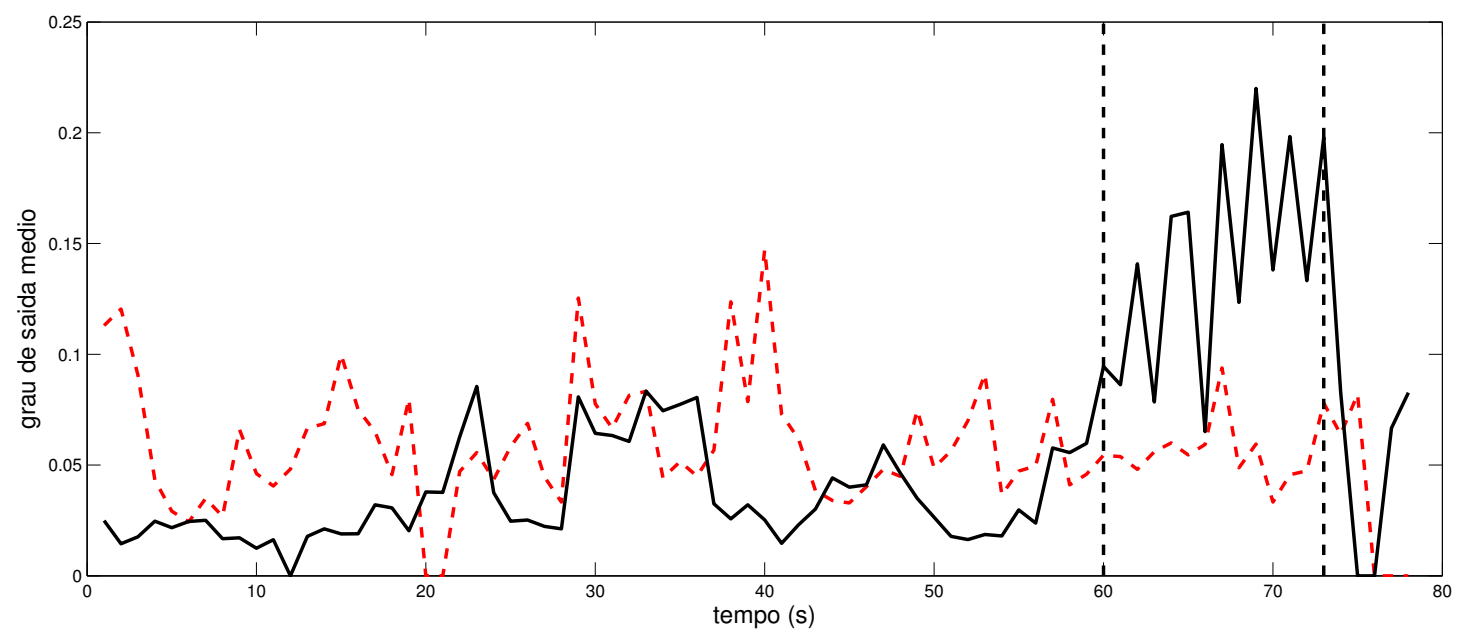

Figura 3.12: Intensidade ao longo do tempo para dois canais do mesmo paciente.

Causalidade de Granger é asociado com o conceito de fluxo de informação (Blinowska et al. , 2004; Dhamala et al., 2008a), dessa forma, esses hubs podem ser interpretados como responsáveis por um papel integrador de informação, conectando diferentes regiões e representando zonas de convergência entre módulos especializados de processamento no cérebro (Meyer e Damasio, 2009). Esse mecanismo de integração é responsável pela emergência da sincronização e de outros padrões dinâmicos que são encontrados em um cérebro saudável (Fries et al., 2007; Singer, 1993). Certamente nós com essas características também aparecem em intervalos livres de crises mas, como as relações causais aumentam durante a crise, mais relações causais surgem de maneira não uniforme, isto é, concentrada em alguns nós específicos. Essa padrão de algumas regiões do cortex aumentar a força de acoplamento com outras regiões pode ser uma assinatura do processo de propagação da crise. 
Note que como as curvas da figura 3.12 apresentam diferentes comportamentos ao longo do tempo e que levam a perguntas abertas como: Qual o papel das regiões que permanecem no nível basal? Essas regiões são necessárias para ocorrência de sincronização? Existe alguma função para esses nós ao longo da crise? Um nó pode ser mais decisivo durante o início, criando conexões fortes com o maior número possível de outros nós, provavelmente para iniciar o processo, enquanto nós que apresentam um acoplamento mais estável, podem estar relacionados com manutenção da hipersincronização. As respostas para essas perguntas podem trazer uma nova maneira de classificar os nós, bem como uma nova forma de caracterizar a epilepsia do ponto de vista de redes.

Uma proposta anterior de classificar nós hubs baseia-se na forma que eles se conectam com outros nós, hubs que se conectam com outros nós da mesma comunidade são chamados de provincial hubs enquanto que os que ligam as comunidades são os connector hubs (Guimera e Amaral, 2005). Essa abordagem ignora o papel do nó na dinâmica da rede e considera apenas a topologia estática do grafo, além disso, é válida apenas para redes que possam ser separadas em comunidades. Outra proposta classifica os hubs baseando-se em como eles conectam ou modulam a ativação de outras subredes do cérebro, revelando três tipos de nós: default network-aligned, dorsal attention networkaligned e dual network-aligned (Spreng et al., 2013). Enquanto que essa abordagem considera a dinâmica entre as redes, seu domínio de aplicação é muito específico, tornado difícil de usar o conceito em outros tipos de redes. Um método genérico de classificar os nós de acordo com sua dinâmica pode melhorar a maneira de se visualizar e entender redes que evoluem ao longo do tempo.

A presença dessas características focais em alguns locais do cérebro combina a definição de crise focal e crise de ausência, já que uma característica chave na última é a falta de um foco claro. Entretanto, outros estudos em epilepsia focal mostram que apenas 35\% dos hubs encontrados em redes de epilepsia são relacionados com foco (Geier et al., 2014), de forma que essas regiões podem possuir alguma outra relação com o início e propagação da crise. Talvez esse nós encontrados em ambos tipos de epilepsia são necessários para manutenção do processo e sua presença está diretamente ligado com sincronização.

\subsection{Conclusões}

Neste capítulo foram apresentados três trabalhos com objetivo de caracterizar a atividade elétrica durante uma crise de epilepsia através de medidas de conectividade. O primeiro tenta associar características da estrutura da rede com um fenômeno observado durante a epilepsia, que é a sincronização. Uma medida levando em conta a presença global de hubs com muitas conexões de saída foi criada e observou-se que grafos com alto valor nessa medida são acompanhados de alto valor de PLV entre os sinais.

No segundo resultado, foi mostrado que a utilização da entropia cruzada como medida sobre o PS leva a um cenário muito mais complexo da dinâmica, que ocorre durante a crise de ausência. Foi revelada a existência de nós que exibem uma atividade diferente, enquanto que a maioria das regiões realizam a mesma atividade durante a crise. O aparecimento desses nós levanta perguntas sobre o funcionamento da crise: eles são parte de um mecanismo inibitório ou estão contribuindo com a crise? Caso exista mesmo um modo de oscilação para esses nós e para o resto, é possível que eles assumam esses dois papéis.

Além disso, esses resultados mostram que as crises de ausência também são bastante dinâmicas, com atividade entre as regiões variando com a duração da crise. Esse dinamismo das crises de ausência leva a uma nova descrição do processo, já que a hipersincronização não parece ser tão sólida durante as crises.

O terceiro resultado detalha o primeiro ao mostrar como os nós hubs evoluem ao longo do tempo, mesmo em um tipo de epilepsia que não apresenta um foco inicial. Também foram revelados nós que mesmo durante a crise, apresentam o mesmo nível de acoplamento que antes da crise, o que leva as perguntas: Como esses nós também estão hipersincronizados sem o mesmo nível de acoplamento ? Quanto de acoplamento é necessário para atingir a sincronização? 


\section{Capítulo 4}

\section{Simulações de redes de epilepsia}

Neste capítulo são apresentadas simulações com neurônios artificiais que tentam reproduzir parte das características dinâmicas observadas durante o período ictal. O objetivo é levantar como a estrutura de conexões entre os neurônios pode levar a sincronização mais elevada, característica das crises.

\subsection{Simulação de redes de neurônios artificiais com estruturas da epilepsia}

Alguns estudos teóricos tentam esclarecer como a estrutura da rede pode influenciar algum processo atuando sobre ela. Resultados teóricos mostram como acontece essa relação entre a rede e seus processos dinâmicos (Barrat et al., 2008), por exemplo a importância do grau do nó em eventos de avalanches (Wu et al., 2008), o papel dos links na dispersão de opiniões em redes sociais (Ehrhardt et al., 2006) e a distribuição dos graus em fenômeno de percolação (Holme et al., 2002).

No capítulo 3, foi apresentado uma possível relação entre dois fenômenos que surgem durante a crise: a sincronização e o aparecimento de hubs na rede funcional. Alguns trabalhos mostram que a presença de nós com muitas conexões pode levar a uma maior sincronização na rede (Gómez-Gardenes et al., 2007; Zhou e Kurths, 2006a,b), embora outros trabalhos apontam para a direção oposta (Nishikawa et al., 2003).

Para entender melhor o papel desses hubs na sincronização, uma simulação foi feita, incrementandose um parâmetro que controla a quantidade desses tipos de nós. Além disso, como essas redes inferidas de pacientes com epilepsia possuem uma topologia dependente do tempo, com dois estados bem claros: o ictal e inter-ictal, foi analisado a influência da rede do período ictal no sinal do pós-ictal, quando a rede sem hubs já está restaurada.

Esses resultados podem ser úteis para entender essa topologia variante no tempo que o cérebro apresenta, mas também pode ser importante para sistemas artificiais onde sincronização é uma característica desejável, como redes de computadores ou modelos inspirados no cérebro.

\subsubsection{Métodos}

O modelo de neurônio artificial usado nesse trabalho foi o neurônio de Izhikevich (Izhikevich et al. , 2003). Este modelo foi escolhido por sua simplicidade de implementação, por exigir relativamente poucos recursos computacionais e por exibir uma grande quantidade de comportamentos encontradas em neurônios reais (Izhikevich, 2004).

As esquações que descrevem o modelo são dadas por:

$$
\begin{aligned}
v^{\prime} & =0,04 v^{2}+5 v+140-u+I \\
u^{\prime} & =a(b v-u)
\end{aligned}
$$


onde $v$ é o potêncial de membrana do neurônio em milivolts e $u$ é a taxa da recuperação da membrana, $a, b, c$ e $d$ são adimensionais e $I$ representa o estímulo que o neurônio recebe do tálamo. Um termo auxiliar é adicionado para resetar essas duas variáveis após o disparo, que ocorre quando $v$ atinge $30 \mathrm{mV}$ :

$$
\left\{\begin{array}{l}
v \leftarrow c \\
u \leftarrow u+d
\end{array}\right.
$$

Vários tipos de padrões de disparos podem ser obtidos alterando os parâmetros $a, b, c, d$, ao menos 22 padrões podem ser obtidos (Izhikevich, 2004). Nessa simulação usamos a proporção entre neurônios excitatórios e inibitórios de 4:1 e os padrâmetros como descrito em Izhikevich et al. (2003): para cada neurônio excitatórios $i,\left(a_{i}, b_{i}\right)$ são fixadas em $(0,02,0,2)$ e $\left(c_{i}, d_{i}\right)$ em $(-65,8)+$ $(15,6) r_{i}^{2}$ onde $r_{i}^{2}$ é uma variável aleatória distribuída uniformemente entre 0 e 1 . Para os neurônios inibitórios os parâmetros são $\left(a_{i}, b_{i}\right)$ é $(0,02,0,25)+(0,08,-0,05) r_{i}$ e $\left(c_{i}, d_{i}\right)$ é $(-65,2)$.

As redes são geradas com 1000 neurônios e começam com 30\% do número máximo de conexões possíveis, mais conexões são adicionadas gradualmente para simular a presença dos hubs. Essa adição de conexões é definida por dois parâmetros: a porcentagem de nós que vai receber mais conexões, tornando-se hubs (HR) e a porcentagem de conexões adicionadas por nó, que nessas simulações foi fixada em 70\%. Por exemplo, HR 0,1 significa que $10 \%$ do total de nós (tanto excitatórios quanto inibitórios) estarão conectados com $70 \%$ dos outros nós. Para comparar o efeito, a mesma quantidade de conexões adicionadas para criar a rede com hubs é adicionada aleatoriamente em outra rede, criada com os mesmos parâmetros aleatórios.

Os métodos empregados para analizar os sinais simulados foram a complexidade de Lempel-Ziv (LZC) e o expoente de Hurst $(H)$ para caracterizar o potêncial de campo gerado (LFP) pela rede, que foi calculado somando-se a saída de todos os neurônios da rede. E uma medida de sincronização discreta chamada SPIKE distance (SD) (Kreuz et al., 2011) para analisar a sincronização entre os disparos dos neurônios.

A LZC é uma medida de complexidade que fornece uma idéia de quantos padrões diferentes (ou substrings) e de sua ocorrência em um sinal. Tem sido amplamente utilizado para análise de sinais biomédicos, é uma medida normalizada entre 0 e 1, em que valores próximos de 0 são relacionados com sinais periódicos e valores próximos de 1 para processos aleatórios (Aboy et al., 2006).

O expoente de Hurst é uma medida que quantifica a presença de memória de longo prazo (similar a autocorrelação) e fractalidade (Willinger et al., 2003). Se $H>0,5$, a série é chamada de persistente e significa que um aumento no presente será provavelmente seguido por um aumento futuro, enquanto que $H<0,5$ indica um regime anti-persistente, ou seja, um aumento no presente é provavelmente seguido de um decréscimo no futuro (Varanda et al., 2000). Essa medida foi utilizada para caracterizar o LFP depois da remoção dos hubs e ter uma ideia do impacto dessa estrutura no sinal.

Além do sinal de campo, também analisou-se a sincronização dos disparos dos neurônios utilizando a medida SD, a qual é inversamente proporcional ao nível de sincronismo entre os disparos. Ao contrário de outras medidas de distância entre os disparos, a SD leva em conta o tempo exato do spike, funcionando bem para grande resolução temporal.

\subsubsection{Resultados}

\section{Aumento na sincronização nas redes com hubs}

A primeira simulação mostra a influência dos hubs na sincronização entre os neurônios. Fig. 4.1 mostra o efeito dos hubs nos spikes individuais dos neurônios e no sinal de campo médio. A parte superior da figura (a) e (b) mostra o LFP para 0,3 e 0,7 HR respectivamente. Note a regularidade do sinal com o aumento do número de hubs. A parte inferior da mesma figura mostra os padrões individuais dos disparos ao longo do tempo, evidenciando a sincronização local que resulta no LFP mostrado acima. Neste caso, quase todos os neurônios estão disparando ao mesmo tempo e a rede se comporta como um único oscilador. 


\begin{tabular}{c|ccc} 
& & & \\
$\mathrm{HR}$ & $S D_{\mathrm{R}}$ & $S D_{\mathrm{NR}}$ & ganho \\
\hline \hline & & & \\
0,1 & 0,267 & 0,267 & 0 \\
0,2 & 0,266 & 0,263 & 0,011 \\
0,3 & 0,264 & 0,230 & 0,128 \\
0,4 & 0,259 & 0,105 & 0,594 \\
0,5 & 0,253 & 0,048 & 0,810 \\
0,6 & 0,239 & 0,033 & 0,861 \\
0,7 & 0,210 & 0,029 & 0,861 \\
0,8 & 0,143 & 0,028 & 0,804 \\
0,9 & 0,064 & 0,027 & 0,578 \\
\hline \hline
\end{tabular}

Tabela 4.1: $S D$ para redes com conexões aleatórias $\left(S D_{R}\right)$ e não-aleatórias $\left(S D_{N R}\right)$. A terceira coluna (ganho) é calculada como $1-S D_{r} / S D_{n r}$

Para cada valor de HR, variando de 0,1 até $0,9,100$ redes foram criadas utilizando o procedimento aleatório e não aleatório (hubs) para as conexões. Então a medida da $S D$ para essas 100 redes foi calculada. Esses resultados estão resumidos na tabela 4.1. A média do SD para as redes com hubs $S D_{\mathrm{NR}}$ ) apresenta um nível de sincronização semelhante as redes com conexões aleatórias $\left(S D_{\mathrm{R}}\right)$ até $H R=0,3$. A partir desse ponto, a sincronização das redes não-aleatórias converge mais rapidamente à medida que mais hubs são adicionados.

A criação dos hubs causou um grande impacto no valor do $S D_{\mathrm{NR}}$ para $\mathrm{HR} 0,4$ e 0,5 , mas após esses valores, a redução do $S D_{\mathrm{NR}}$ permanece constante, porém mais lenta. Este pode ser um indicativo que existe um limite superior para a sincronização da rede através da adição de conexões não aleatórias (Atay et al., 2006).

O $S D_{\mathrm{R}}$ permanece próximo de 0,2 até HR 0,8 e 0,9, quando passa a exibir um nível de sincronização similar ao $S D_{\mathrm{NR}}$, mas essa similaridade é devido ao grande número de conexões adicionadas. Isto é, quando o número de conexões é muito grande, a presença de hubs é diluída e a estrutura de ambas as redes ficam bastante próximas.

A coluna ganho na tabela 4.1 , definida como $1-S D_{\mathrm{R}} / S D_{\mathrm{NR}}$, é uma razão para comparar o impacto da adição dos hubs ao invés de conexões aleatórias. O pico dessa medida foi entre o intervalo 0,5 e 0,8. Em 0,8, existe uma queda nessa razão, refletindo a perda da eficiência de adicionar hubs.

Em relação à epilepsia focal, um trabalho anterior mostra que apenas $35 \%$ dos nós classificados como hubs encontrados durante a crise são relacionados com o foco. Isso sugere que outras regiões que não o foco também podem possuir um papel importante na evolução da crise (Geier et al. , 2015; Kalitzin et al., 2005). O resultado apresentado aqui aponta para a importância desses nós hubs na emergência da sincronização em redes de neurônios. Entretanto, pouco é conhecido sobre os mecanismos por trás da formação desses nós durante a crise. Como as redes do cérebro mudam de um estado saudável para um não-saudável quando o número de hubs aumenta?

Além disso, essa simulação mostrou uma maneira de gerar um sinal sincronizado, como encontrado durante as crises, mas sem alterar os parâmetros dos neurônios, apenas as conexões entre eles. Essa pode ser uma abordagem mais realística para modelar crises, já que a epilepsia é provavelmente uma consequência de uma conectividade anômala do cérebro (Lemieux et al., 2011).

\section{Redes organizadas exibem um LFP menos complexo}

Além da análise dos disparos dos neurônios, o LZC também foi calculado para o LFP das duas redes. Para calcular o LZC, 100 redes foram criadas para as duas configurações de conexões: com hubs e aleatórias. Com essa distribuição do LZC, as medianas foram comparadas através de um teste estatístico. 
(a)
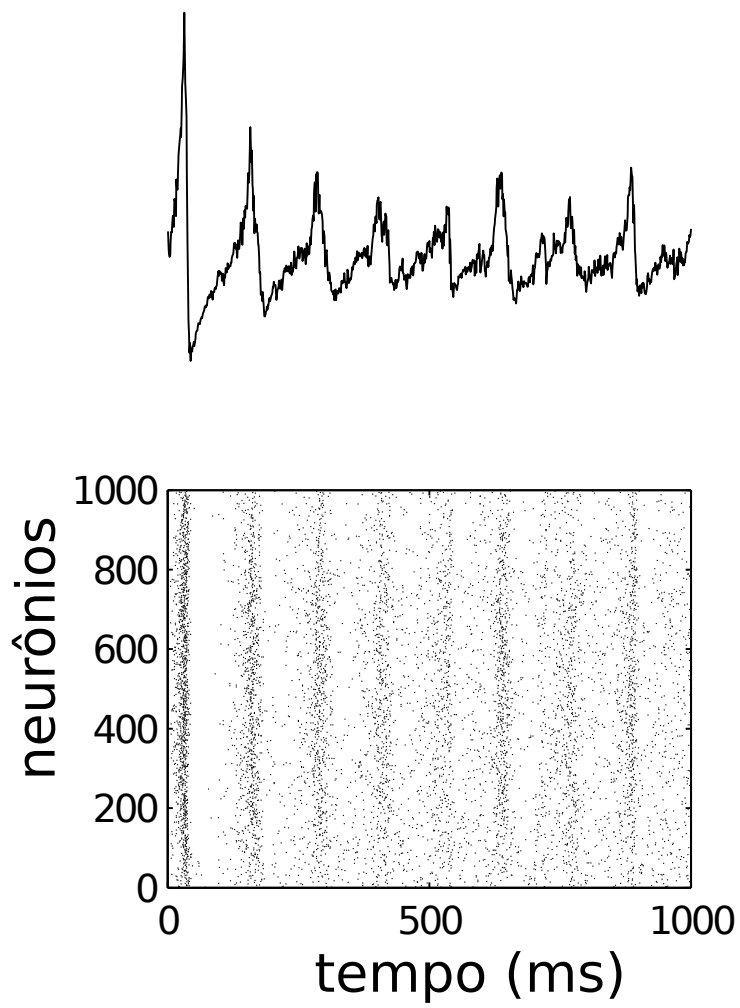

(b)
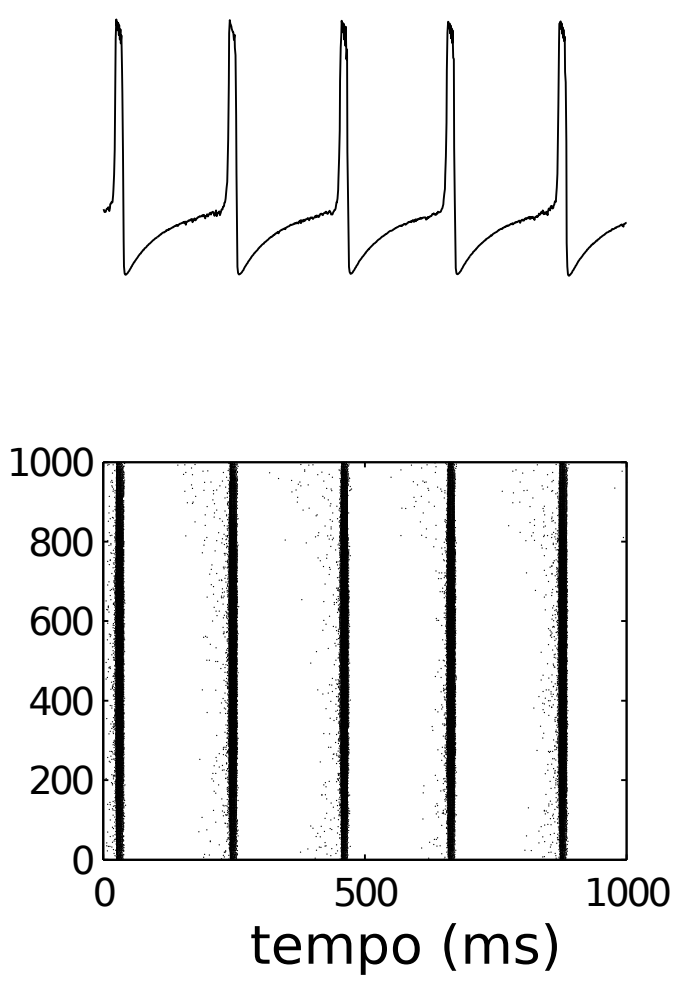

Figura 4.1: Um exemplo do LFP e disparos de neurônios com HR 0,3 (esquerda) e 0,7 (direita). Adaptado de Rodrigues, Abner Cardoso et al. (2016). 
(a)

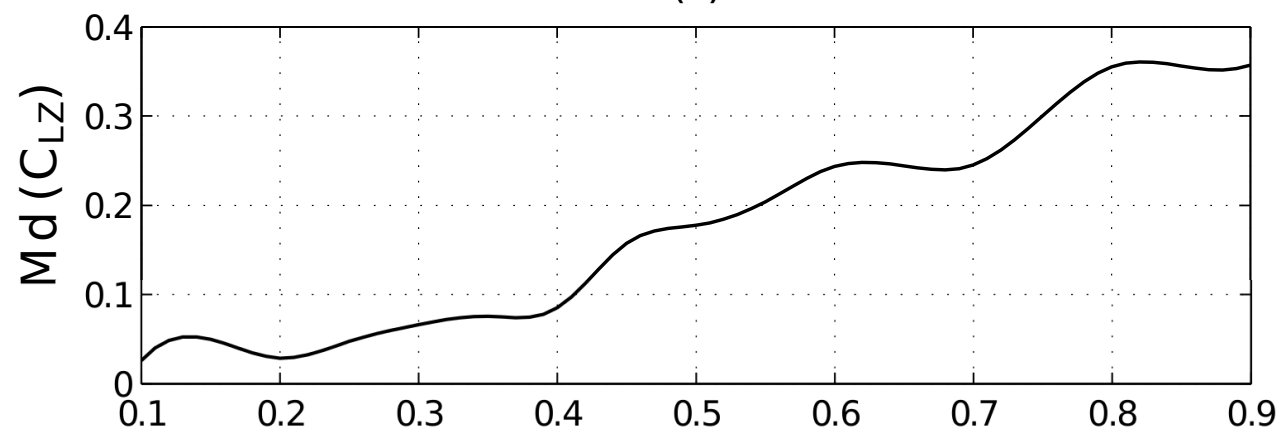

(b)

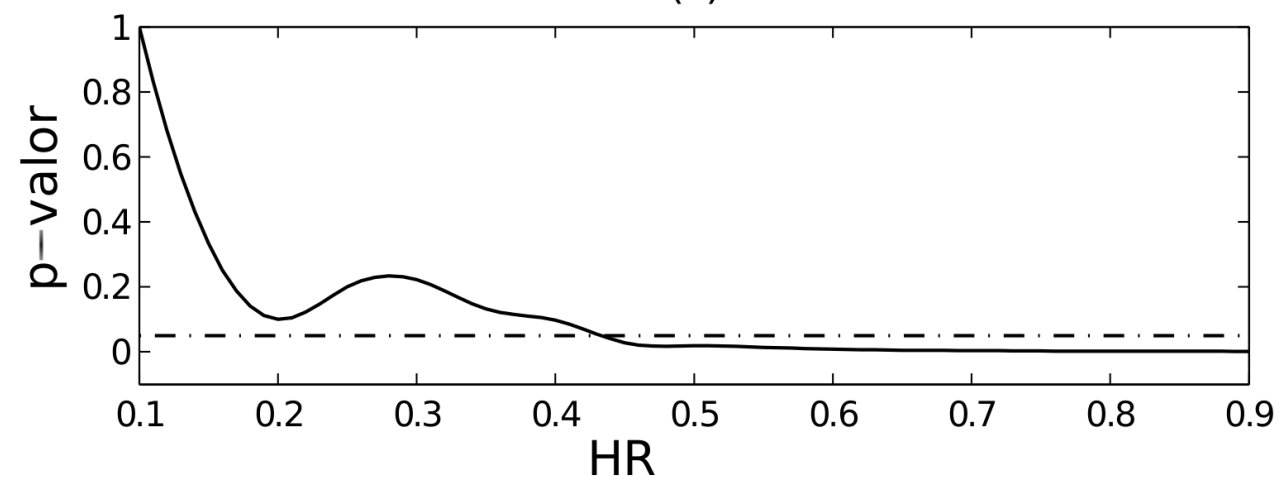

Figura 4.2: (a) Diferença entre a mediana da LZC para as redes aleatórias e não aleatórias. As redes com conexões aleatórias apresentam um LFP de maior complexidade que as redes não-aleatórias. (b) p-valor do teste de Wilcoxon entre os LZC para as redes aleatórias e não-aleatórias. A linha tracejada indica o alpha de 0,01. Adaptado de Rodrigues, Abner Cardoso et al. (2016).

Fig. 4.2(a) mostra a diferença na mediana da LZC para o LFP das redes com conexões aleatórias $\left(\mathrm{N}_{\mathrm{R}}\right)$ e com hubs $\left(\mathrm{N}_{\mathrm{NR}}\right)$ em função do HR. Uma tendência positiva é bem definida do 0,4 até 0,8, quando então se estabiliza. Note que o comportamento do LZC lembra aquele do SD da tabela 4.1, já que para HR maior que 0,8 ambas as redes possuem um grande nível de sincronização e consequentemente, LFP parecidos. No intervalo entre 0,4 e 0,8 os neurônios das redes não-aleatórias estão mais sincronizados, e com LFP menos complexo que o das redes aleatórias.

Esses resultados estão de acordo com os apresentados em Stam (2005), que argumenta que a crise está relacionado com uma perda de complexidade do sinal. Além disso, essa medida pode dar uma ideia sobre como a estrutura da rede e o mecanismo gerador do sinal: uma estrutura mais organizada leva a uma maior sincronização e menor complexidade.

A parte inferior da figura mostra p p-valor para o teste de Wilcoxon realizado para as duas distribuições usadas na parte superior da figura. A diferença entre os dois conjuntos é significativa para HR 0,4, em acordo com os resultados demonstrados pela SD. A partir desse ponto, os possíveis valores de LZC passam a ser diferentes.

\section{O impacto da estrutura emergente do ictal no sinal do pós-ictal}

Redes cerebrais funcionais exibem uma estrutura bastante dinâmica, já que estão sempre modificandose a medida que diferentes tarefas cognitivas são realizadas. Essa estrutura dinâmica também é presente durante as crises, por exemplo as medidas de centralidade dos nós exibem uma evolução temporal (Kramer et al., 2008). Uma importante pergunta para entender a epilepsia é como a rede ativa durante o período ictal afeta o pós-ictal ou mesmo seu efeito sobre as redes saudáveis encontradas entre as crises. Apesar das possíveis consequências para o pós-ictal, poucos estudos 

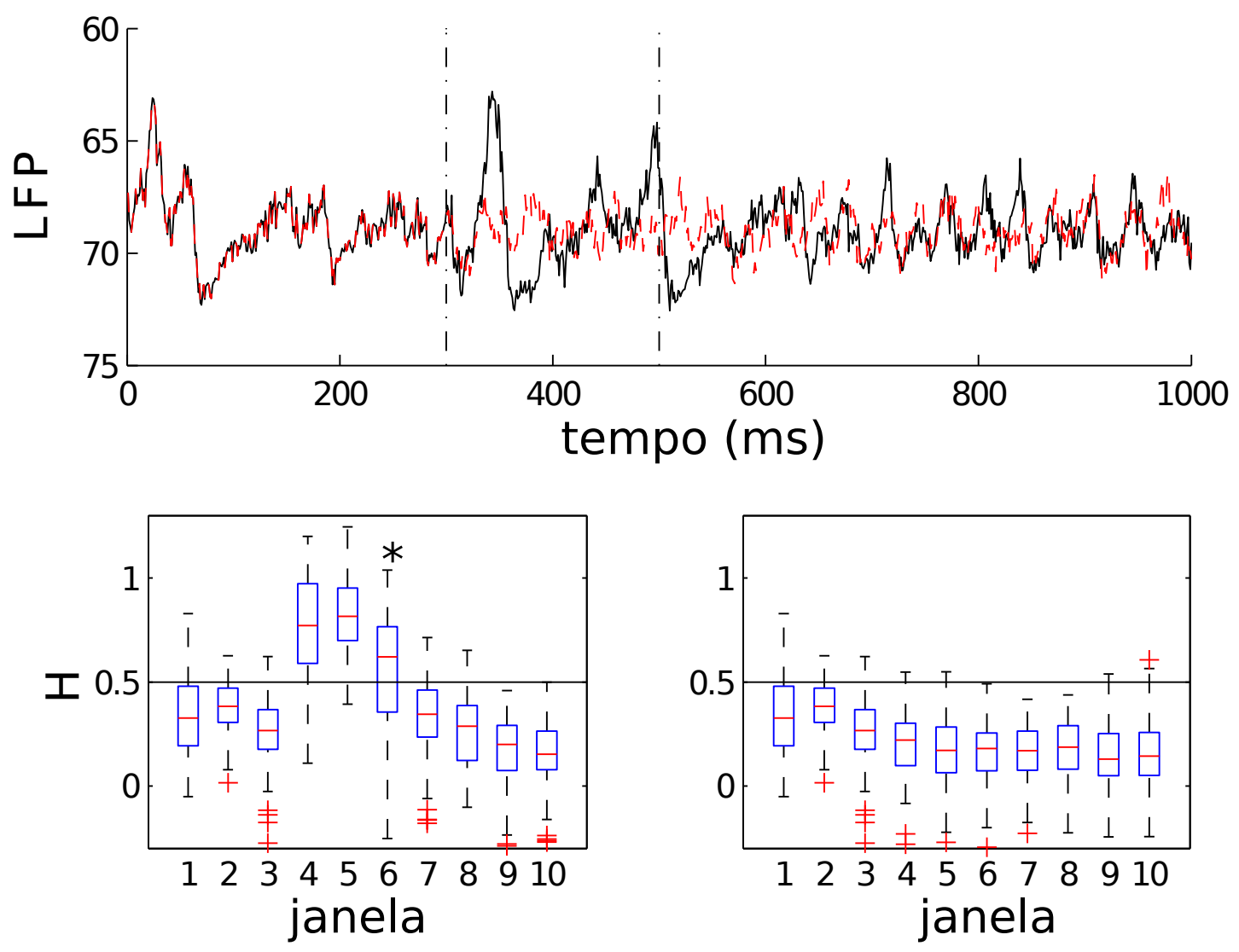

Figura 4.3: (a) Evolução dos dois sinais de LFP ao longo do tempo, o vermelho é a rede que não recebeu hubs enquanto que o preto recebe hubs para o intervalo de 300 até $500 \mathrm{~ms}$. As linhas verticais marcam o período de tempo onde os hubs estavam presentes no sinal preto. (b) boxplot para o H calculado para 10 janelas de tempo com 100 pontos cada. Adaptado de Rodrigues, Abner Cardoso et al. (2016).

dedicam-se a análise desse período, que é comumente negligenciado por estudos clínicos sobre epilepsia (Fisher e Schachter, 2000; Theodore, 2010).

Para investigar os efeitos da topologia do ictal sobre o pós-ictal, os hubs foram adicionados apenas durante um intervalo de tempo da simulação, entre 300 até $500 \mathrm{~ms}$. Depois disso, a matriz de adjacência é restaurada para os valores anteriores a adição dos hubs. A parte superior da figura 4.3 mostra dois sinais de campo dessa simulação, onde, antes de $300 \mathrm{~ms}$ ambos eram iguais, quando as conexões são modificadas, os sinais divergem.

Essa diferença foi atribuída à presença de memória longa devido à presença dos hubs. Para averiguar essa hipótese, o expoente de Hurst foi calculado em diferentes janelas de tempo. O $H$ foi persistente mesmo depois de a matriz ter sido restaurada e os hubs eliminados, o que mostra o efeito da estrutura do ictal no pós-ictal. Fig. 4.3 mostra o boxplot para o $H$ em cada janela de tempo, para a rede com hubs (esquerda) e aleatória (direita). O LFP das redes aleatórias mostra um $H<0,5$ para todas as janelas de tempo, enquanto que ao adicionar os hubs o valor fica $H>0,5$ durante o intervalo. Isso mostra que o sincronismo na rede tem um efeito de longo prazo.

Além disso, a janela de número 6, imediatamente depois da eliminação dos hubs mostra um $H>0,5$ para mais da metade das simulações. Esse comportamento lembra o pós-ictal, onde o sincronismo entre as regiões do cérebro permanece alto por um curto período, mesmo com o fim da crise. 


\subsection{Conclusões}

Neste capítulo foi apresentado uma simulação que tentam modelar propriedades encontradas no sinal durante o período ictal. O objetivo foi verificar como as estruturas que aparecem na crise (os hubs) alteram o sinal, especialmente em relação à sincronização, visto que no capítulo anterior foi levantado uma possível relação entre os hubs e a sincronização. Além dessa relação, foi visto que a estrutura também pode alterar a complexidade do sinal e adicionar características de memória longa por algum intervalo de tempo. Note que, embora foi obtido maior sincronização entre os neurônios ao adicionar hubs na rede, pouco se sabe sobre como essas conexões funcionais se formam durante uma crise de epilepsia. 


\section{Capítulo 5}

\section{Conclusões}

\subsection{Considerações Finais}

Neste trabalho, investigou-se como a estrutura das redes funcionais encontradas durante as crises de epilepsia influenciam um fenômeno característico desse estado: a sincronização. Em um primeiro momento foram analisados dados reais de epilepsia focal e de ausência, onde na primeira análise, foi desenvolvida uma medida de grafos que fornece uma ideia da presença de hubs que enviam conexões na rede e comparamos essa medida com a sincronização entre os canais. Na segunda análise, uma nova medida de inferência de redes foi aplicada entre as séries, revelando outras características em alguns nós que podem estar relacionadas com a epilepsia.

Em uma segunda parte, características encontradas nas redes foram simuladas utilizando modelos artificiais. Na primeira simulação, mostramos que duas formas diferentes de acoplamento direcionado levam a maior sincronização no subsistema receptor, mesmo que os sistemas não fiquem sincronizados entre si. Além disso, foi mostrado que apesar da sincronização ter emergido, um dos sistemas teve aumento na complexidade enquanto que em outro diminuiu. Na segunda simulação, foi adicionados hubs na rede, para ver como essa estrutura altera o sinal e a sincronização entre os neurônios.

Esses resultados mostraram que durante a crise, a rede apresenta um papel bastante dinâmico, alterando sua topologia com o tempo e com os nós assumindo diferentes papeis. Essas estruturas foram classificadas e analisada as suas relações com o processo de sincronização, o que pode ser útil não só para compreensão de sistemas biológicos, mas também de sistemas artificiais onde é desejável alterar o sincronismo entre as partes.

\subsection{Sugestões para Pesquisas Futuras}

Como possíveis trabalhos futuros sugerem-se:

- Analisar a influência de outras estruturas na sincronização (hierarquias, motifs, agrupamentos).

- Explorar a existência de um possível limite superior para sincronização em redes.

- Fazer um paralelo entre as redes de outros estados que levam a sincronização entre regiões do cérebro e as redes da epilepsia. As duas apresentam a mesma estrutura de sincronização? No que elas diferem estruturalmente?

- Analisar como essas redes podem ser úteis para por exemplo, estimulação do cérebro com objetivo de evitar ou diminuir as crises. É possível alterar a estrutura e evitar sincronização?

- Levantar a relação entre outras estruturas na rede em outras dinâmicas, por exemplo no surgimento de avalanches ou na plasticidade. 
CONCLUSÕES 


\section{Apêndice A}

\section{Sincronização em sistemas não-lineares acoplados}

Neste apêndice analisamos como o acoplamento entre sistemas complexos pode levar a emergência de uma estrutura de sincronização. Os dois sistemas utilizados foram o Rössler-Lorenz com acoplamento direcionado e uma rede de neurônios artificiais. O objetivo dessa análise é complementar os resultados das simulações do capítulo 4 e comparar as propriedades sinal gerado pelos neurônios artificiais com um sistema não linear bastante conhecido (Rössler-Lorenz).

Para analisar a sincronização, foi utilizada uma versão com lags do PLV, isto é, é calculado o quanto um sinal está sincronizado com um segundo sinal, defasando-se este último em alguns lags. Além disso, para caracterizar o sinal, foi utilizado a complexidade de Lempel-Ziv (LZC), uma medida normalizada entre 0 e 1 , onde 0 para sistemas periódicos, por volta do 0,5 para sistemas caóticos e 1 para processos aleatórios (Kaspar e Schuster, 1987; Lempel e Ziv, 1976; Ziv e Lempel, 1977).

\section{A.0.1 Métodos}

\section{O sistema Rössler-Lorenz}

Considere o sistema a seguir, como descrito em Le Van Quyen et al. (1999), definido pelo acoplamento partindo de um sistema Rössler

$$
\begin{aligned}
& \dot{x}_{1}=-6\left(x_{2}+x_{3}\right) \\
& \dot{x}_{2}=6\left(x_{1}+0,2 x_{2}\right) \\
& \dot{x}_{3}=6\left(0,2+x_{3}\left(x_{1}-5,7\right)\right),
\end{aligned}
$$

em um sistema Lorenz

$$
\begin{aligned}
& \dot{y_{1}}=10\left(y_{2}-y_{1}\right) \\
& \dot{y}_{2}=28 y_{1}-y_{2}-y_{1} y_{3}+\beta x_{2}^{2}, \\
& \dot{y}_{3}=y_{1} y_{2}-8 / 3 y_{3},
\end{aligned}
$$

onde $\beta$ é o parâmetro de acoplamento. A perturbação é aplicada apenas na segunda equação do Lorenz e não possui retroalimentação. Na figura A.1 pode-se ver a reconstrução do atrator de Lorenz para $\beta=0$ (fig. A.1B) e acoplado (fig. A.1D), e as respectivas projeções no plano $\left(y_{1}, \tilde{y}_{1}\right)$ (figs. A.1C e E). A solução $y_{1}$ usou condições iniciais diferentes das usadas em $\tilde{y}_{1}$. É possível notar que o sistema causador distorce as trajetórias no atrator de Lorenz.

Para caracterizar a relação de causalidade entre os dois sistemas, foi utilizado o método proposto em Le Van Quyen et al. (1999). Considerando as reconstruções do espaço de estados x $(t)$ e $\mathbf{y}(t)$, 
B

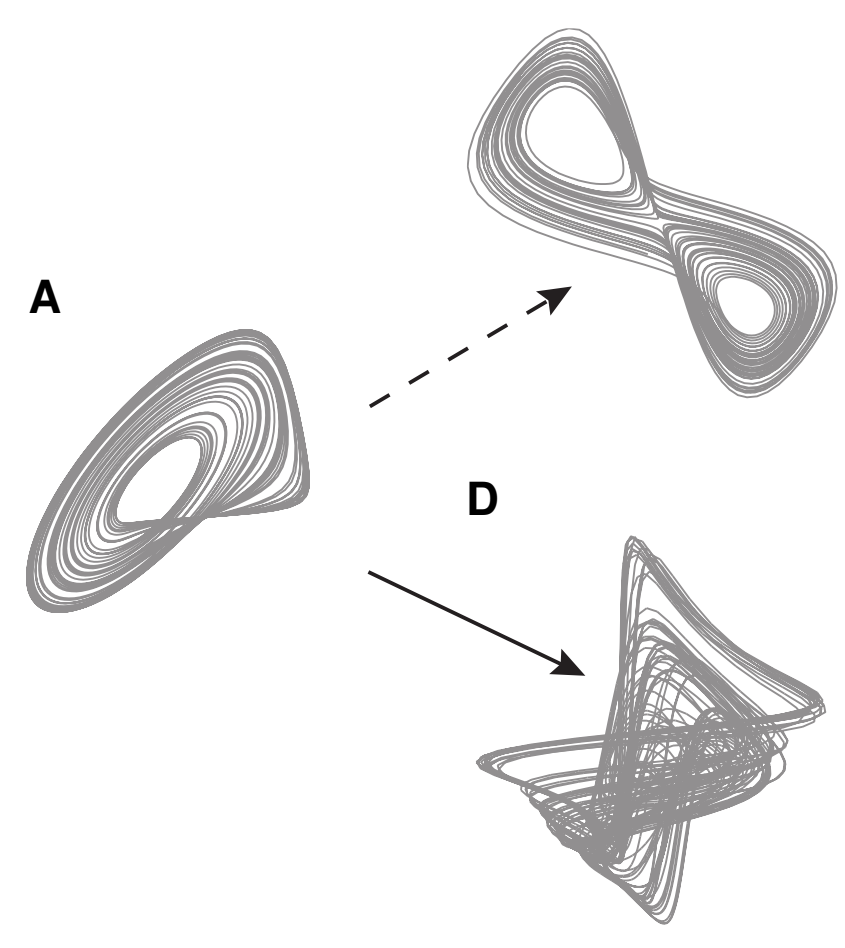

C

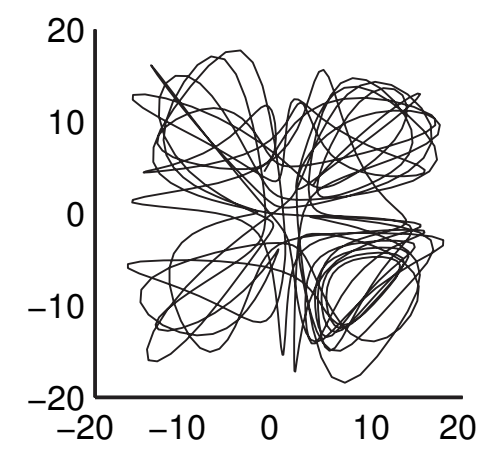

E

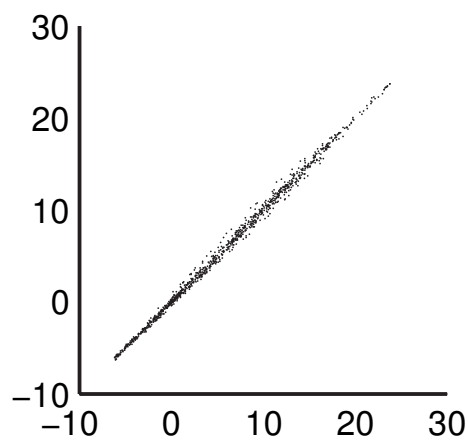

Figura A.1: (A) Reconstrução do espaço de estados do Rössler e (B) Lorenz, com parâmetro de acoplamento $\beta=0$. (C) Projeção no plano $\left(y_{1}, \tilde{y}_{1}\right) ; y_{1}(t)$ e $\tilde{y}_{1}(t)$ são duas séries com condições iniciais diferentes $y_{1}(0) \neq \tilde{y}_{1}(0)$. (D) O atrator de Lorenz depois de acoplado com o Rössler e (E) as respectivas projeções $\left(y_{1}, \tilde{y}_{1}\right)$. A diagonal $y_{1}(t)=\tilde{y}_{1}(t)$ indica que os dois sistemas estão funcionalmente relacionados. Adaptado de Martins, V.S.G. et al. (2016). 


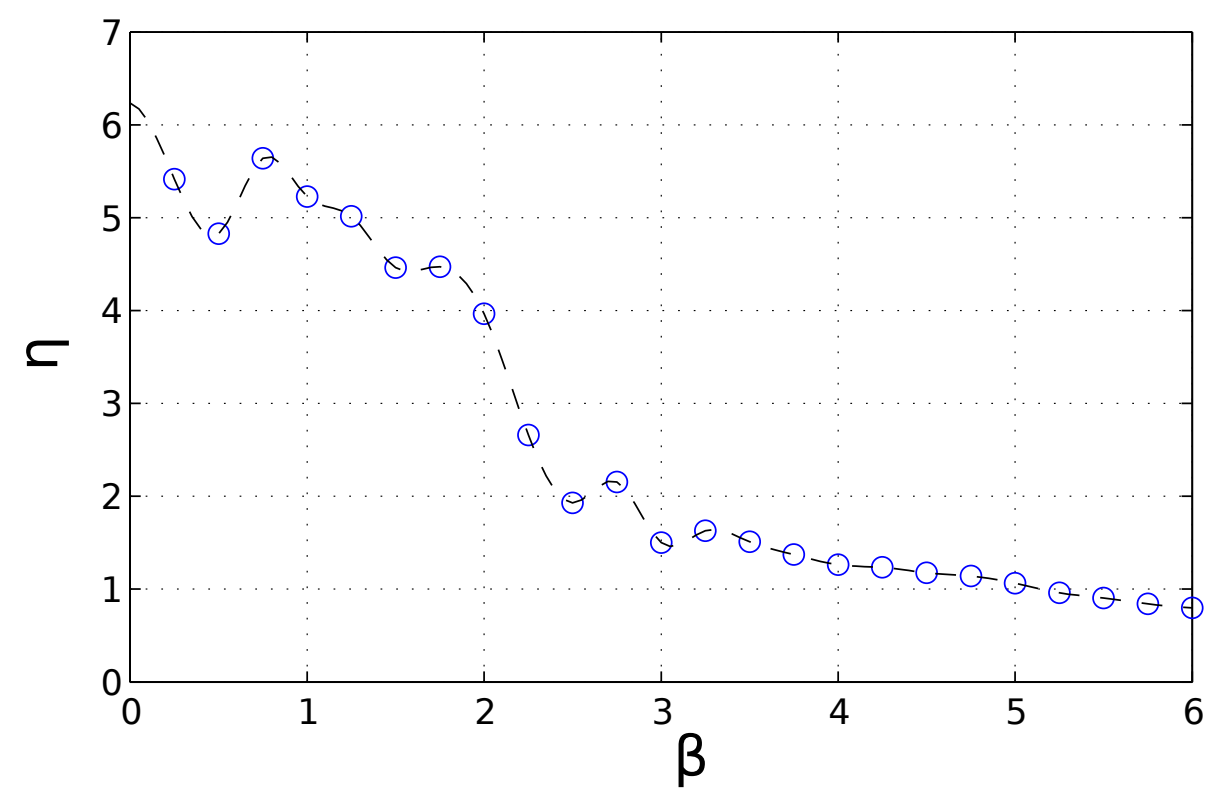

Figura A.2: Erro de previsão $\eta$ em função de $\beta$. A predição foi calculada considerando a dependência causal $x \rightarrow y$. Adaptado de Martins, V.S.G. et al. (2016).

a predição de $y$ dado $x$ é:

$$
\hat{y}(t+1)=\frac{1}{\left|U_{\varepsilon}(\mathbf{x}(t))\right|_{\#}} \sum_{\tau / \mathbf{x}(\tau) \in U_{\varepsilon}(\mathbf{x}(t))} y(\tau+1),
$$

onde $U_{\varepsilon}(\mathbf{x}(t))=\{\mathbf{x}(\tau):\|\mathbf{x}(t)-\mathbf{x}(\tau)\|<\epsilon\}$ é a vizinhança de $\mathbf{x}(t)$ com raio $\varepsilon$ e $\left|U_{\varepsilon}(\mathbf{x}(t))\right|_{\#}$ é o número de elementos nesta vizinhança. Dessa forma, a predição pode ser definida como:

$$
\eta=\sqrt{\frac{\sum_{t=1}^{T}(\hat{y}(t)-y(t))^{2}}{T}} .
$$

Na figura. A.2 é mostrada a dependência causal em função do parâmetro de acoplamento. Para $\beta \geq 3$ a relação de causalidade entre os sistemas Rössler e Lorenz fica bem caracterizada.

\section{Neurônios de Izhikevich}

Na segunda simulação, uma rede foi criada utilizando o modelo de neurônio de Izhikevich, o qual é uma classe de pulse coupled neurons, primeiramente descrito em Izhikevich et al. (2003). Quatro redes foram criadas com 1000 neurônios cada, com parâmetros iniciais escolhidos da mesma maneira que em Izhikevich et al. (2003) e seguindo a proporção no número de neurônios excitatórios e inibitórios de 4:1. A simulação foi calculada pelo método de Euler, com passo de 0,05 ms. Uma média da saída dos neurônios de cada rede foi calculada para representar um campo, semelhante à ideia de um local field potential (LFP). Esses sinais foram então analisados usando a medida de lag-PLV. As quatro redes, $z_{1}, z_{2}, z_{3}$ e $z_{4}$, foram conectadas seguindo a regra: $z_{i} \rightarrow z_{j}$ para cada par $j>i$, como pode ser visto na figura A.3. Por exemplo, os neurônios de $z_{1}$ se conectam aos neurônios de todas as outras redes, mas não recebe conexões de nenhuma delas. 


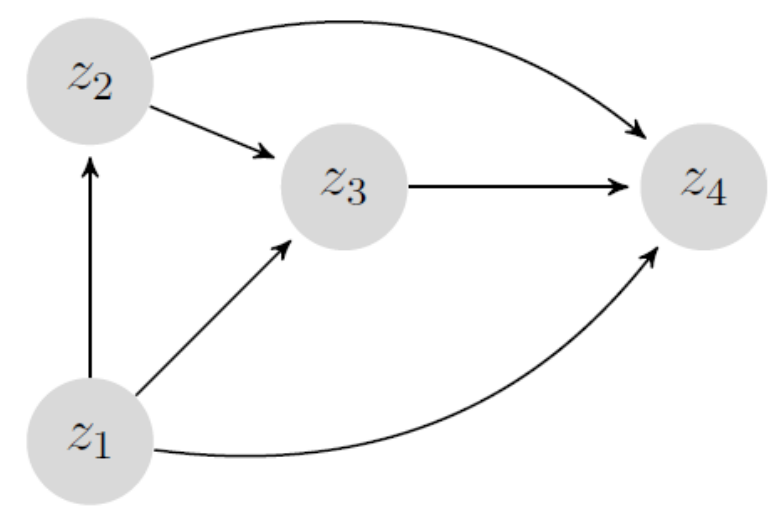

Figura A.3: Diagrama de conectividade da rede de neurônios. Adaptado de Martins, V.S.G. et al. (2016).

\section{A.0.2 Resultados}

\section{O acoplamento no sistema Rössler-Lorenz leva a sincronização no subsistema Lorenz}

Considerando as soluções $x_{1}, x_{2}$ da equação A.2), e $y_{1}, y_{2}$ da equação A.3), aplicamos o PLV(d) considerando duas configurações de $\beta=0$ (não acoplado) e $\beta=5$ (acoplado). Foi considerado $d=3$ (ou seja, 3 lags) e foi feita uma permutação aleatória no sinal de referência para se obter um nível de significância. Valores abaixo desse limiar não são considerados significativos.

Para $\beta=0$ a sincronização ficou alta em todos os lags para o sistema Rössler - pares $\left(x_{1}, x_{1}\right)$, $\left(x_{1}, x_{2}\right),\left(x_{2}, x_{1}\right),\left(x_{2}, x_{2}\right)$ - enquanto que o Lorenz possui um valor significativo apenas para o lag zero, caindo rapidamente após este - pares $\left(y_{1}, y_{1}\right),\left(y_{1}, y_{2}\right),\left(y_{2}, y_{1}\right),\left(y_{2}, y_{2}\right)$. Esses resultados podem ser observados na figura A.4. Além disso, não foi detectada sincronização entre os componentes do Rössler e Lorenz - os pares $(x, y)$.

Para o caso acoplado $(\beta=5)$, pode ser observado na figura A.5 os mesmos padrões de sincronização, exceto para os pares $\left(y_{1}, y_{1}\right),\left(y_{1}, y_{2}\right),\left(y_{2}, y_{1}\right),\left(y_{2}, y_{2}\right)$, onde acontece a emergência da sincronização, aumentando a complexidade nas componentes do Lorenz. O LZC aumenta de $0,042 \rightarrow 0,118$ para o componente $x_{1}$ e $0,063 \rightarrow 0,122$ para o $x_{2}$. Além disso, um novo modo oscilatório surgiu, como fica evidente na curva do PLV dos componentes do Lorenz.

\section{Subredes de neurônios de Izhikevich mostram diferentes níveis de sincronização}

Neste exemplo, foi calculado a sincronização de fase em cada subrede $\left(z_{1}, z_{2}, z_{3} e z_{4}\right)$, usando o LFP calculado através da rede de Izikevich como descrito na seção A.0.1. Para fazer a comparação de como essas conexões influenciam a sincronização, também foi gerado o sinal com as redes desconectadas.

A figura A.6 mostra os elementos da diagonal do diagrama $\operatorname{PLV}_{i j}(d)$. A curva azul é o $\operatorname{PLV}_{i i}(d)$ para cada LFP quando as subredes estão conectadas, enquanto que a linha preta é o $\mathrm{PLV}_{i i}(d)$ quando as subredes estão desconectadas. É possível notar um aumento na divergência entre essas curvas a medida que o número de conexões recebidas também aumenta. Por exemplo, na figura A.6A, que corresponde ao $\operatorname{PLV}_{11}(d)$, uma subrede que não recebe conexões, resulta em uma pequena distância entre as duas curvas. Na figura A.6D, que corresponde ao $\operatorname{PLV}_{44}(d)-\operatorname{com} z_{4}$ recebendo conexões causais de $z_{1}, z_{2}$ e $z_{3}-$, a distância entre as curvas é maior.

Para este exemplo, o LZC diminui em relação à quantidade de conexões, sendo seu valor para cada rede: $\operatorname{LZC}\left(z_{1}\right)=0,609, \operatorname{LZC}\left(z_{2}\right)=0,597, \operatorname{LZC}\left(z_{3}\right)=0,523$ e $\operatorname{LZC}\left(z_{4}\right)=0,398$. Esses resultados, em contraste com os encontrados para o sistema Rössler-Lorenz, mostram uma diminuição na complexidade acompanhada por um aumento na sincronização. 

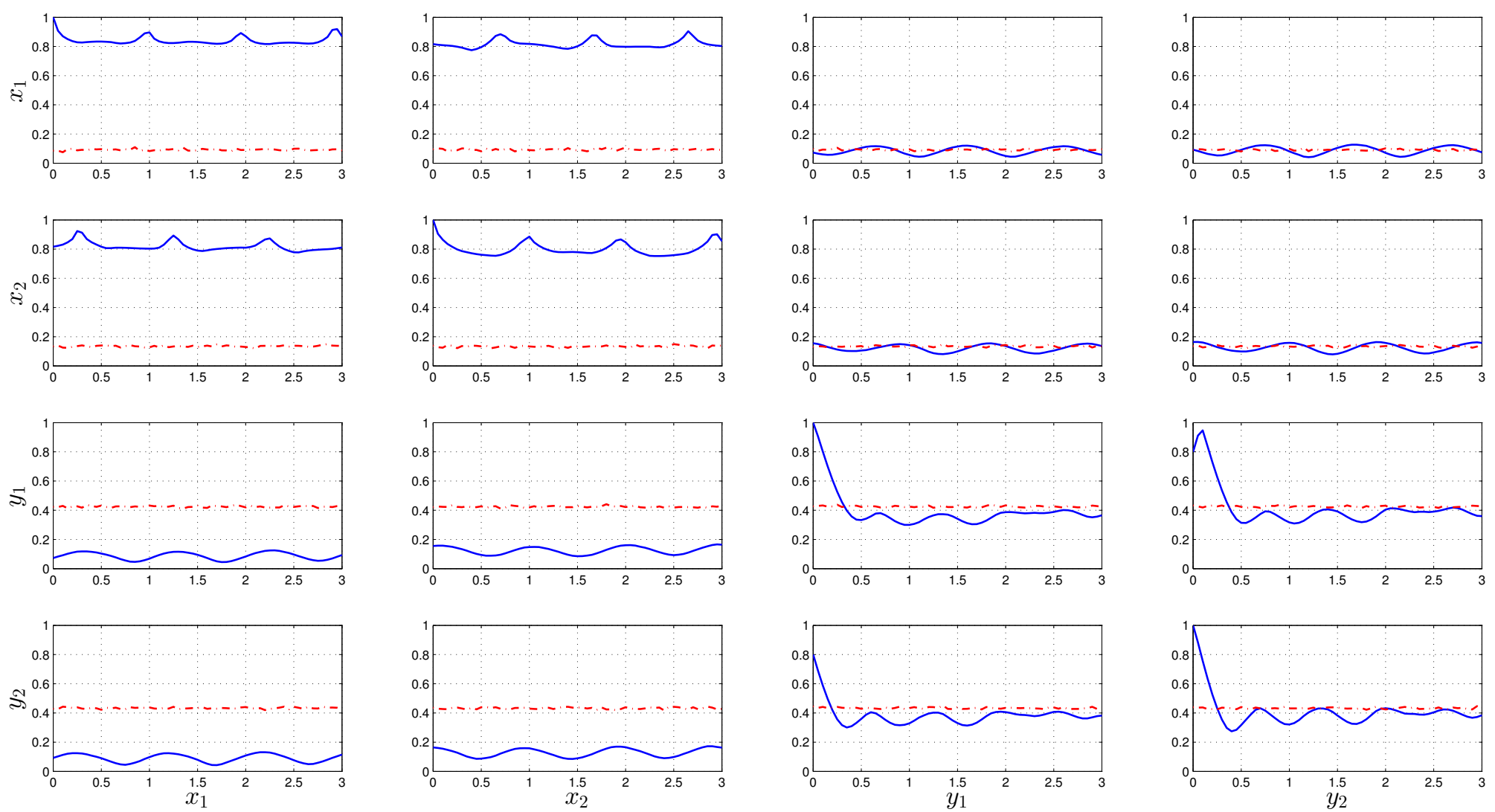

Figura A.4: PLV para o sistema Rössler-Lorenz usando parâmetro de acoplamento $\beta=0$. A curva azul é o $\operatorname{PLV}_{i j}(d)$ para dois sinais $i$ e $j$, enquanto que a linha tracejada em vermelho corresponde ao PLV com o sinal permutado de j. Adaptado de Martins, V.S.G. et al. (2016). 

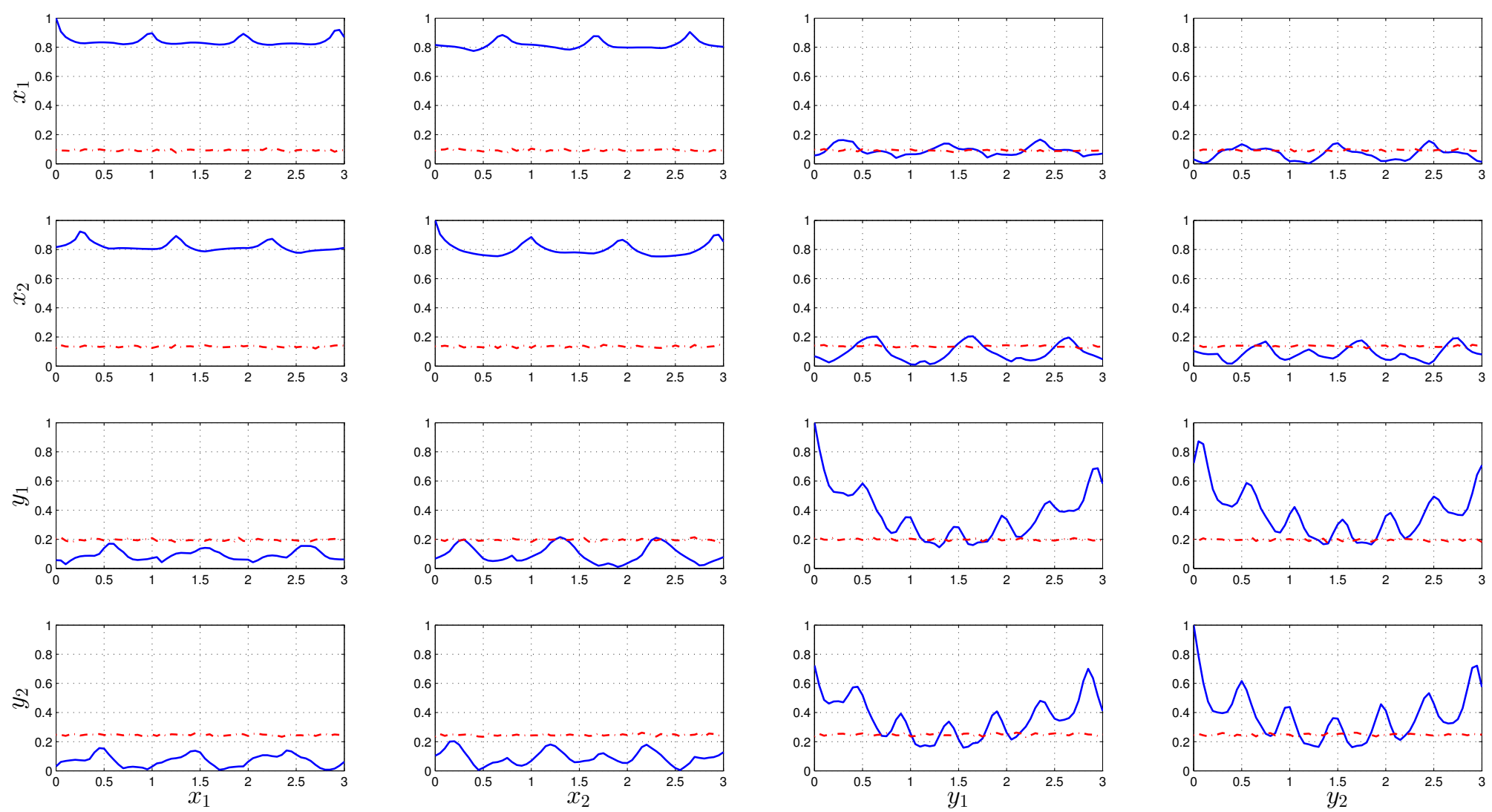

Figura A.5: PLV para o sistema Rössler-Lorenz usando parâmetro de acoplamento $\beta=5$. A curva azul corresponde ao $\mathrm{PLV}_{i j}(d)$ para dois sinais $i$ e $j$, enquanto que a linha tracejada em vermelho corresponde ao PLV do sinal permutado de j Adaptado de Martins, V.S.G. et al. (2016). 
A

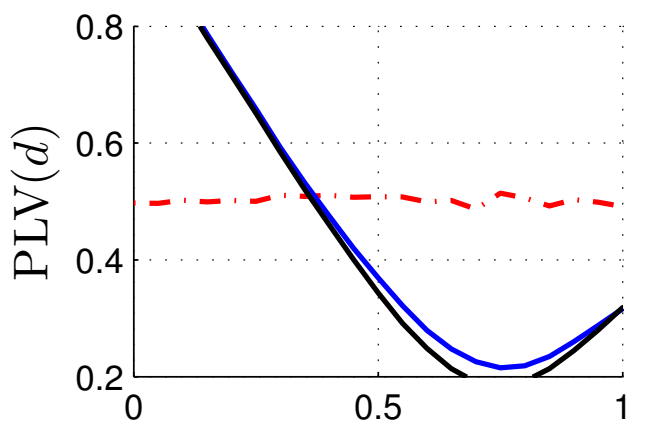

C

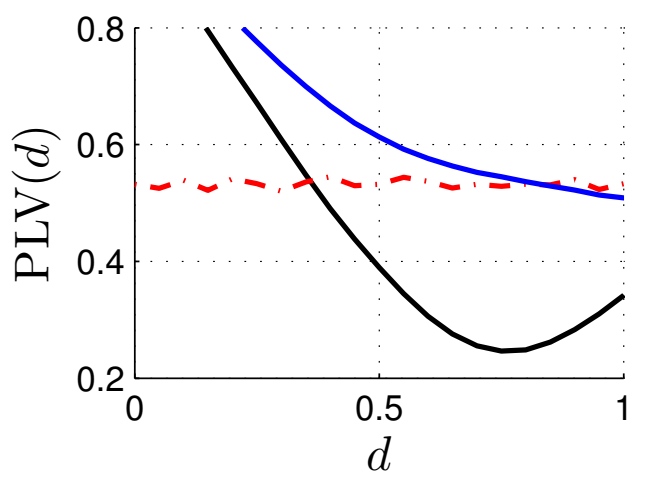

B

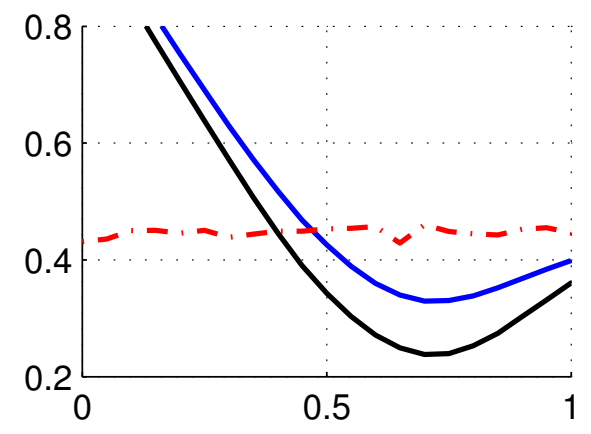

D

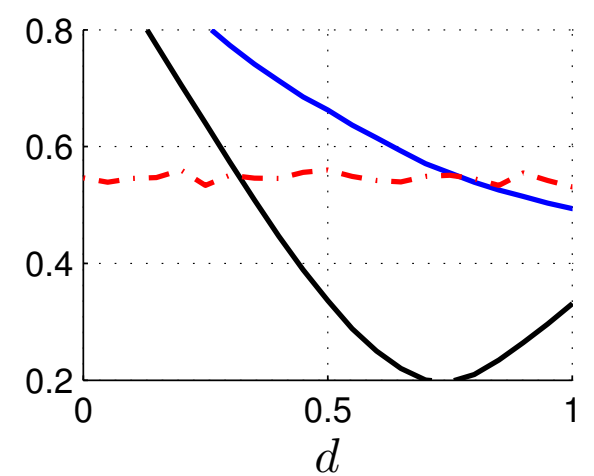

Figura A.6: (A) PLV(d) para o par $\left(z_{1}, z_{1}\right)$, (B) para $z_{2}$, (C) para $z_{3}$, e (D) para $z_{4}$. A linha azul é o $P L V(d)$ considerando o acoplamento entre as redes enquanto que a linha preta é para as redes desconectadas. Adaptado de Martins, V.S.G. et al. (2016). 
APÊNDICE A 


\section{Apêndice B}

\section{Uso dos dados}

Esse trabalho utilizou dois conjuntos de dados de EEG de pacientes, um do Hospital das Clínicas de Ribeirão Preto e o outro do Hospital Israelita Alber Einstein. A utilização de ambos os conjuntos de dados foi aprovada pelo comitê de ética das respectivas instituições. 
APÊNDICE B 


\section{Referências Bibliográficas}

Aboy et al. (2006) Mateo Aboy, Roberto Hornero, Daniel Abásolo e Daniel Álvarez. Interpretation of the lempel-ziv complexity measure in the context of biomedical signal analysis. Biomedical Engineering, IEEE Transactions on, 53(11):2282-2288. Citado na pág. 30

Ancona et al. (2004) Nicola Ancona, Daniele Marinazzo e Sebastiano Stramaglia. Radial basis function approach to nonlinear granger causality of time series. Physical Review E, 70(5):056221. doi: 10.1103/PhysRevE.70.056221. URL http://link.aps.org/doi/10.1103/PhysRevE.70.056221. Citado na pág. 10

Atay et al. (2006) Fatihcan M Atay, Türker Bıyıkoğlu e Jürgen Jost. Network synchronization: Spectral versus statistical properties. Physica D: Nonlinear Phenomena, 224(1):35-41. Citado na pág. 31

Barrat et al. (2008) Alain Barrat, Marc Barthelemy e Alessandro Vespignani. Dynamical processes on complex networks. Cambridge University Press. Citado na pág. 29

Barrett et al. (2010) Adam B. Barrett, Lionel Barnett e Anil K. Seth. Multivariate granger causality and generalized variance. Physical Review E, 81(4):041907. doi: 10.1103/PhysRevE.81. 041907. URL http://link.aps.org/doi/10.1103/PhysRevE.81.041907. Citado na pág. 10

Bassett et al. (2008) Danielle S. Bassett, Edward Bullmore, Beth A. Verchinski, Venkata S. Mattay, Daniel R. Weinberger e Andreas Meyer-Lindenberg. Hierarchical organization of human cortical networks in health and schizophrenia. The Journal of Neuroscience, 28(37): 9239-9248. ISSN 0270-6474, 1529-2401. doi: 10.1523/JNEUROSCI.1929-08.2008. URL http: //www.jneurosci.org/content/28/37/9239. PMID: 18784304. Citado na pág. 1

Bassett e Bullmore (2006) Danielle Smith Bassett e ED Bullmore. Small-world brain networks. The neuroscientist, 12(6):512-523. Citado na pág. 1

Bialonski (2012) Stephan Bialonski. Inferring complex networks from time series of dynamical systems: pitfalls, misinterpretations, and possible solutions. arXiv preprint arXiv:1208.0800. Citado na pág. 11

Bialonski et al. (2011) Stephan Bialonski, Martin Wendler e Klaus Lehnertz. Unraveling spurious properties of interaction networks with tailored random networks. PLoS One, 6(8):e22826. Citado na pág. 11

Blinowska et al. (2004) Katarzyna J Blinowska, Rafał Kuś e Maciej Kamiński. Granger causality and information flow in multivariate processes. Physical Review E, 70(5):050902. Citado na pág. 27

Bressler e Seth (2011) Steven L Bressler e Anil K Seth. Wiener-granger causality: a well established methodology. Neuroimage, 58(2):323-329. Citado na pág. 10

Costa et al. (2007) L. da F. Costa, F. A. Rodrigues, G. Travieso e P. R. Villas Boas. Characterization of complex networks: A survey of measurements. Advances in Physics, 56(1): 167-242. ISSN 0001-8732. doi: 10.1080/00018730601170527. URL http://dx.doi.org/10.1080/ 00018730601170527. Citado na pág. 2, 6, 8 
Costa et al. (2011) Luciano da Fontoura Costa, Osvaldo N. Oliveira, Gonzalo Travieso, Francisco Aparecido Rodrigues, Paulino Ribeiro Villas Boas, Lucas Antiqueira, Matheus Palhares Viana e Luis Enrique Correa Rocha. Analyzing and modeling real-world phenomena with complex networks: a survey of applications. Advances in Physics, 60(3):329-412. doi: 10.1080/00018732.2011.572452. URL http://dx.doi.org/10.1080/00018732.2011.572452. Citado na pág. 1

Dhamala et al. (2008a) Mukeshwar Dhamala, Govindan Rangarajan e Mingzhou Ding. Analyzing information flow in brain networks with nonparametric granger causality. NeuroImage, 41(2):354362. Citado na pág. 27

Dhamala et al. (2008b) Mukeshwar Dhamala, Govindan Rangarajan e Mingzhou Ding. Analyzing information flow in brain networks with nonparametric granger causality. NeuroImage, 41(2): 354 - 362. ISSN 1053-8119. doi: http://dx.doi.org/10.1016/j.neuroimage.2008.02.020. URL http://www.sciencedirect.com/science/article/pii/S1053811908001328. Citado na pág. 10

Ding et al. (2006) Mingzhou Ding, Yonghong Chen e Steven L. Bressler. Granger causality: Basic theory and application to neuroscience. arXiv:q-bio/0608035. URL http://arxiv.org/abs/q-bio/ 0608035. Handbook of Time Series Analysis, ed. B. Schelter, M. Winterhalder, and J. Timmer, Wiley-VCH Verlage, 2006: 451-474. Citado na pág. 9

Eguiluz et al. (2005) Victor M Eguiluz, Dante R Chialvo, Guillermo A Cecchi, Marwan Baliki e A Vania Apkarian. Scale-free brain functional networks. Physical review letters, 94(1):018102. Citado na pág. 1

Ehrhardt et al. (2006) George Ehrhardt, Matteo Marsili e Fernando Vega-Redondo. Diffusion and growth in an evolving network. International Journal of Game Theory, 34(3):383-397. Citado na pág. 29

Fisher e Schachter (2000) Robert S Fisher e Steven C Schachter. The postictal state: a neglected entity in the management of epilepsy. Epilepsy \& Behavior, 1(1):52-59. Citado na pág. 34

Fisher et al. (2005) Robert S Fisher, Walter van Emde Boas, Warren Blume, Christian Elger, Pierre Genton, Phillip Lee e Jerome Engel. Epileptic seizures and epilepsy: definitions proposed by the international league against epilepsy (ilae) and the international bureau for epilepsy (ibe). Epilepsia, 46(4):470-472. Citado na pág. 2

Fornito e Bullmore (2015) Alex Fornito e Edward T Bullmore. Connectomics: a new paradigm for understanding brain disease. European Neuropsychopharmacology, 25(5):733-748. Citado na pág. 1

Freeman (1977) Linton C. Freeman. A set of measures of centrality based on betweenness. Sociometry, 40(1):35. ISSN 00380431. doi: 10.2307/3033543. Citado na pág. 8

Fries et al. (2007) Pascal Fries, Danko Nikolić e Wolf Singer. The gamma cycle. Trends in neurosciences, 30(7):309-316. Citado na pág. 27

Friston et al. (2003) K. J. Friston, L. Harrison e W. Penny. Dynamic causal modelling. NeuroImage, 19(4):1273-1302. ISSN 1053-8119. doi: 10.1016/S1053-8119(03)00202-7. URL http://www.sciencedirect.com/science/article/pii/S1053811903002027. Citado na pág. 5

Friston (1994) Karl J. Friston. Functional and effective connectivity in neuroimaging: A synthesis. Human Brain Mapping, 2(1-2):56-78. ISSN 1097-0193. doi: 10.1002/hbm.460020107. URL http: //onlinelibrary.wiley.com/doi/10.1002/hbm.460020107/abstract. Citado na pág. 5

Friston et al. (1995) Karl J Friston, G Tononi, O Sporns e GM Edelman. Characterising the complexity of neuronal interactions. Human Brain Mapping, 3(4):302-314. Citado na pág. 1 
Gastner e Newman (2006) M. T. Gastner e M. E. J. Newman. The spatial structure of networks. The European Physical Journal B - Condensed Matter and Complex Systems, 49(2):247-252. ISSN 1434-6028, 1434-6036. doi: 10.1140/epjb/e2006-00046-8. URL http://link.springer.com/article/ 10.1140/epjb/e2006-00046-8. Citado na pág. 1

Geier et al. (2014) Christian Geier, Stephan Bialonski, Christian E Elger e Klaus Lehnertz. How important is the seizure onset zone for seizure dynamics? Seizure. Citado na pág. 28

Geier et al. (2015) Christian Geier, Stephan Bialonski, Christian E Elger e Klaus Lehnertz. How important is the seizure onset zone for seizure dynamics? Seizure, 25:160-166. Citado na pág. 11, 12,31

Gómez-Gardenes et al. (2007) Jesús Gómez-Gardenes, Yamir Moreno e Alex Arenas. Paths to synchronization on complex networks. Physical review letters, 98(3):034101. Citado na pág. 29

Granger (1969) C. W. J. Granger. Investigating causal relations by econometric models and cross-spectral methods. Econometrica, 37(3):424. ISSN 00129682. doi: 10.2307/1912791. Citado na pág. 9

Guimera e Amaral (2005) Roger Guimera e Luis A Nunes Amaral. Functional cartography of complex metabolic networks. Nature, 433(7028):895-900. Citado na pág. 28

Guimera e Nunes Amaral (2005) Roger Guimera e Luis A. Nunes Amaral. Functional cartography of complex metabolic networks. Nature, 433(7028):895-900. ISSN 0028-0836. doi: 10.1038/nature03288. URL http://dx.doi.org/10.1038/nature03288. Citado na pág. 1

Guimerà et al. (2005) R. Guimerà, S. Mossa, A. Turtschi e L. a. N. Amaral. The worldwide air transportation network: Anomalous centrality, community structure, and cities' global roles. Proceedings of the National Academy of Sciences, 102(22):7794-7799. ISSN 0027-8424, 10916490. doi: 10.1073/pnas.0407994102. URL http://www.pnas.org/content/102/22/7794. PMID: 15911778. Citado na pág. 1

Gupta et al. (2011) Disha Gupta, Pauly Ossenblok e Gilles van Luijtelaar. Space-time network connectivity and cortical activations preceding spike wave discharges in human absence epilepsy: a meg study. Medical $\mathcal{E}$ biological engineering $\&$ computing, 49(5):555-565. Citado na pág. 11, 12

Han e Kim (2008) Sangman Han e Beom Jun Kim. Network analysis of an online community. Physica A: Statistical Mechanics and its Applications, 387(23):5946 - 5951. ISSN 03784371. doi: http://dx.doi.org/10.1016/j.physa.2008.06.053. URL http://www.sciencedirect.com/ science/article/pii/S037843710800589X. Citado na pág. 1

Holme et al. (2002) Petter Holme, Beom Jun Kim, Chang No Yoon e Seung Kee Han. Attack vulnerability of complex networks. Physical Review E, 65(5):056109. Citado na pág. 29

Horstmann et al. (2010) Marie-Therese Horstmann, Stephan Bialonski, Nina Noennig, Heinke Mai, Jens Prusseit, Jörg Wellmer, Hermann Hinrichs e Klaus Lehnertz. State dependent properties of epileptic brain networks: Comparative graph-theoretical analyses of simultaneously recorded eeg and meg. Clinical Neurophysiology, 121(2):172-185. Citado na pág. 11, 12

Hu e Wang (2009) Hai-Bo Hu e Xiao-Fan Wang. Disassortative mixing in online social networks. EPL (Europhysics Letters), 86(1):18003. ISSN 0295-5075. doi: 10.1209/0295-5075/86/18003. URL http://iopscience.iop.org/0295-5075/86/1/18003. Citado na pág. 1

Izhikevich (2004) Eugene M Izhikevich. Which model to use for cortical spiking neurons? IEEE transactions on neural networks, 15(5):1063-1070. Citado na pág. 29, 30

Izhikevich et al. (2003) Eugene M Izhikevich et al. Simple model of spiking neurons. IEEE Transactions on neural networks, 14(6):1569-1572. Citado na pág. 29, 30, 41 
Jeong et al. (2001) H. Jeong, S. P. Mason, A.-L. Barabasi e Z. N. Oltvai. Lethality and centrality in protein networks. Nature, 411(6833):41-42. ISSN 0028-0836. doi: 10.1038/35075138. URL http://dx.doi.org/10.1038/35075138. Citado na pág. 1

Kalitzin et al. (2005) S Kalitzin, D Velis, P Suffczynski, J Parra e F Lopes da Silva. Electrical brain-stimulation paradigm for estimating the seizure onset site and the time to ictal transition in temporal lobe epilepsy. Clinical neurophysiology, 116(3):718-728. Citado na pág. 31

Kaspar e Schuster (1987) F Kaspar e HG Schuster. Easily calculable measure for the complexity of spatiotemporal patterns. Physical Review A, 36(2):842. Citado na pág. 39

Kramer et al. (2008) Mark A Kramer, Eric D Kolaczyk e Heidi E Kirsch. Emergent network topology at seizure onset in humans. Epilepsy research, 79(2):173-186. Citado na pág. 11, 12, 33

Kramer et al. (2010) Mark A Kramer, Uri T Eden, Eric D Kolaczyk, Rodrigo Zepeda, Emad N Eskandar e Sydney S Cash. Coalescence and fragmentation of cortical networks during focal seizures. The Journal of neuroscience, 30(30):10076-10085. Citado na pág. 11, 12

Krause et al. (2003) Ann E. Krause, Kenneth A. Frank, Doran M. Mason, Robert E. Ulanowicz e William W. Taylor. Compartments revealed in food-web structure. Nature, 426(6964):282-285. ISSN 0028-0836. doi: 10.1038/nature02115. URL http://dx.doi.org/10.1038/nature02115. Citado na pág. 1

Kreuz et al. (2011) Thomas Kreuz, Daniel Chicharro, Martin Greschner e Ralph G Andrzejak. Time-resolved and time-scale adaptive measures of spike train synchrony. Journal of neuroscience methods, 195(1):92-106. Citado na pág. 30

Kuhnert et al. (2010) Marie-Therese Kuhnert, Christian E Elger e Klaus Lehnertz. Long-term variability of global statistical properties of epileptic brain networks. Chaos: An Interdisciplinary Journal of Nonlinear Science, 20(4):043126. Citado na pág. 11, 12

Kurths et al. (2001) Jürgen Kurths, Arkady Pikovsky e Michael Rosenblum. Synchronization, a universal concept in non-linear science. Cambridge Nonlinear Science. Citado na pág. 10

Ladroue et al. (2009) Christophe Ladroue, Shuixia Guo, Keith Kendrick e Jianfeng Feng. Beyond element-wise interactions: Identifying complex interactions in biological processes. PLoS ONE, 4(9):e6899. doi: 10.1371/journal.pone.0006899. URL http://dx.doi.org/10.1371/journal.pone. 0006899. Citado na pág. 10

Le Van Quyen et al. (1999) Michel Le Van Quyen, Jacques Martinerie, Claude Adam e Francisco J Varela. Nonlinear analyses of interictal eeg map the brain interdependences in human focal epilepsy. Physica D: Nonlinear Phenomena, 127(3):250-266. Citado na pág. 39

Lehnertz (2011) Klaus Lehnertz. Assessing directed interactions from neurophysiological signalsian overview. Physiological Measurement, 32(11):1715. ISSN 0967-3334. doi: 10.1088/ 0967-3334/32/11/R01. URL http://iopscience.iop.org/0967-3334/32/11/R01. Citado na pág. 1

Lehnertz et al. (2014) Klaus Lehnertz, Gerrit Ansmann, Stephan Bialonski, Henning Dickten, Christian Geier e Stephan Porz. Evolving networks in the human epileptic brain. Physica D: Nonlinear Phenomena, 267(0):7 - 15. ISSN 0167-2789. doi: http://dx.doi.org/10.1016/j.physd. 2013.06.009. URL http://www.sciencedirect.com/science/article/pii/S0167278913001826. Evolving Dynamical Networks. Citado na pág. 2, 11, 25

Leistedt et al. (2009) Samuël J.J. Leistedt, Nathalie Coumans, Martine Dumont, Jean-Pol Lanquart, Cornelis J. Stam e Paul Linkowski. Altered sleep brain functional connectivity in acutely depressed patients. Human Brain Mapping, 30(7):2207-2219. ISSN 1097-0193. doi: 10.1002/hbm.20662. URL http://onlinelibrary.wiley.com/doi/10.1002/hbm.20662/abstract. Citado na pág. 1 
Lemieux et al. (2011) Louis PhD Lemieux, Jean Daunizeau e Matthew Walker. Concepts of connectivity and human epileptic activity. Frontiers in Systems Neuroscience, 5:12. doi: 10.3389/ fnsys.2011.00012. URL http://journal.frontiersin.org/Journal/10.3389/fnsys.2011.00012/full. Citado na pág. 2,31

Lempel e Ziv (1976) Abraham Lempel e Jacob Ziv. On the complexity of finite sequences. Information Theory, IEEE Transactions on, 22(1):75-81. Citado na pág. 39

Marinazzo et al. (2008) Daniele Marinazzo, Mario Pellicoro e Sebastiano Stramaglia. Kernel method for nonlinear granger causality. Physical Review Letters, 100(14):144103. doi: 10.1103/ PhysRevLett.100.144103. URL http://link.aps.org/doi/10.1103/PhysRevLett.100.144103. Citado na pág. 10

Markus (2012) Keith A Markus. Principles and practice of structural equation modeling by rex b. kline. Structural Equation Modeling: A Multidisciplinary Journal, 19(3):509-512. Citado na pág. 8

Martins, V.S.G. et al. (2016) Martins, V.S.G., Rodrigues, A.C., Cerdeira, H.A. e Machado, B.S. Phase-lag synchronization analysis in complex systems with directed inter-relations. Eur. Phys. J. Special Topics, 225(1):41-49. doi: 10.1140/epjst/e2016-02618-7. URL http://dx.doi.org/10. 1140/epjst/e2016-02618-7. Citado na pág. xv, 40, 41, 42, 43, 44, 45

Meeren et al. (2005) Hanneke Meeren, Gilles van Luijtelaar, Fernando Lopes da Silva e Anton Coenen. Evolving concepts on the pathophysiology of absence seizures: the cortical focus theory. Archives of neurology, 62(3):371-376. Citado na pág. 23

Meeren et al. (2002) Hanneke KM Meeren, Jan Pieter M Pijn, Egidius LJM Van Luijtelaar, Anton ML Coenen e Fernando H Lopes da Silva. Cortical focus drives widespread corticothalamic networks during spontaneous absence seizures in rats. The Journal of neuroscience, 22(4):14801495. Citado na pág. 23

Meyer e Damasio (2009) Kaspar Meyer e Antonio Damasio. Convergence and divergence in a neural architecture for recognition and memory. Trends in neurosciences, 32(7):376-382. Citado na pág. 27

Morgan e Soltesz (2008) Robert J Morgan e Ivan Soltesz. Nonrandom connectivity of the epileptic dentate gyrus predicts a major role for neuronal hubs in seizures. Proceedings of the National Academy of Sciences, 105(16):6179-6184. Citado na pág. 17

Motter et al. (2006) Adilson E. Motter, Manuel A. Matías, Jürgen Kurths e Edward Ott. Dynamics on complex networks and applications. Physica D: Nonlinear Phenomena, 224 (1¿2):vii - viii. ISSN 0167-2789. doi: http://dx.doi.org/10.1016/j.physd.2006.09.012. URL http://www.sciencedirect.com/science/article/pii/S0167278906003721. Dynamics on Complex Networks and Applications. Citado na pág. 2

Nedungadi et al. (2009) Aatira G. Nedungadi, Govindan Rangarajan, Neeraj Jain e Mingzhou Ding. Analyzing multiple spike trains with nonparametric granger causality. Journal of Computational Neuroscience, 27(1):55-64. ISSN 0929-5313, 1573-6873. doi: 10.1007/s10827-008-0126-2. URL http://link.springer.com/article/10.1007/s10827-008-0126-2. Citado na pág. 10

Newman (2001) M. E. J. Newman. The structure of scientific collaboration networks. Proceedings of the National Academy of Sciences, 98(2):404-409. ISSN 0027-8424, 1091-6490. doi: 10.1073/ pnas.98.2.404. URL http://www.pnas.org/content/98/2/404. Citado na pág. 1

Nishikawa et al. (2003) Takashi Nishikawa, Adilson E Motter, Ying-Cheng Lai e Frank C Hoppensteadt. Heterogeneity in oscillator networks: Are smaller worlds easier to synchronize? Physical review letters, 91(1):014101. Citado na pág. 29 
Papo et al. (2014a) David Papo, Massimiliano Zanin e Javier M Buldú. Reconstructing functional brain networks: have we got the basics right? Frontiers in human neuroscience, 8. Citado na pág. 20

Papo et al. (2014b) David Papo, Massimiliano Zanin e Javier M Buldú. Reconstructing functional brain networks: have we got the basics right? Frontiers in human neuroscience, 8. Citado na pág. 20

Pereda et al. (2005) Ernesto Pereda, Rodrigo Quian Quiroga e Joydeep Bhattacharya. Nonlinear multivariate analysis of neurophysiological signals. Progress in Neurobiology, 77:1 - 37. ISSN 03010082. doi: http://dx.doi.org/10.1016/j.pneurobio.2005.10.003. URL http://www.sciencedirect. com/science/article/pii/S030100820500119X. Citado na pág. 1

Ponten et al. (2007) SC Ponten, F Bartolomei e CJ Stam. Small-world networks and epilepsy: graph theoretical analysis of intracerebrally recorded mesial temporal lobe seizures. Clinical neurophysiology, 118(4):918-927. Citado na pág. 11, 12

Ponten et al. (2009) SC Ponten, L Douw, F Bartolomei, JC Reijneveld e CJ Stam. Indications for network regularization during absence seizures: weighted and unweighted graph theoretical analyses. Experimental neurology, 217(1):197-204. Citado na pág. 11, 12

Richardson (2012) Mark P. Richardson. Large scale brain models of epilepsy: dynamics meets connectomics. Journal of Neurology, Neurosurgery \& Psychiatry, 83(12):1238-1248. ISSN , 1468330X. doi: 10.1136/jnnp-2011-301944. URL http://jnnp.bmj.com/content/83/12/1238. PMID: 22917671. Citado na pág. 2

Rodrigues et al. (submetido) Abner C Rodrigues, Birajara S Machado, Luís O Caboclo, André Fujita, Luíz A da Baccalá e Koichi Sameshima. Source and sink nodes in absence seizures. Preprint submitted to 38th Annual International Conference of the IEEE Engineering in Medicine and Biology Society. Citado na pág. xiv, 26, 27

Rodrigues et al. (2014) AC Rodrigues, BS Machado, G Florence, AP Hamad, AC Sakamoto, A Fujita, LA Baccalá, E Amaro Jr e K Sameshima. Brain network dynamics characterization in epileptic seizures. The European Physical Journal Special Topics, 223(13):2933-2941. Citado na pág. xiii, xvii, 17, 18, 19

Rodrigues, Abner Cardoso et al. (2016) Rodrigues, Abner Cardoso, Cerdeira, Hilda A. e Machado, Birajara Soares. The influence of hubs in the structure of a neuronal network during an epileptic seizure. Eur. Phys. J. Special Topics, 225(1):75-82. doi: 10.1140/epjst/e2016-02626-7. URL http://dx.doi.org/10.1140/epjst/e2016-02626-7. Citado na pág. xiv, 32, 33, 34

Rubinov e Sporns (2010) Mikail Rubinov e Olaf Sporns. Complex network measures of brain connectivity: Uses and interpretations. NeuroImage, 52(3):1059-1069. Citado na pág. xiii, 5, 6

Schindler et al. (2008) Kaspar A Schindler, Stephan Bialonski, Marie-Therese Horstmann, Christian E Elger e Klaus Lehnertz. Evolving functional network properties and synchronizability during human epileptic seizures. Chaos: An Interdisciplinary Journal of Nonlinear Science, 18 (3):033119. Citado na pág. 11, 12

Schuele e Lüders (2008) Stephan U Schuele e Hans O Lüders. Intractable epilepsy: management and therapeutic alternatives. The Lancet Neurology, 7(6):514-524. Citado na pág. 2

Shore e Johnson (1980) John Shore e Rodney Johnson. Axiomatic derivation of the principle of maximum entropy and the principle of minimum cross-entropy. Information Theory, IEEE Transactions on, 26(1):26-37. Citado na pág. 20

Singer (1993) Wolf Singer. Synchronization of cortical activity and its putative role in information processing and learning. Annual review of physiology, 55(1):349-374. Citado na pág. 27 
Sporns (2014) Olaf Sporns. Towards network substrates of brain disorders. Brain, 137(8):21172118. Citado na pág. 1

Sporns e Kötter (2004) Olaf Sporns e Rolf Kötter. Motifs in brain networks. PLoS Biol, 2(11): e369. Citado na pág. 1

Sporns et al. (2004) Olaf Sporns, Dante R Chialvo, Marcus Kaiser e Claus C Hilgetag. Complex networks: small-world and scale-free architectures. Trends in Cognitive Sciences, 9(8):418-425. Citado na pág. 1

Spreng et al. (2013) R Nathan Spreng, Jorge Sepulcre, Gary R Turner, W Dale Stevens e Daniel L Schacter. Intrinsic architecture underlying the relations among the default, dorsal attention, and frontoparietal control networks of the human brain. Journal of cognitive neuroscience, 25(1): 74-86. Citado na pág. 28

Stacey e Litt (2008) William C Stacey e Brian Litt. Technology insight: neuroengineering and epilepsy ¿designing devices for seizure control. Nature Clinical Practice Neurology, 4(4):190-201. Citado na pág. 2

Stam et al. (2009) C. J. Stam, W. de Haan, A. Daffertshofer, B. F. Jones, I. Manshanden, A. M. van Cappellen van Walsum, T. Montez, J. P. A. Verbunt, J. C. de Munck, B. W. van Dijk, H. W. Berendse e P. Scheltens. Graph theoretical analysis of magnetoencephalographic functional connectivity in alzheimer's disease. Brain, 132(1):213-224. doi: 10.1093/brain/awn262. URL http://brain.oxfordjournals.org/content/132/1/213.abstract. Citado na pág. 1

Stam et al. (2007) CJ Stam, BF Jones, G Nolte, M Breakspear e Ph Scheltens. Small-world networks and functional connectivity in alzheimer's disease. Cerebral Cortex, 17(1):92-99. doi: 10.1093/cercor/bhj127. URL http://cercor.oxfordjournals.org/content/17/1/92.abstract. Citado na pág. 1

Stam (2005) Cornelis J Stam. Nonlinear dynamical analysis of eeg and meg: review of an emerging field. Clinical Neurophysiology, 116(10):2266-2301. Citado na pág. 33

Theodore (2010) William H Theodore. The postictal state: effects of age and underlying brain dysfunction. Epilepsy \& Behavior, 19(2):118-120. Citado na pág. 34

Tononi et al. (1994) Giulio Tononi, Olaf Sporns e Gerald M Edelman. A measure for brain complexity: relating functional segregation and integration in the nervous system. Proceedings of the National Academy of Sciences, 91(11):5033-5037. Citado na pág. 1

van den Heuvel e Sporns (2011) Martijn P van den Heuvel e Olaf Sporns. Rich-club organization of the human connectome. The Journal of neuroscience, 31(44):15775-15786. Citado na pág. 1

van den Heuvel e Sporns (2013) Martijn P van den Heuvel e Olaf Sporns. Network hubs in the human brain. Trends in cognitive sciences, 17(12):683-696. Citado na pág. 21

van den Heuvel et al. (2012) Martijn $\mathrm{P}$ van den Heuvel, René S Kahn, Joaquín Goñi e Olaf Sporns. High-cost, high-capacity backbone for global brain communication. Proceedings of the National Academy of Sciences, 109(28):11372-11377. Citado na pág. 1

Varanda et al. (2000) Wamberto A Varanda, Larry S Liebovitch, Jose N Figueiroa e Romildo A Nogueira. Hurst analysis applied to the study of single calcium-activated potassium channel kinetics. Journal of theoretical biology, 206(3):343-353. Citado na pág. 30

Varotto et al. (2012) Giulia Varotto, Laura Tassi, Silvana Franceschetti, Roberto Spreafico e Ferruccio Panzica. Epileptogenic networks of type ii focal cortical dysplasia: a stereo-eeg study. Neuroimage, 61(3):591-598. Citado na pág. 11, 12 
Vlooswijk et al. (2011) MCG Vlooswijk, MJ Vaessen, JFA Jansen, MCFTM de Krom, HJM Majoie, PAM Hofman, AP Aldenkamp e WH Backes. Loss of network efficiency associated with cognitive decline in chronic epilepsy. Neurology, 77(10):938-944. Citado na pág. 11, 12

von Bünau et al. (2009) Paul von Bünau, Frank C Meinecke, Franz C Király e Klaus-Robert Müller. Finding stationary subspaces in multivariate time series. Physical Review Letters, 103 (21):214101. Citado na pág. 10

Wang et al. (2009) Liang Wang, Chaozhe Zhu, Yong He, Yufeng Zang, QingJiu Cao, Han Zhang, Qiuhai Zhong e Yufeng Wang. Altered small-world brain functional networks in children with attention-deficit/hyperactivity disorder. Human Brain Mapping, 30(2):638-649. ISSN 1097-0193. doi: 10.1002/hbm.20530. URL http://onlinelibrary.wiley.com/doi/10.1002/hbm.20530/abstract. Citado na pág. 1

Wang et al. (2010) Liang Wang, Chunshui Yu, Hai Chen, Wen Qin, Yong He, Fengmei Fan, Yujin Zhang, Moli Wang, Kuncheng Li, Yufeng Zang, Todd S. Woodward e Chaozhe Zhu. Dynamic functional reorganization of the motor execution network after stroke. Brain, 133(4):1224-1238. doi: 10.1093/brain/awq043. URL http://brain.oxfordjournals.org/content/133/4/1224.abstract. Citado na pág. 1

Watts e Strogatz (1998) Duncan J. Watts e Steven H. Strogatz. Collective dynamics of /'smallworld/' networks. Nature, 393(6684):440-442. ISSN 0028-0836. doi: 10.1038/30918. URL http: //dx.doi.org/10.1038/30918. Citado na pág. 1, 7

Welch (1967) Peter Welch. The use of fast fourier transform for the estimation of power spectra: a method based on time averaging over short, modified periodograms. IEEE Transactions on audio and electroacoustics, páginas 70-73. Citado na pág. 20

Wiener (1956) Norbert Wiener. Modern mathematics for the engineer. New York: McGraw-Hill. Citado na pág. 9

Wilke et al. (2011) Christopher Wilke, Gregory Worrell e Bin He. Graph analysis of epileptogenic networks in human partial epilepsy. Epilepsia, 52(1):84-93. Citado na pág. 11, 12

Willinger et al. (2003) Walter Willinger, Vern Paxson, Rolf H Riedi e Murad S Taqqu. Longrange dependence and data network traffic. Theory and applications of long-range dependence, páginas 373-407. Citado na pág. 30

Wu et al. (2008) Zhi-Xi Wu, Gang Peng, Wen-Xu Wang, Sammy Chan e Eric Wing-Ming Wong. Cascading failure spreading on weighted heterogeneous networks. Journal of Statistical Mechanics: Theory and Experiment, 2008(05):P05013. Citado na pág. 29

Zhang et al. (2011) Zhiqiang Zhang, Wei Liao, Huafu Chen, Dante Mantini, Ju-Rong Ding, Qiang $\mathrm{Xu}$, Zhengge Wang, Cuiping Yuan, Guanghui Chen, Qing Jiao et al. Altered functional-structural coupling of large-scale brain networks in idiopathic generalized epilepsy. Brain, 134(10):29122928. Citado na pág. 11, 12

Zhou e Kurths (2006a) Changsong Zhou e Jürgen Kurths. Hierarchical synchronization in complex networks with heterogeneous degrees. Chaos: An Interdisciplinary Journal of Nonlinear Science, 16(1):015104. Citado na pág. 29

Zhou e Kurths (2006b) Changsong Zhou e Jürgen Kurths. Dynamical weights and enhanced synchronization in adaptive complex networks. Physical review letters, 96(16):164102. Citado na pág. 29

Zhou et al. (2006) Changsong Zhou, Lucia Zemanová, Gorka Zamora, Claus C Hilgetag e Jürgen Kurths. Hierarchical organization unveiled by functional connectivity in complex brain networks. Physical review letters, 97(23):238103. Citado na pág. 1 
Ziv e Lempel (1977) Jacob Ziv e Abraham Lempel. A universal algorithm for sequential data compression. IEEE Transactions on information theory, 23(3):337-343. Citado na pág. 39 


\section{Índice Remissivo}

A

área do trabalho

fundamentos, 5

assortatividade, 11

C

caminho de um grafo, 6

caminho mínimo característico, 7

causalidade de granger, 9

coeficiente de agrupamento, 8

coerência parcial direcionada, 10

correlação de pearson, 9

E

entropia cruzada, 20

G

grafos, 5

grau do grafo, 7

I

inferência das redes, 8

M

matriz de adjacência, 5

medidas de centralidade, 8

medidas de grafos, 6

$\mathbf{N}$

neurônios de Izhikevich, 41

neurônios de izhikevich, 29

$\mathbf{P}$

phase locking value, 10

$\mathbf{R}$

redes funcionais na epilepsia, 11

características dos nós, 11

características durante o interictal, 11

coeficiente de agrupamento e caminho mínimo, 11

$\mathbf{S}$

sistema Rossler-Lorenz, 39 